Florida International University

FIU Digital Commons

GIS Center

GIS Center

2021

\title{
Miami-Dade County Urban Tree Canopy Analysis
}

\author{
Hartwig $\mathrm{H}$. Hochmair \\ University of Florida, hhochmair@ufl.edu \\ Adam Benjamin \\ University of Florida \\ Daniel Gann \\ Florida International University, gannd@fiu.edu \\ Levente Juhasz \\ Florida International University, ljuhasz@fiu.edu \\ Paulo C. Olivas \\ Florida International University, poliv001@fiu.edu
}

See next page for additional authors

Follow this and additional works at: https://digitalcommons.fiu.edu/gis

\section{Recommended Citation}

Hochmair, Hartwig H.; Benjamin, Adam; Gann, Daniel; Juhasz, Levente; Olivas, Paulo C.; and Fu, Zhaohui, "Miami-Dade County Urban Tree Canopy Analysis" (2021). GIS Center. 89.

https://digitalcommons.fiu.edu/gis/89

This work is brought to you for free and open access by the GIS Center at FIU Digital Commons. It has been accepted for inclusion in GIS Center by an authorized administrator of FIU Digital Commons. For more information, please contactdcc@fiu.edu. 


\section{Authors}

Hartwig H. Hochmair, Adam Benjamin, Daniel Gann, Levente Juhasz, Paulo C. Olivas, and Zhaohui Fu 


\title{
Miami-Dade County Urban Tree Canopy Analysis
}

\author{
Report prepared for Miami-Dade County and American Forests
}

Date Prepared: 10/2/21 


\section{Acknowledgements}

Funding for this assessment has been provided by the residents and civic leaders of Miami-Dade County. This assessment and other urban forestry efforts in Miami-Dade County would not be possible without the support of the Million Trees Miami initiative, which includes Neat Streets Miami and the Parks, Recreation and Open Spaces Department. Their continued leadership is essential to accomplishing community forestry goals.

American Forests is pleased to support their efforts through its Community ReLeaf initiative.

This Miami-Dade County assessment was created by Hartwig Henry Hochmair and Adam Benjamin of the Geomatics Program at the University of Florida, as well as Daniel Gann, Levente Juhász, Paulo Olivas, and Zhaohui Jennifer Fu of Florida International University's Geographic Information Systems and Remote Sensing Center.

\section{Our Partners}

MIAMI-DADE COUNTY

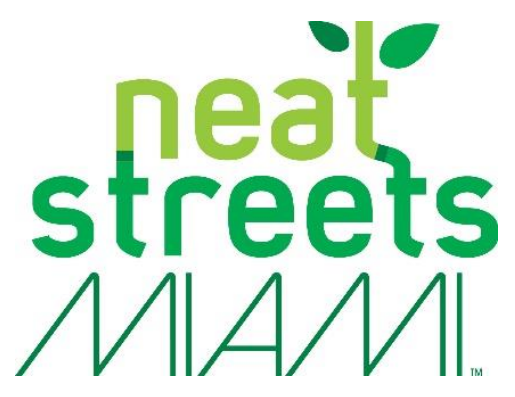

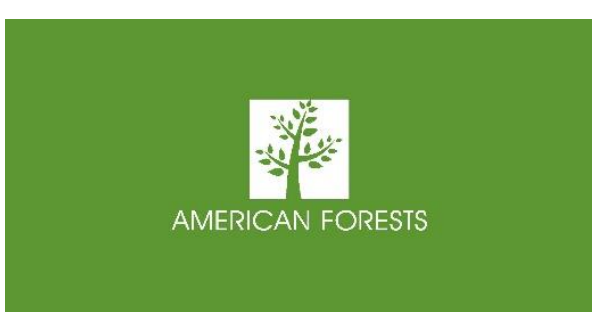




\section{Table of Contents}

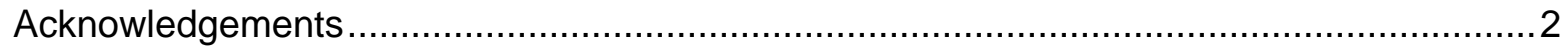

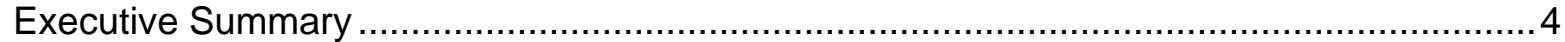

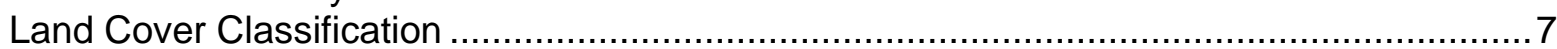

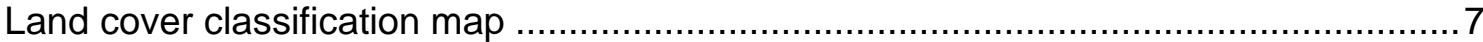

Land cover statistics .................

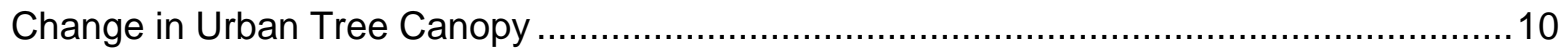

Canopy change maps

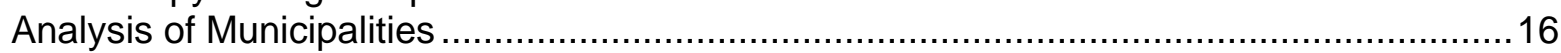

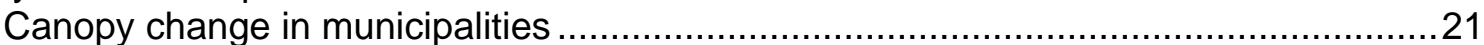

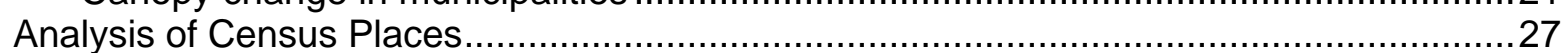

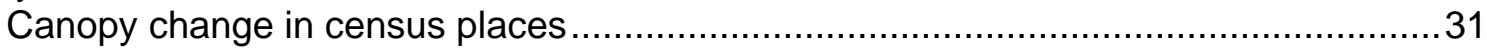

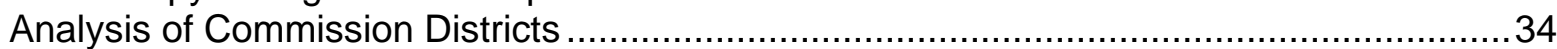

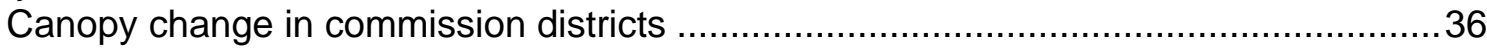

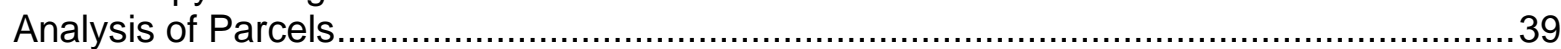

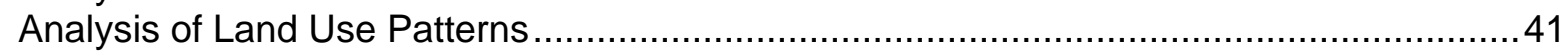

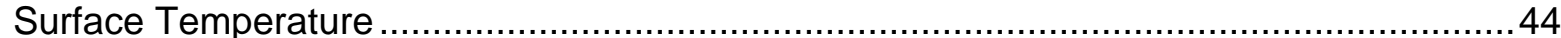

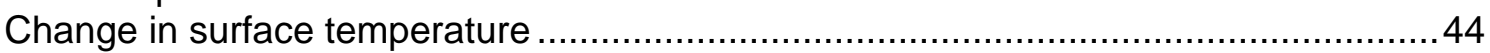

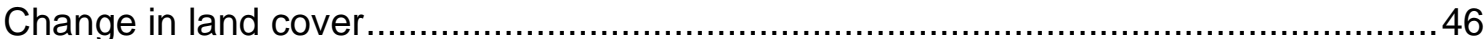

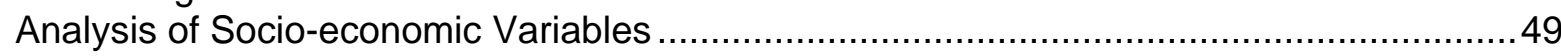

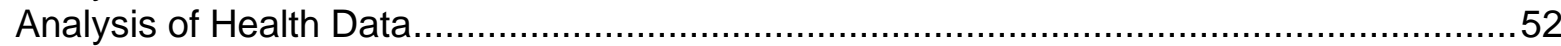

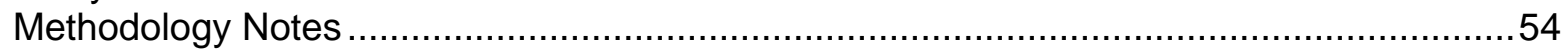

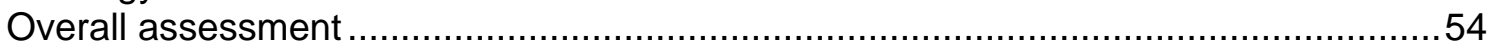

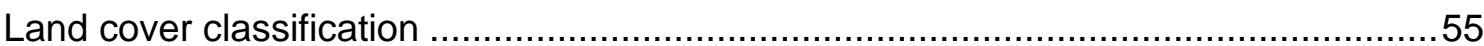

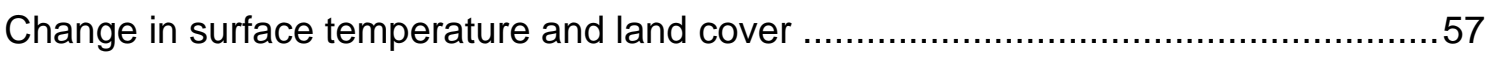

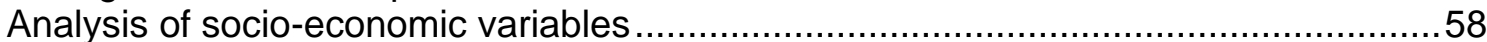

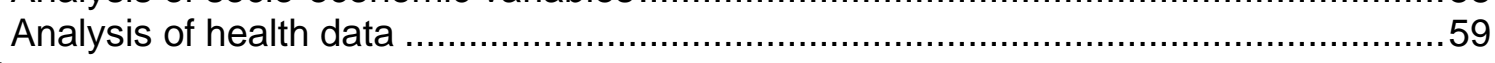

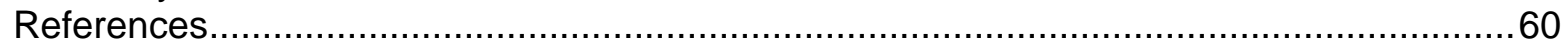




\section{Executive Summary}

This assessment focuses on describing urban tree canopy (UTC) within the Urban Development Boundary of Miami-Dade County, as defined by the Miami-Dade County Transportation Planning Organization (Figure 1). The area (intracoastal water areas excluded) encompasses approximately $1147 \mathrm{~km}^{2}\left(443 \mathrm{mi}^{2}\right)$. A combination of remote sensing and publicly available vector data was used to classify the following land cover classes: tree canopy/shrubs, grass, bare ground, wetland, water, building, street/railroad, other impervious surfaces, and cropland.

\section{Primary Goals:}

1) Establish baseline data on the extent and function of the existing urban forest and provide a resource to guide future community forest management and reforestation efforts. To that end, the assessment estimates the area with existing urban tree canopy (EUTC), the area of possible urban tree canopy (PUTC), and the area currently unsuitable for tree canopy, based on various other land cover categories. Assessments are made for the entire urban area as well as in parcels, census places, municipalities, and commission districts to support strategic planning and implementation.

2) Compare EUTC between 2016 and 2020 to highlight local areas of tree canopy gain or loss over this time period due to various causes, such as building construction or reforestation efforts.

3) Analyze the association between change in EUTC and change in surface temperature, socioeconomic patterns, and hospital intake rates.

\section{Results:}

- Overall tree canopy within the Miami-Dade Urban Development Boundary is $20.1 \%$ in 2020 , which is only slightly higher than the $19.9 \%$ of UTC from 2016 and not statistically distinct from that value.

- A large portion of the project area offers the potential for additional urban tree canopy, at least in theory. These areas consist of pervious surfaces (grass, bare ground) and impervious surfaces (asphalt). In practice, however, many of these areas are already dedicated to a specific purpose, such as a golf courses or airports, which would prevent adding new trees.

- Whereas overall tree canopy has not significantly changed for the study area as a whole, tree canopy change in individual municipalities is more pronounced by reaching a change in EUTC coverage of up to around 10 percentage points in some cases.

- Increases in surface temperature could be observed from 2016 to 2020 at locations where a) tree canopy was replaced by pervious or impervious surfaces, or b) pervious surfaces were changed to impervious surfaces. A decrease can be observed when replacing pervious surfaces or trees with water or wetland. 
- Census block groups with higher median household incomes tend to have more EUTC. Meanwhile, census block groups with a high percentage of Hispanic population tend to have less EUTC. No significant relationship could be observed for census block groups with a high percentage of African American population, which is a change from previous analyses in 2016.

- On a per resident basis, zip codes with higher percent EUTC tend to have fewer respiratory-related illnesses and overall hospitalization rates. This effect declined when compared to the 2016 analysis. 


\section{Figure 1: Urban Area of Miami-Dade County}

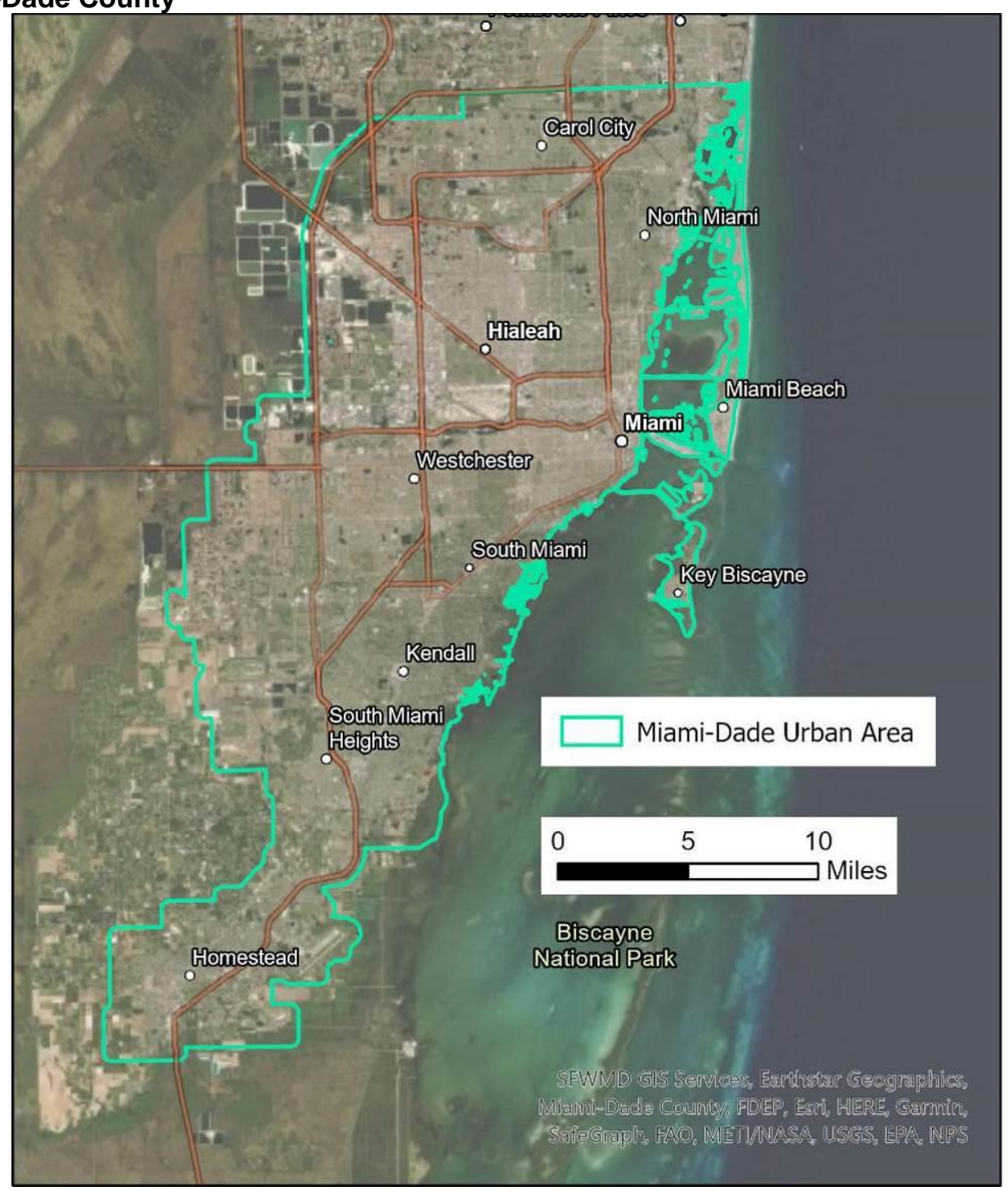




\section{Land Cover Classification}

\section{Land cover classification map}

Figure 2 shows the land cover classification map with its nine classes, where shrubs and trees are combined into one class. Cropland occurs primarily on the southwestern edges of the study area. Inland water bodies (lakes, ponds, canals, rivers) are also shown on the land cover classification map, whereas coastal water areas (bay, ocean) were excluded from the land cover generation process and the computation of land cover statistics. 


\section{Figure 2. Land cover classification map}

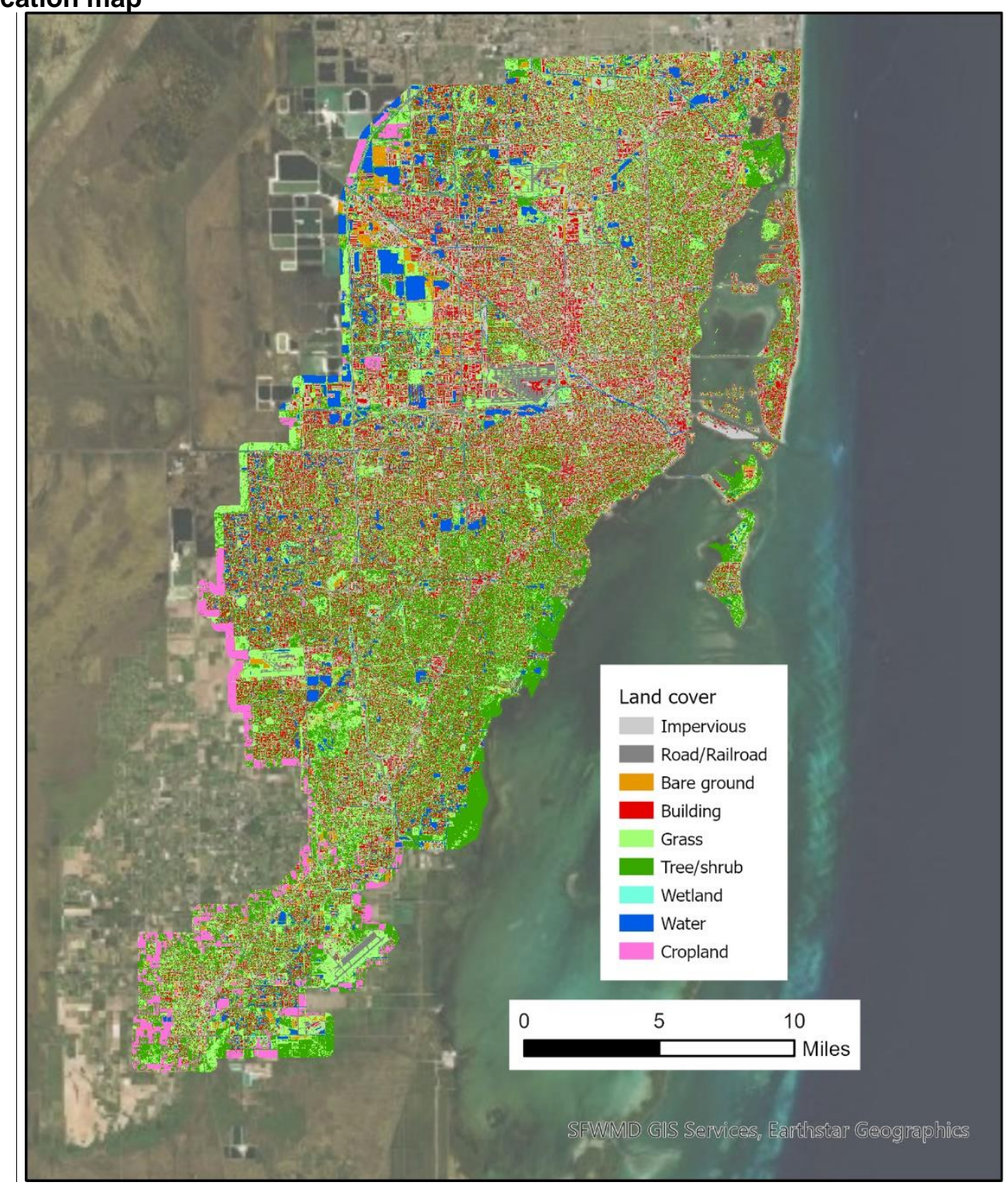




\section{Land cover statistics}

The project area covers approximately $1147 \mathrm{~km}^{2}\left(443 \mathrm{mi}^{2}\right)$. Grass has the largest percent cover of $24.8 \pm 1.6 \%$, followed by tree canopy including shrubs (20.1 $\pm 1.5 \%)$, and buildings (17.7 $\pm 0.7 \%$ ) (Figure 3, Table 1Error! Reference source not found.). Total additional PUTC, which includes grass, bare ground, and impervious surface (e.g., paved parking lots, but not buildings, streets, or railroads) make up $41.8 \%$, and the remaining $38.1 \%$ of the study area include streets and railroads, buildings, wetlands, water bodies, and cropland which are generally unsuitable for UTC improvement.

Even though wetland areas are suitable for native wetland tree species (e.g., pond apple trees, cypress trees), they were not counted toward PUTC areas since the wetland area was only $0.5 \pm 0.3 \%$ of the entire mapped area. Within possible tree canopy areas, pervious surfaces (grass, bare ground) cover $26.8 \%$. Total area in $\mathrm{km}^{2}$ and $\mathrm{mi}^{2}$, percent cover and classification accuracies for each land cover class are provided in Error! Reference source not found.1.

\section{Figure 3. Percentage of land cover classes}

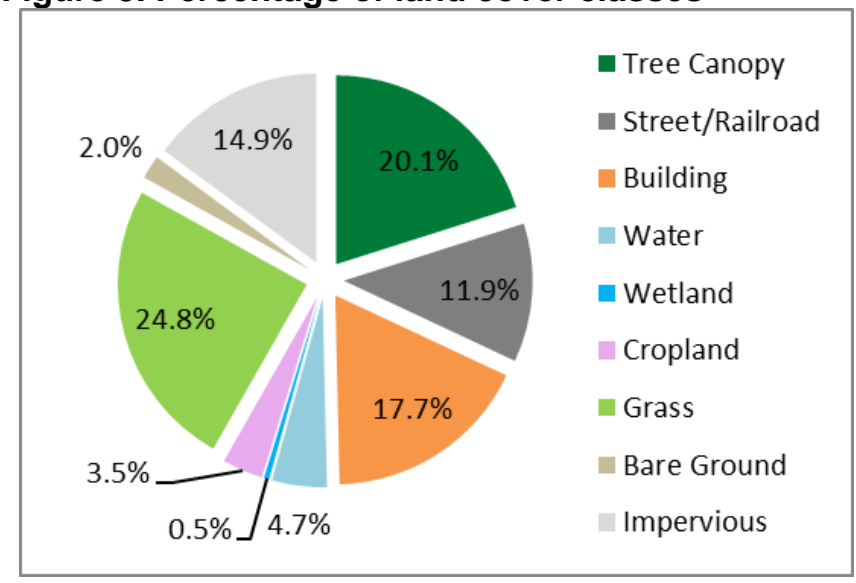

a)

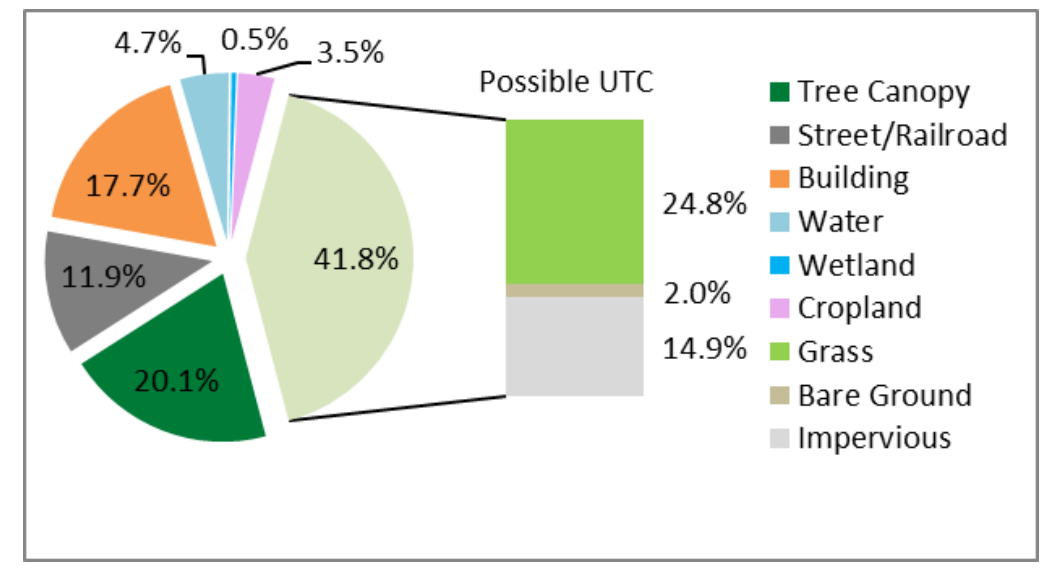

b) 
Table 1. Area, percent cover, and user's accuracy of land cover classes and their standard error (SE) estimates (SE * \pm 1.96 provides $95 \%$ confidence intervals). Area and percent cover are accuracy adjusted estimates.

\begin{tabular}{ccccc}
\hline Class & Area $\left(\mathbf{k m}^{\mathbf{2}}\right)$ & Area $\left(\mathbf{m i}^{\mathbf{2}}\right)$ & Percent cover $(\%)$ & Accuracy $(\%)$ \\
\hline \hline Tree Canopy & $230.6( \pm 17.0)$ & $89.0( \pm 6.6)$ & $20.1( \pm 1.5)$ & $85.1( \pm 4.4)$ \\
Street/Railroad & $136.0( \pm 2.1)$ & $52.5( \pm 0.8)$ & $11.9( \pm 0.2)$ & $98.5( \pm 1.5)$ \\
Building & $202.6( \pm 8.5)$ & $78.2( \pm 3.3)$ & $17.7( \pm 0.7)$ & $95.5( \pm 2.5)$ \\
Water & $53.7( \pm 1.3)$ & $20.7( \pm 0.5)$ & $4.7( \pm 0.1)$ & $97.0( \pm 2.1)$ \\
Wetland & $5.2( \pm 3.3)$ & $2.0( \pm 1.3)$ & $0.5( \pm 0.3)$ & $92.9( \pm 5.0)$ \\
Cropland & $39.8( \pm 0.9)$ & $15.4( \pm 0.4)$ & $3.5( \pm 0.1)$ & $98.5( \pm 1.5)$ \\
Grass & $284.9( \pm 17.9)$ & $110.0( \pm 6.9)$ & $24.8( \pm 1.6)$ & $80.6( \pm 4.9)$ \\
Bare ground & $23.1( \pm 2.0)$ & $8.9( \pm 0.8)$ & $2.0( \pm 0.2)$ & $67.2( \pm 5.8)$ \\
Impervious & $170.9( \pm 10.3)$ & $66.0( \pm 4.0)$ & $14.9( \pm 0.9)$ & $86.6( \pm 4.2)$ \\
\hline Total & $\mathbf{1 1 4 6 . 8}$ & $\mathbf{4 4 2 . 8}$ & $\mathbf{1 0 0 . 0 \%}$ & Overall Accuracy = 87.4\% $( \pm \mathbf{1 . 5} \%)$
\end{tabular}

\section{Change in Urban Tree Canopy}

Comparison of accuracy adjusted estimates of tree canopy for the Miami-Dade Urban Area between 2016 (19.9\%) and 2020 (20.1\%) reveals virtually no overall change in EUTC percent cover. Table 2 and Figure 4 show accuracy adjusted estimates of percent tree canopy with $95 \%$ confidence intervals $(\mathrm{Cl})$ for both analyses. Since confidence intervals are overlapping, the slight gain in canopy between both years cannot be considered statistically significant. The analysis labeled " 2016 " is based on satellite imagery taken between 2011 and 2014 (depending on the location within the Miami-Dade Urban Area), and the 2020 analysis is based on satellite imagery taken between 2019 and 2020.

Table 2. Accuracy adjusted estimates of percent tree canopy in the Miami-Dade Urban Area with $95 \%$ confidence intervals which are computed as Estimated \% \pm standard error $(\mathrm{SE})$ * 1.96 .

\begin{tabular}{ccccc}
\hline Year & Estimated \% & SE (\%) & Lower Cl & Upper Cl \\
\cline { 2 - 5 } 2016 & 19.9 & 1.2 & 17.5 & 22.3 \\
2020 & 20.1 & 1.5 & 17.2 & 23.0 \\
\hline
\end{tabular}


Figure 4. Percent tree canopy in the Miami-Dade Urban Area between 2016 and 2020 with 95\% confidence intervals Comparison of tree canopy (with $95 \% \mathrm{Cl}$ )

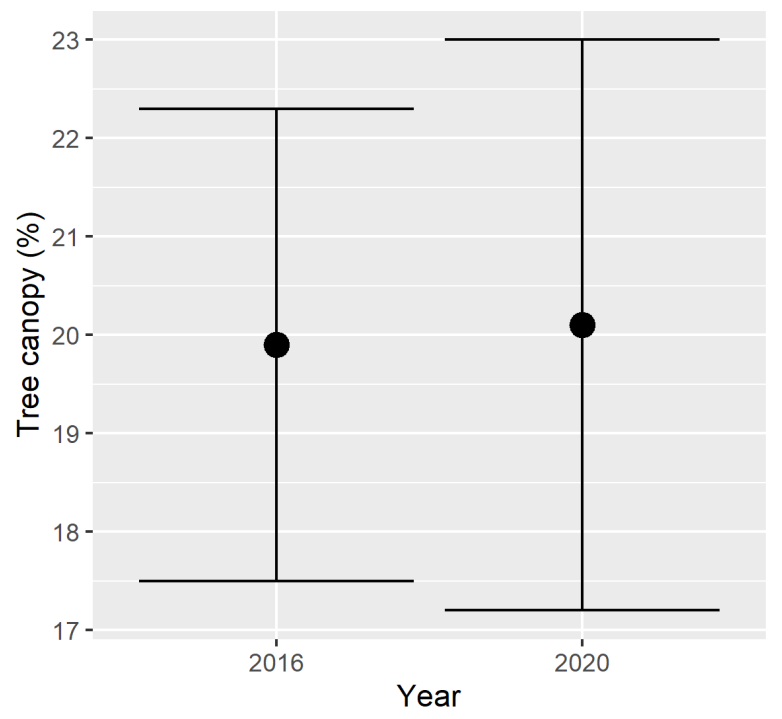

\section{Canopy change maps}

Comparison of landcover classification maps generated for 2016 and 2020 allows one to idenfity tree canopy change (i.e., gain and loss) over the years for selected locations. Figures 5-8 showcase several examples of canopy change for different scenes in the study area. Each figure juxtaposes aerial photographs from different years of landcover classification with a canopy loss/gain map.

Figure 5 visualizes the case of a replaced residential building. It shows the loss of tree canopy originally in front of the old building (1) and its backyard to the east (2). Tree canopy was also replaced with lawn and a paved walkway in the front of the new building (3), and some canopy was lost between the old building and the neighboring building (4). Canopy has grown in front of the neighboring building to the north (5). 
Figure 5. Tree canopy loss and gain for a residential area

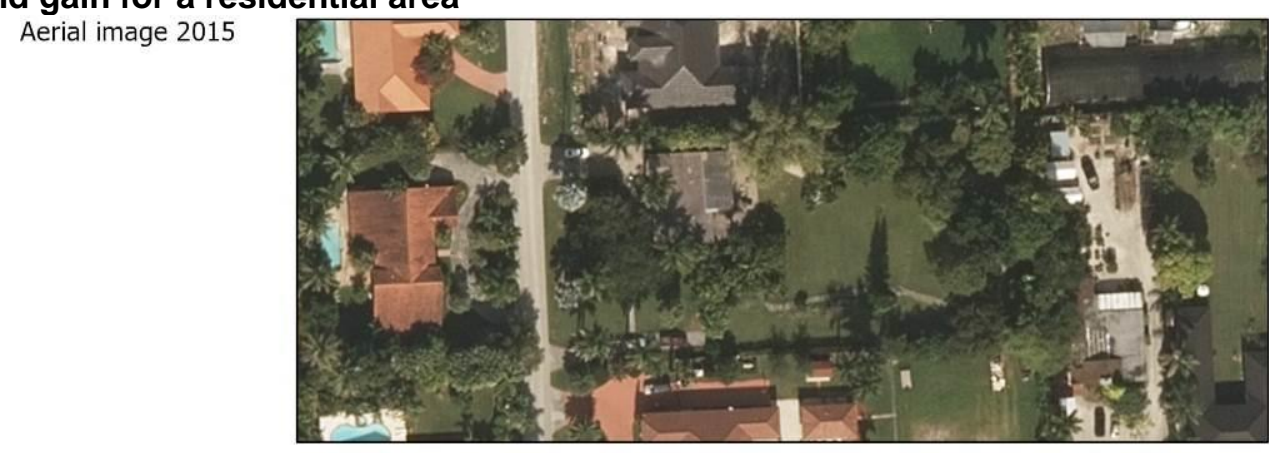

Aerial image 2020
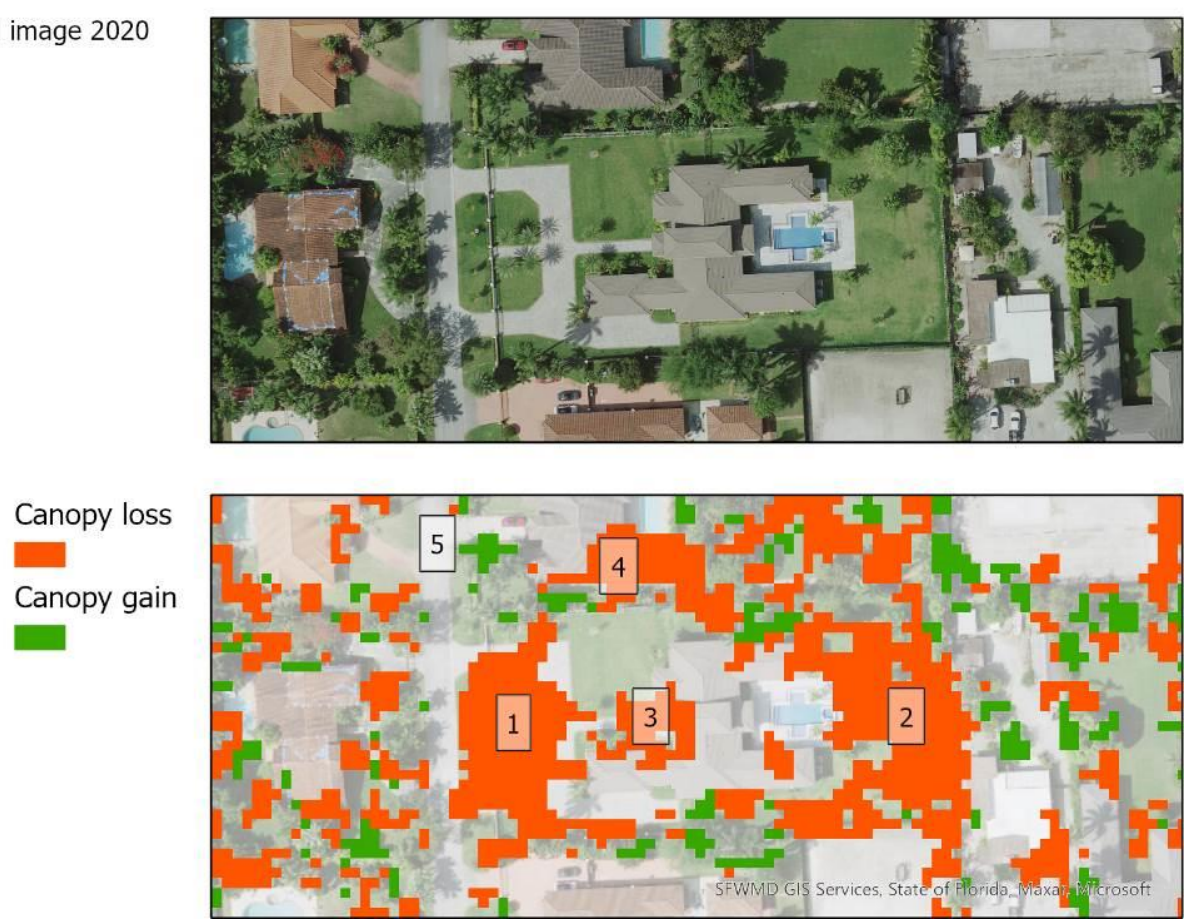

Figure 6 shows the effects of redesigning the Bicentennial Park in Miami. Previous trees to the east were removed and replaced by lawn (1), whereas new trees have been planted along the Frost Museum of Science (2) and to the south of the park (3). 
Figure 6. Tree canopy loss and gain in a Miami park area

Aerial image 2013

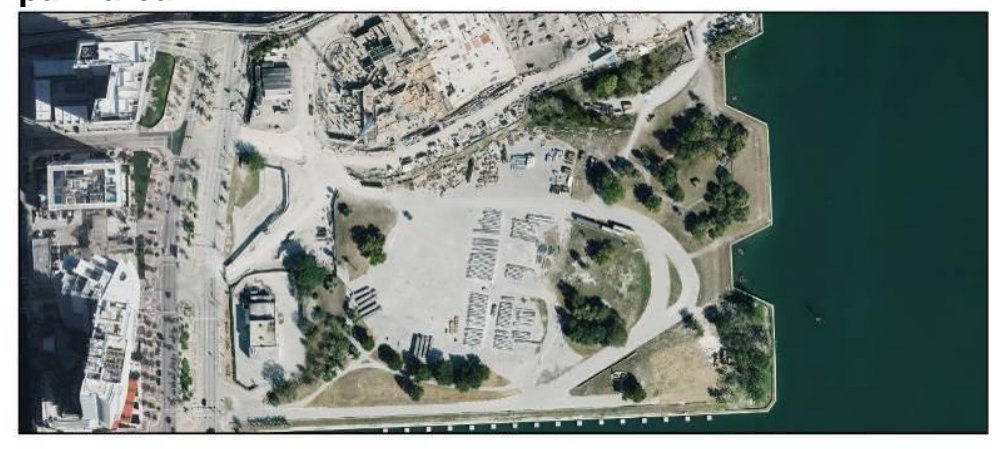

Aerial image 2020
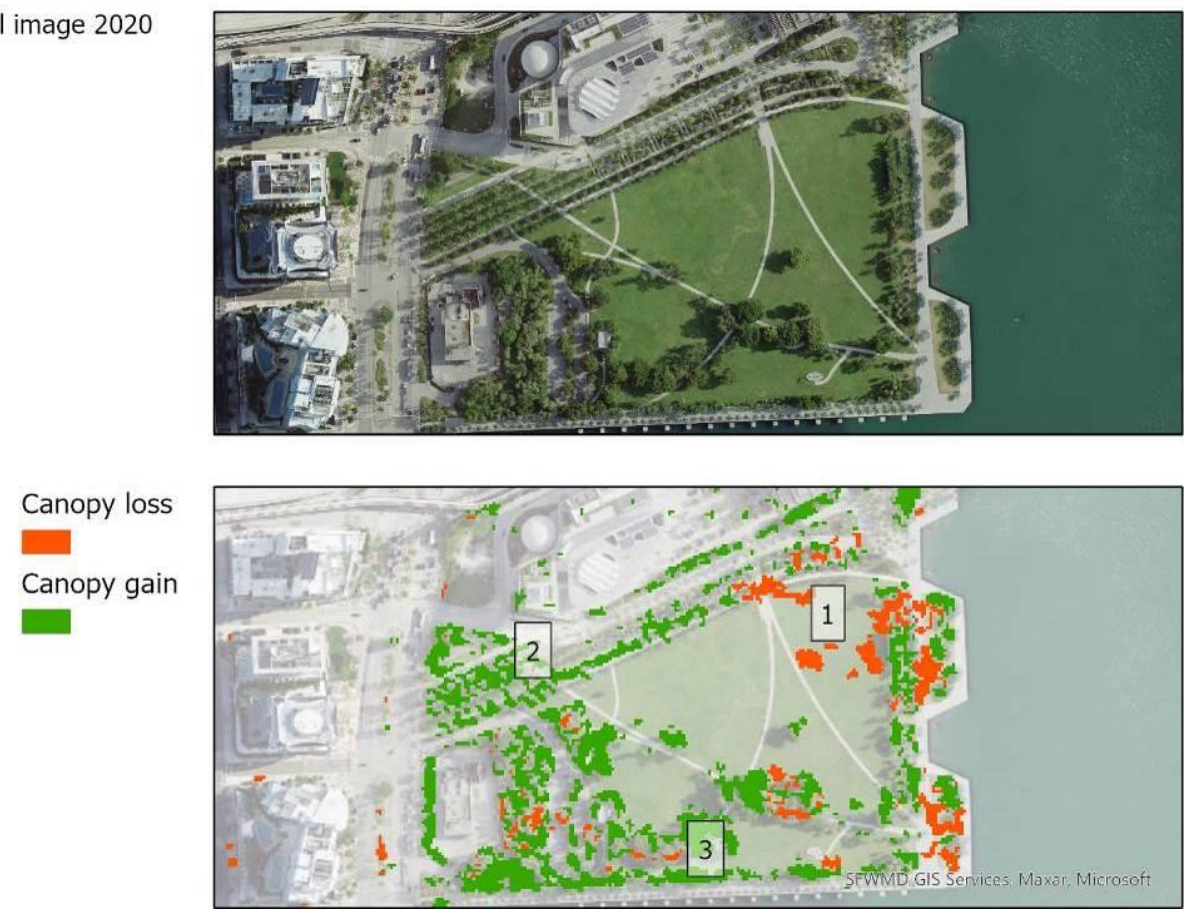

Figure 7 shows the effects of the gradual reforestation of a former sand pit. Whereas the center area shows forest regrowth (1), perimeter areas mainly to the southeast (2) and northeast (3) lost tree canopy over the same time period. 
Figure 7. Tree canopy loss and gain in a wilderness area

Aerial image 2013

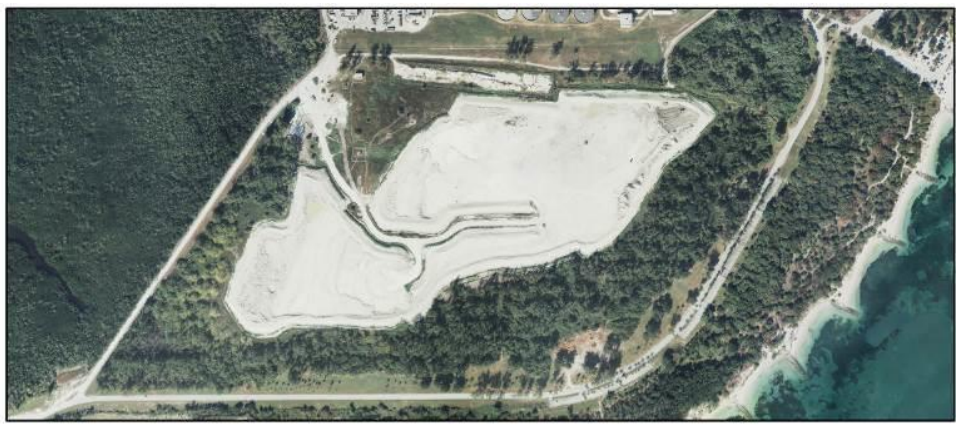

Aerial image 2020
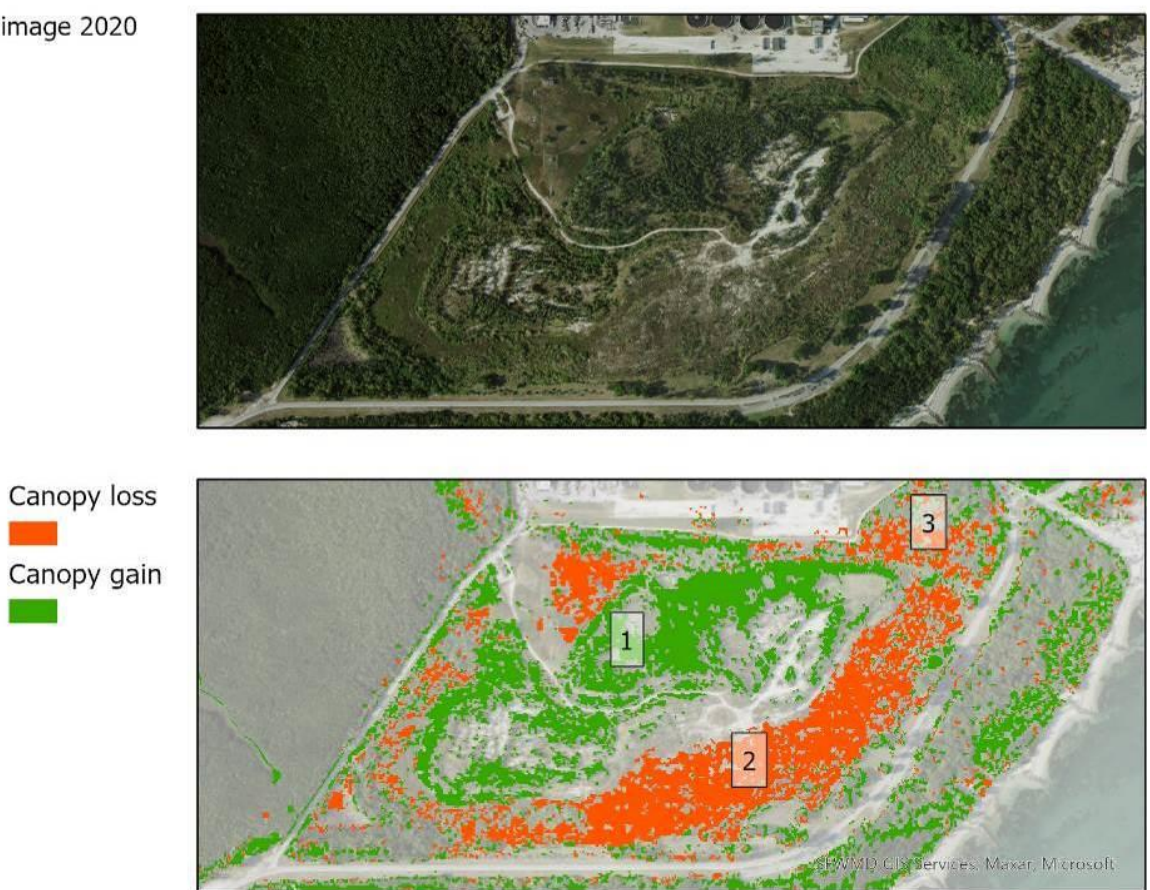

Lastly, tree canopy change around a newly constructed retail area in North Miami is shown in Figure 8. Tree loss is clearly discernible at the location of the new retail center (1) as well as in the newly developed areas to the south (2) and inside and around 
a newly established recreational pond to the east (3). Newly planted trees can be identified around an enhanced access road to the south and on its median (4).

Figure 8. Tree canopy loss and gain around a new retail center

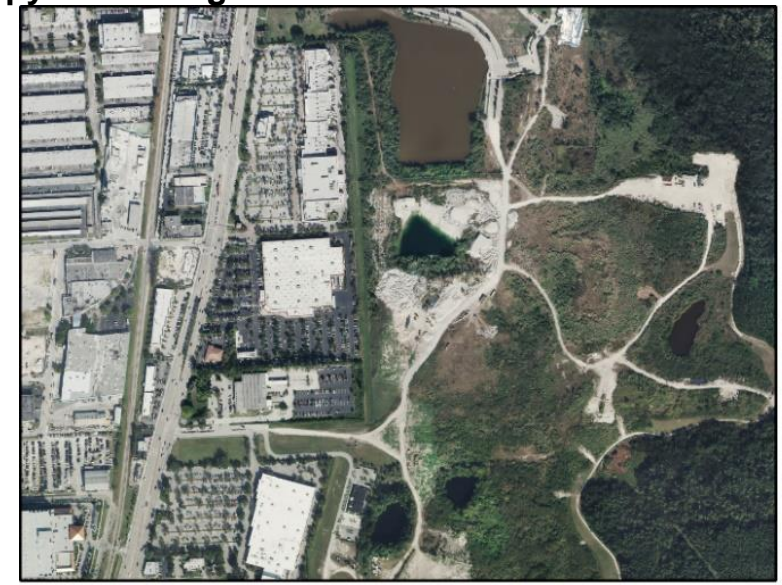

Aerial image 2013

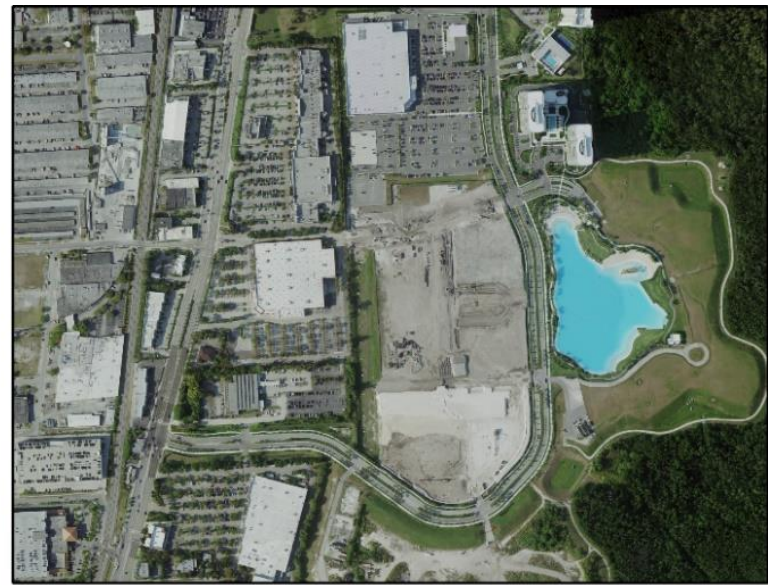

Aerial image 2020

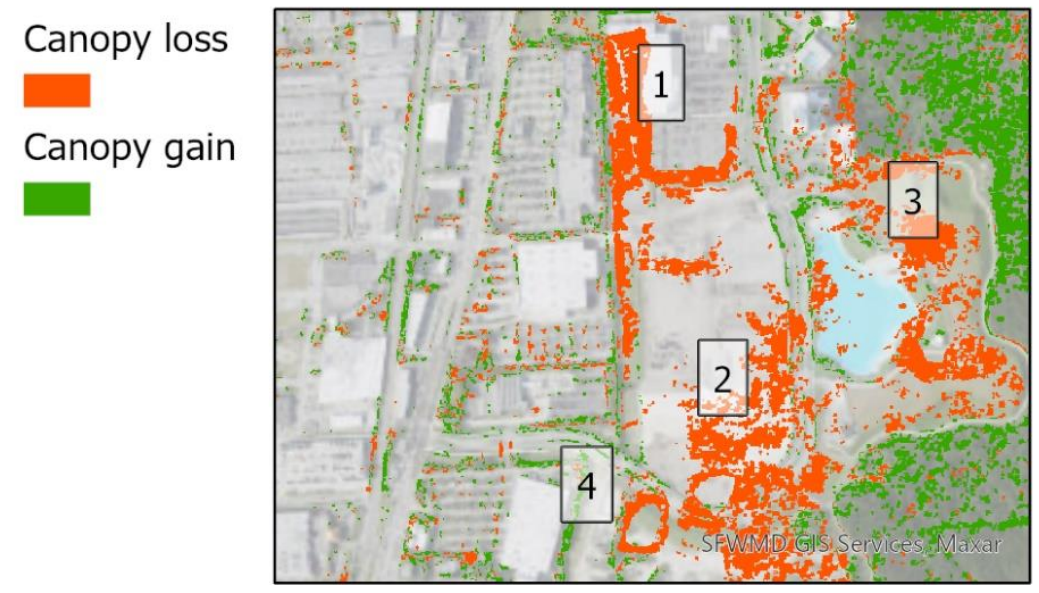




\section{Analysis of Municipalities}

Canopy patterns were analyzed for 34 municipalities falling into the study area (ocean and bay water removed). For the municipality analysis, polygons were clipped to the Urban Development Boundary (Figure 9).

Figure 9. 34 municipalities clipped to the Miami-Dade Urban Area

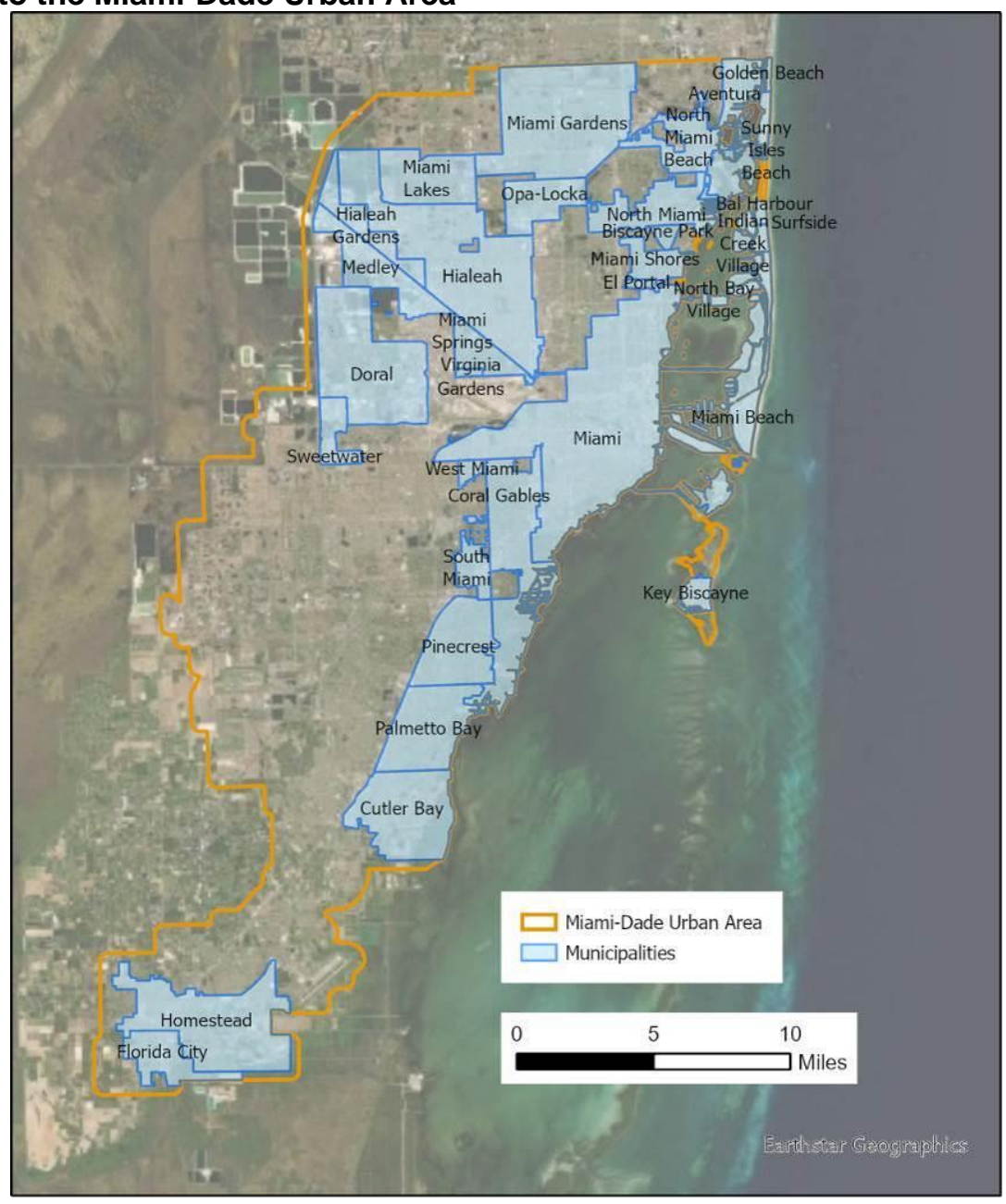


UTC metrics by municipality for 2020 are summarized in Figure 10. The bars in the left figure (Figure 10a) show percent UTC type by municipality, sorted by percent EUTC from largest to smallest. In addition, the bars in the right figure (Figure 10b) show UTC metrics in $\mathrm{km}^{2}$.

The municipalities with the largest percent of EUTC are:

- Coral Gables (44.1\%)

- Pinecrest $(40.1 \%)$

- Cutler Bay (36.5\%)

The municipalities with the smallest percent of EUTC are:

- Medley $(4.6 \%)$

- Hialeah $(7.4 \%)$

- Opa-Locka (8.0\%)

When sorting municipalities by the size of EUTC covered area (Figure 10b), the largest three municipalities are:

- Miami $\left(15.5 \mathrm{~km}^{2} / 6.0 \mathrm{mi}^{2}\right)$

- Coral Gables $\left(15.3 \mathrm{~km}^{2} / 5.9 \mathrm{mi}^{2}\right)$

- Cutler Bay $\left(9.7 \mathrm{~km}^{2} / 3.7 \mathrm{mi}^{2}\right)$ 


\section{Figure 10. UTC metrics summarized by municipality}

a)

UTC Metrics for Municipalities (in \%)

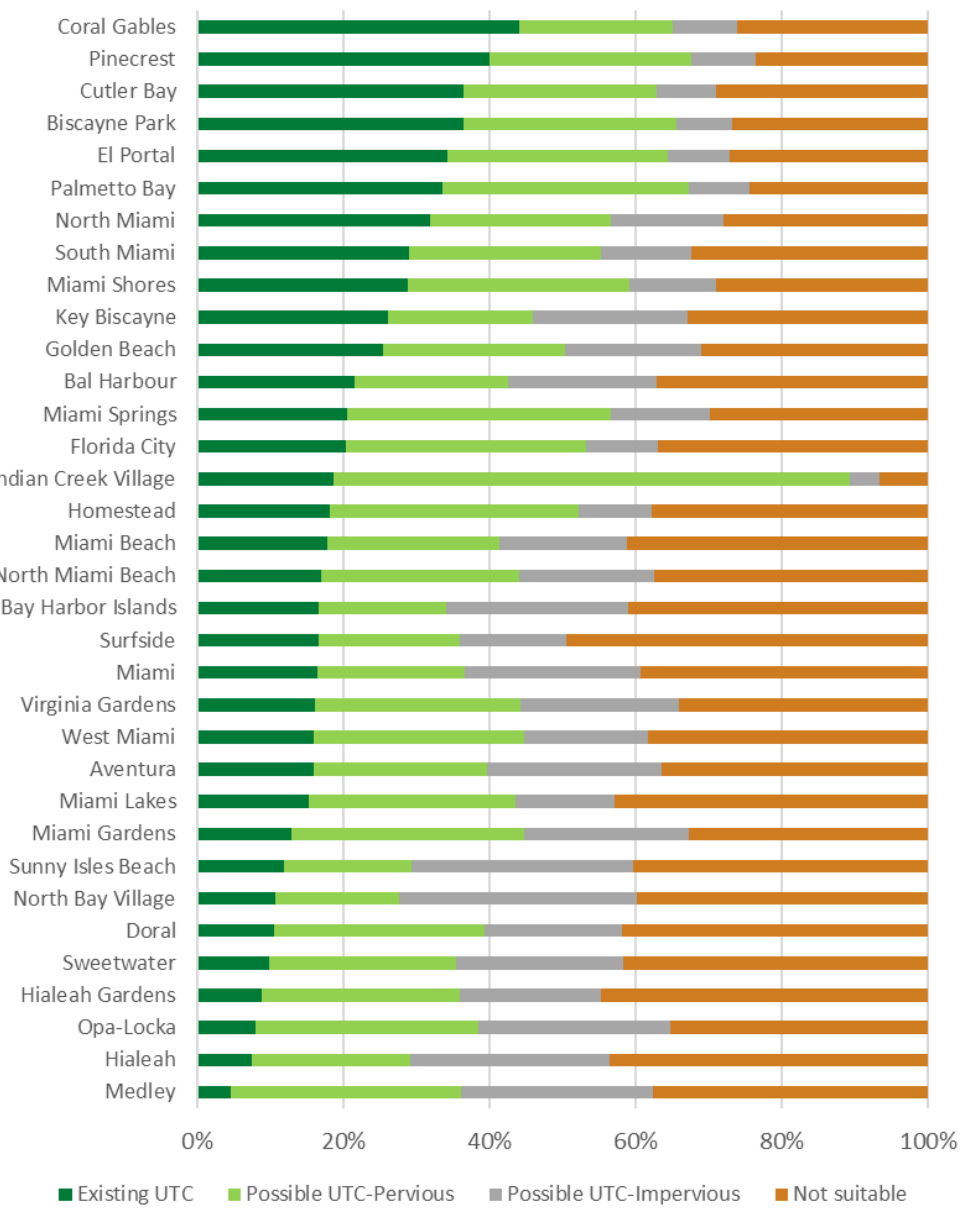

b)

UTC Metrics for Municipalities (in $\mathrm{km}^{2}$ )

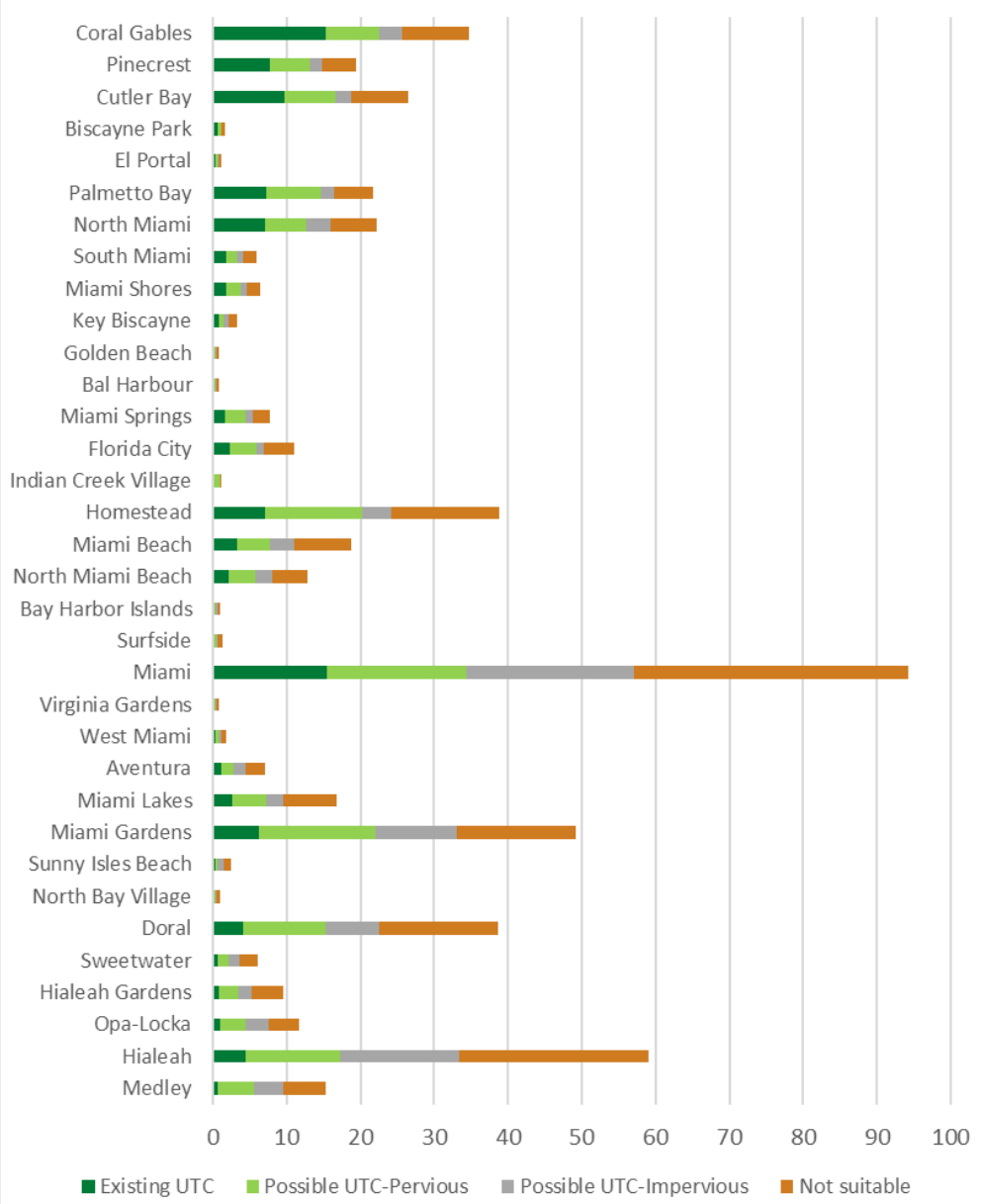

Figure 11 and Figure 12 map the different percent related tree canopy metrics by municipality which demonstrate clear differences in EUTC and PUTC between the different municipalities. Municipalities to the southeast exhibit the highest percentage of EUTC. 


\section{Figure 11. Percent EUTC (a) and PUTC with pervious surface (b); summarized by municipality}

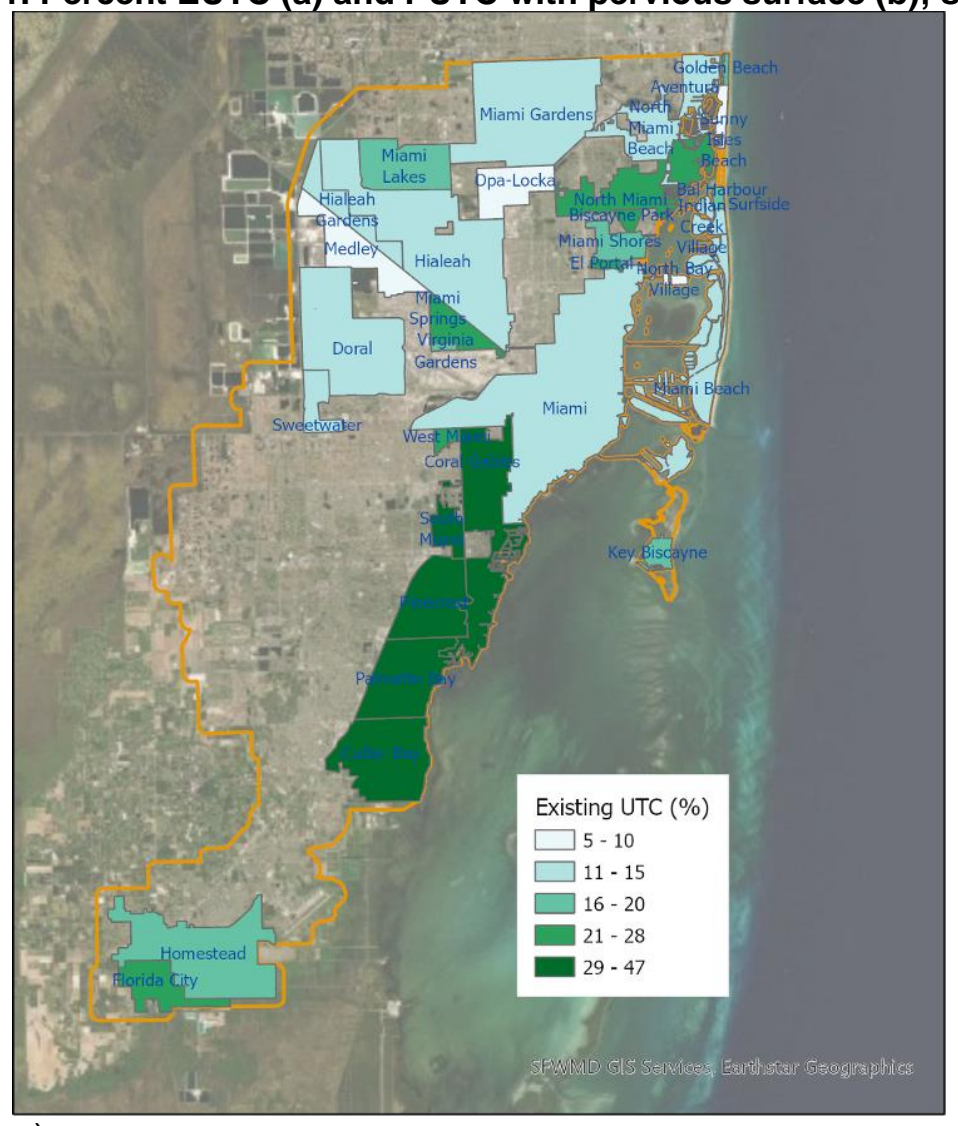

a)

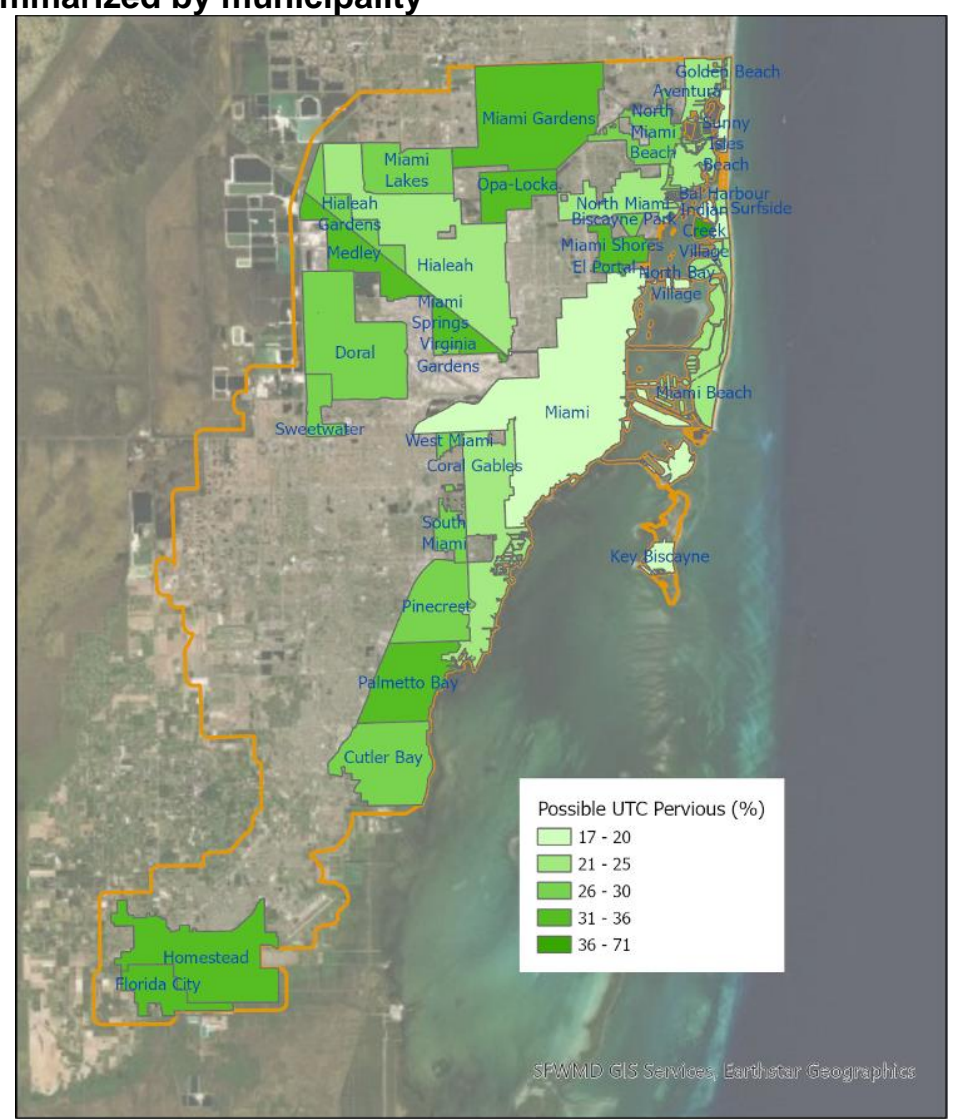

b) 
Figure 12. Percent PUTC on impervious surface (a) and percent not suitable for UTC (b); summarized by municipality

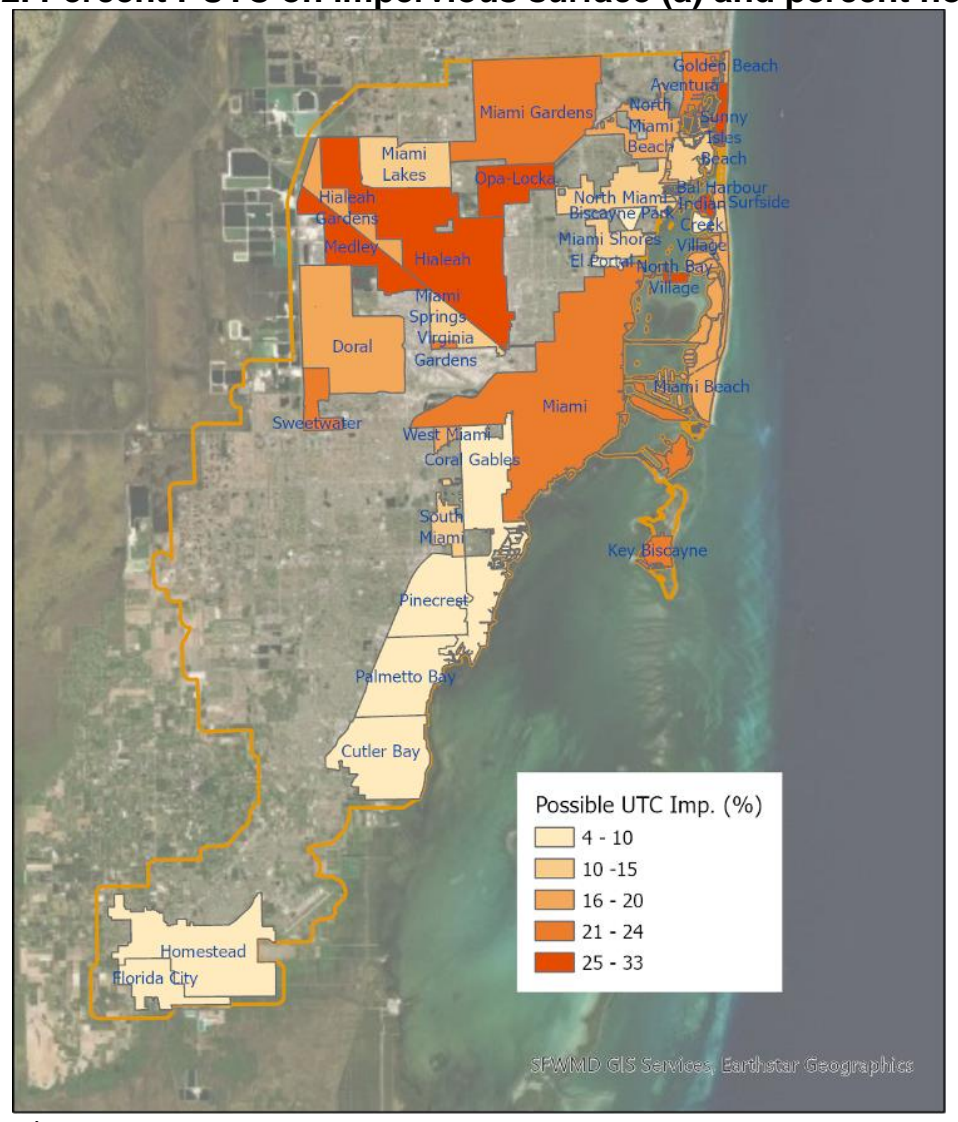

a)

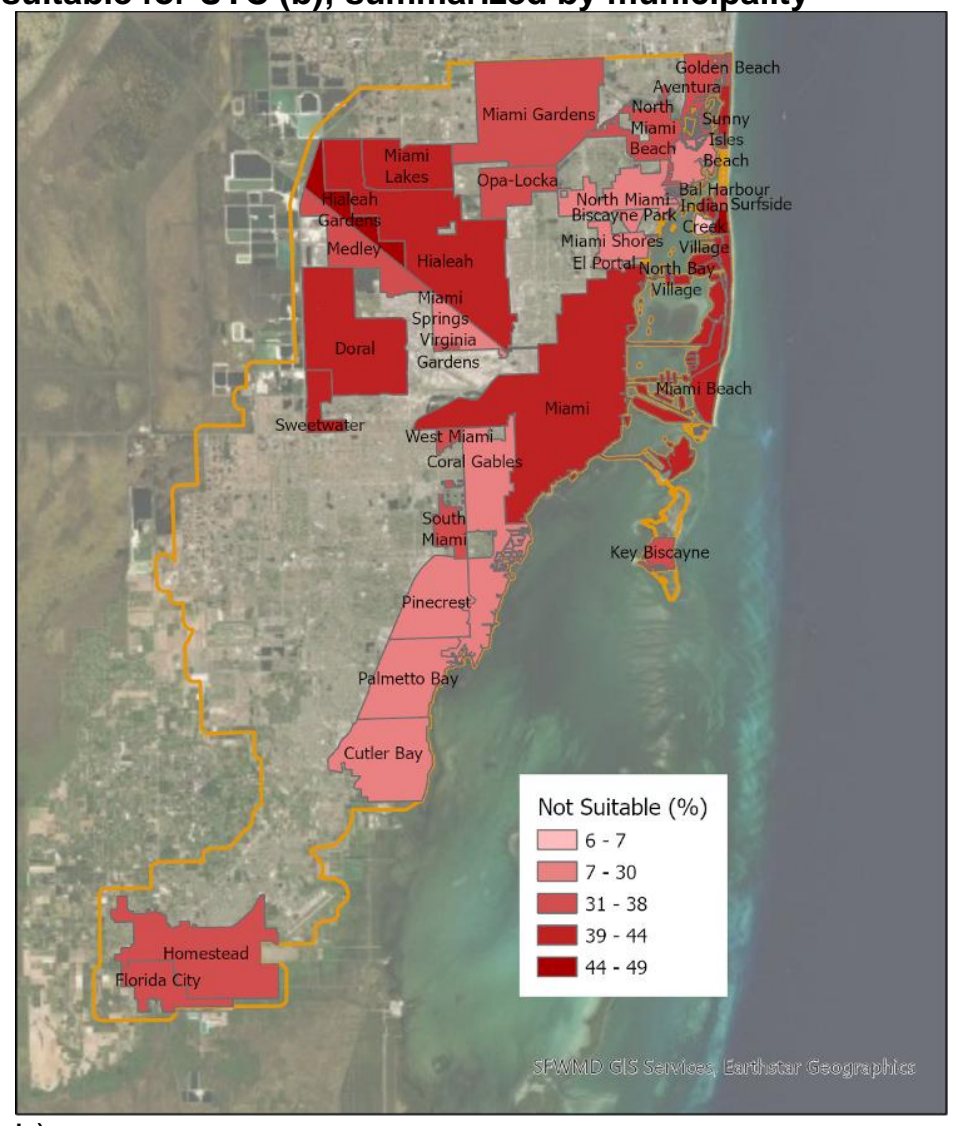

b)

The largest percent of PUTC on pervious surface (grass, bare soil) is found in:

- Indian Creek Village (70.8\%)

- Miami Springs (36.1\%)

- Homestead (34.1\%)

When measuring absolute acreage, the municipalities with the largest area of possible UTC on pervious surface are:

- Miami $\left(18.9 \mathrm{~km}^{2} / 7.3 \mathrm{mi}^{2}\right)$

- Miami Gardens $\left(15.7 \mathrm{~km}^{2} / 6.1 \mathrm{mi}^{2}\right)$ 
- Homestead $\left(13.2 \mathrm{~km}^{2} / 5.1 \mathrm{mi}^{2}\right)$

Undesignated areas in the Miami-Dade Urban area, which is in this context the stretch of land outside any municipality, cover a total of $596 \mathrm{~km}^{2}$, and demonstrate the following UTC metrics (not included in Figure 10):

- EUTC: $16.5 \% / 98.1 \mathrm{~km}^{2} / 37.9 \mathrm{mi}^{2}$

- PUTC (pervious): $32.8 \% / 195.7 \mathrm{~km}^{2} / 75.6 \mathrm{mi}^{2}$

- PUTC (impervious): $12.7 \% / 75.7 \mathrm{~km}^{2} / 29.3 \mathrm{mi}^{2}$

- Not suitable for UTC: $38.0 \% / 226.5 \mathrm{~km}^{2} / 87.5 \mathrm{mi}^{2}$, which includes $31.9 \mathrm{~km}^{2}$ of cropland

\section{Canopy change in municipalities}

Figure 13a shows the gain (positive) or loss (negative) of \% EUTC between 2016 and 2020 for municipalities based on land cover classification, and Figure 13b shows those changes in acreage $\left(\mathrm{km}^{2}\right)$. It should be noted that, since no accuracy assessment of the land cover classification was performed at the municipality level, no statement can be made about whether these changes in tree canopy are significant or not. However, larger change values do possibly indicate substantial structural or land use changes in a given municipality. 


\section{Figure 13. Change in \% EUTC (a) and area $\left(\mathrm{km}^{2}\right)$ EUTC (b) for municipalities between 2016 and 2020}

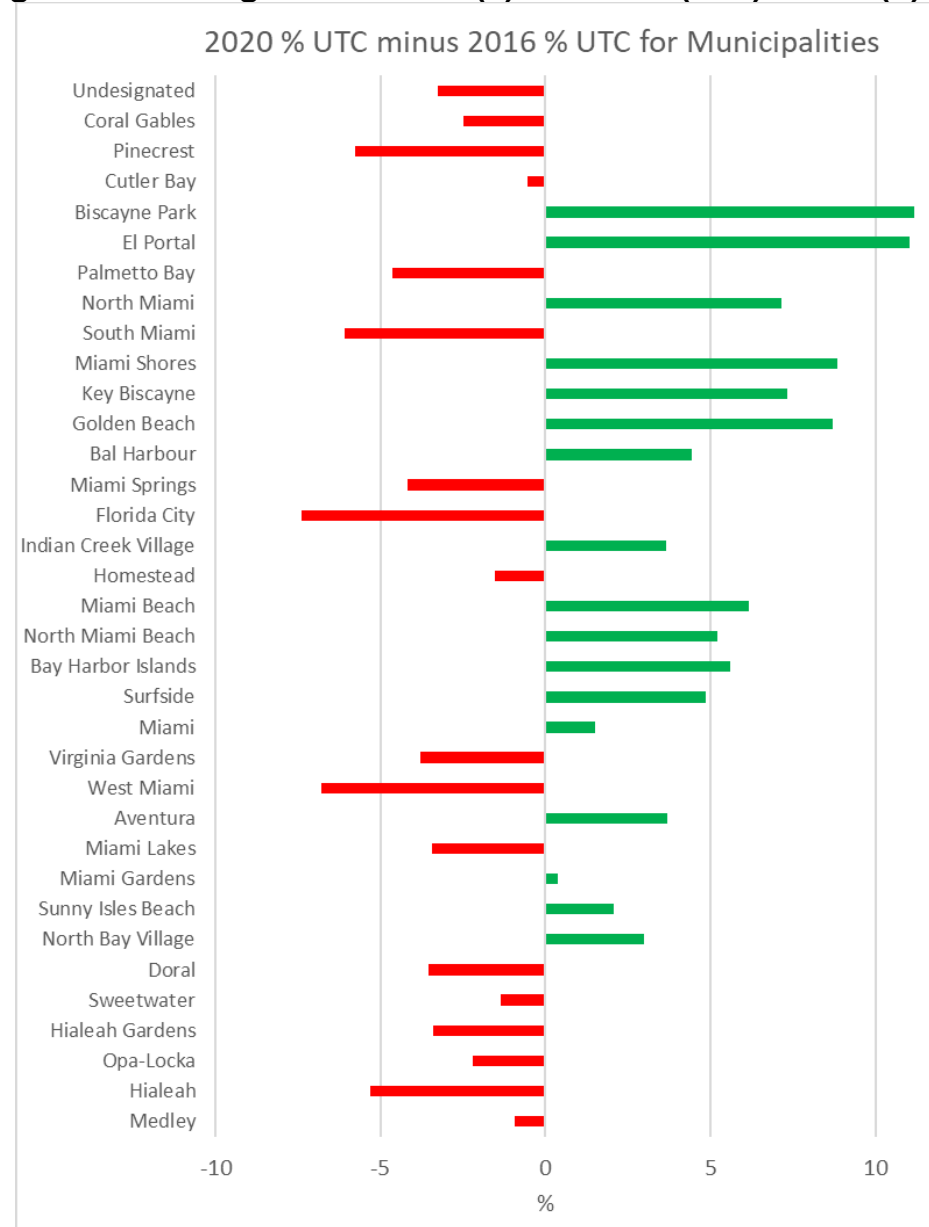

a)

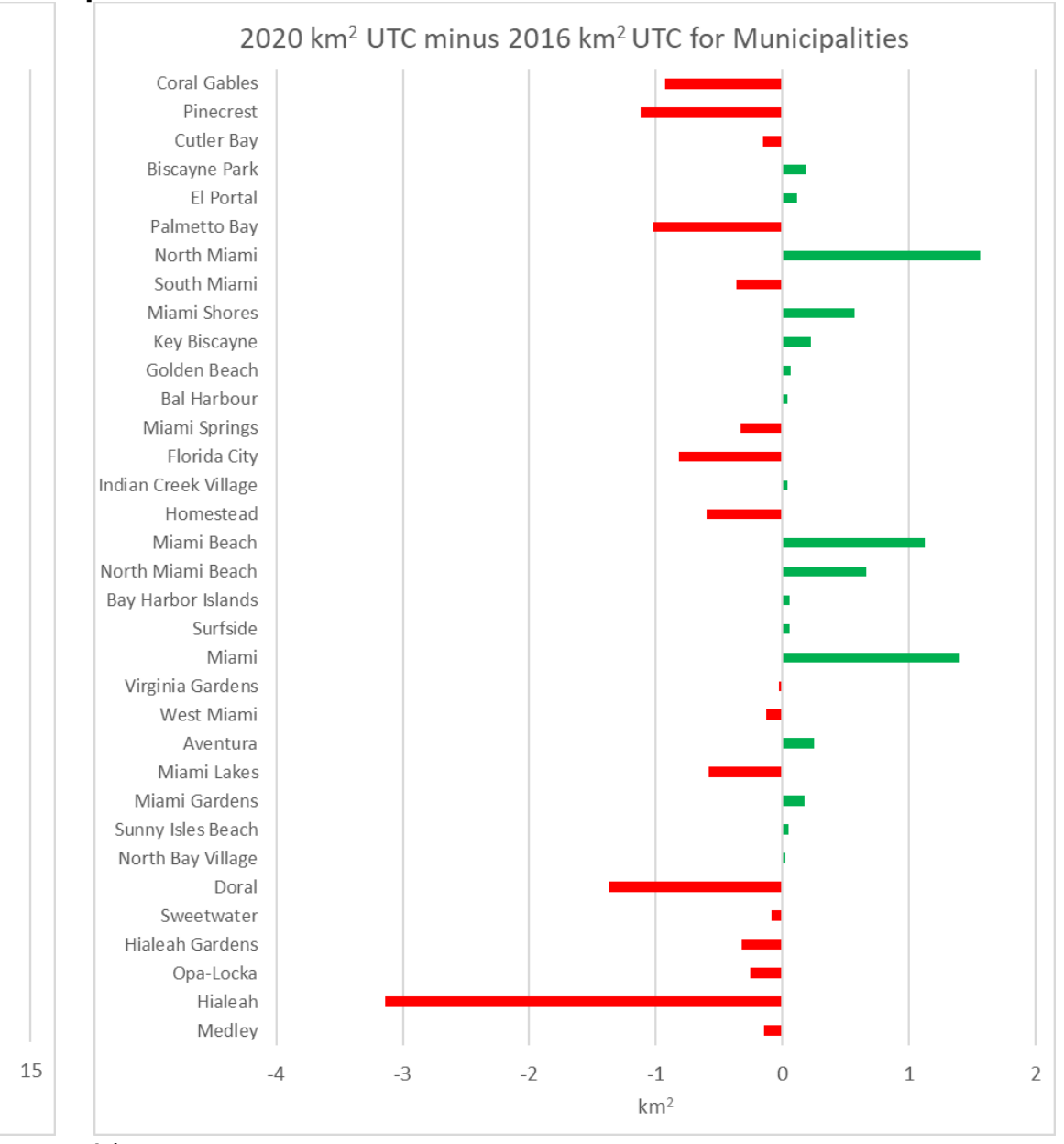

b)

Figure 14 maps the statistics from Figure 13a, suggesting a tree gain taking place mostly in the northeast portion of the Urban Area including beach areas. 


\section{Figure 14. Mapping percent change of EUTC in municipalities}

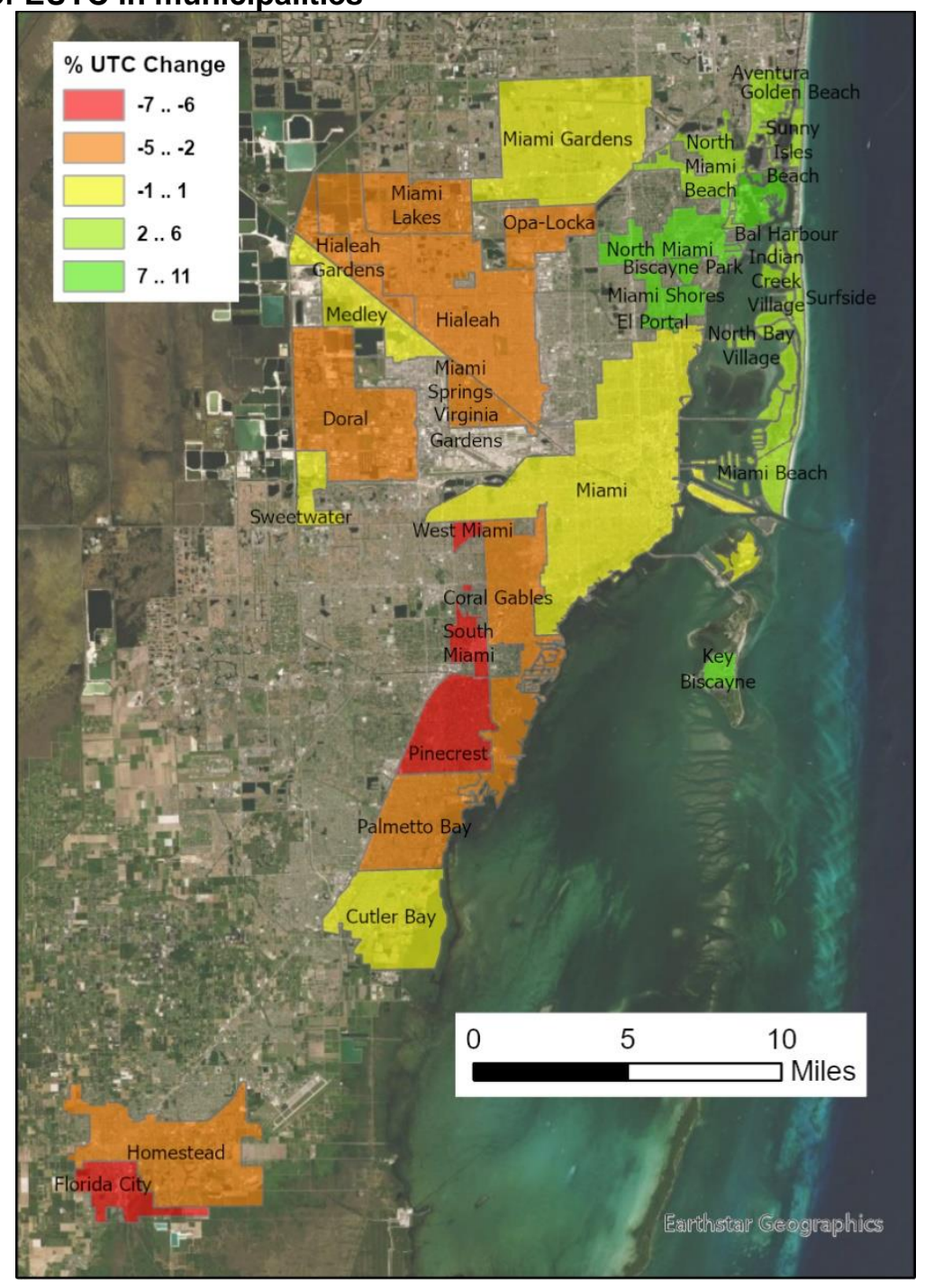


An example of a municipality which gained a high percentage of EUTC is El Portal (see Figure 15), where a mobile home park to the east was taken out and grown over by tree canopy over the years (1). This area contributed to the increase in tree canopy from $23.2 \%(2013)$ to $34.3 \%(2020)$. 


\section{Figure 15. Area with tree canopy gained in El Porta} Aerial image 2013

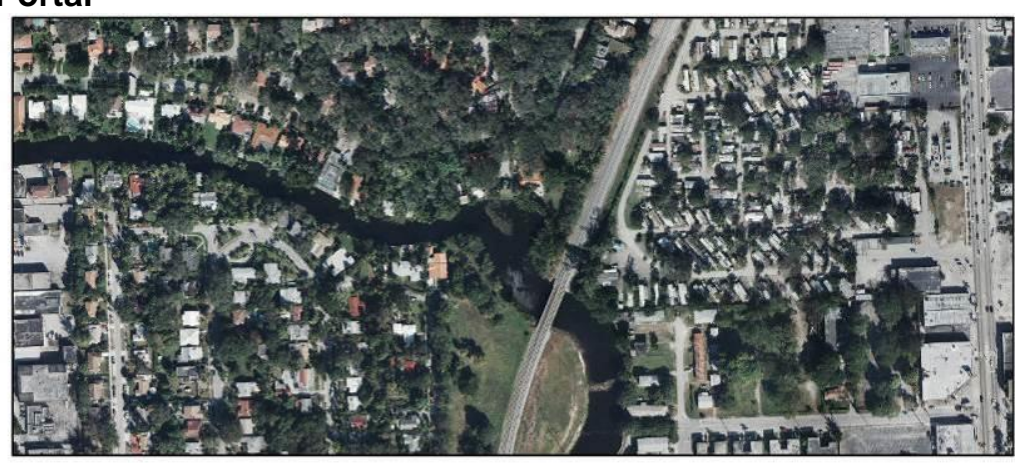

Aerial image 2020
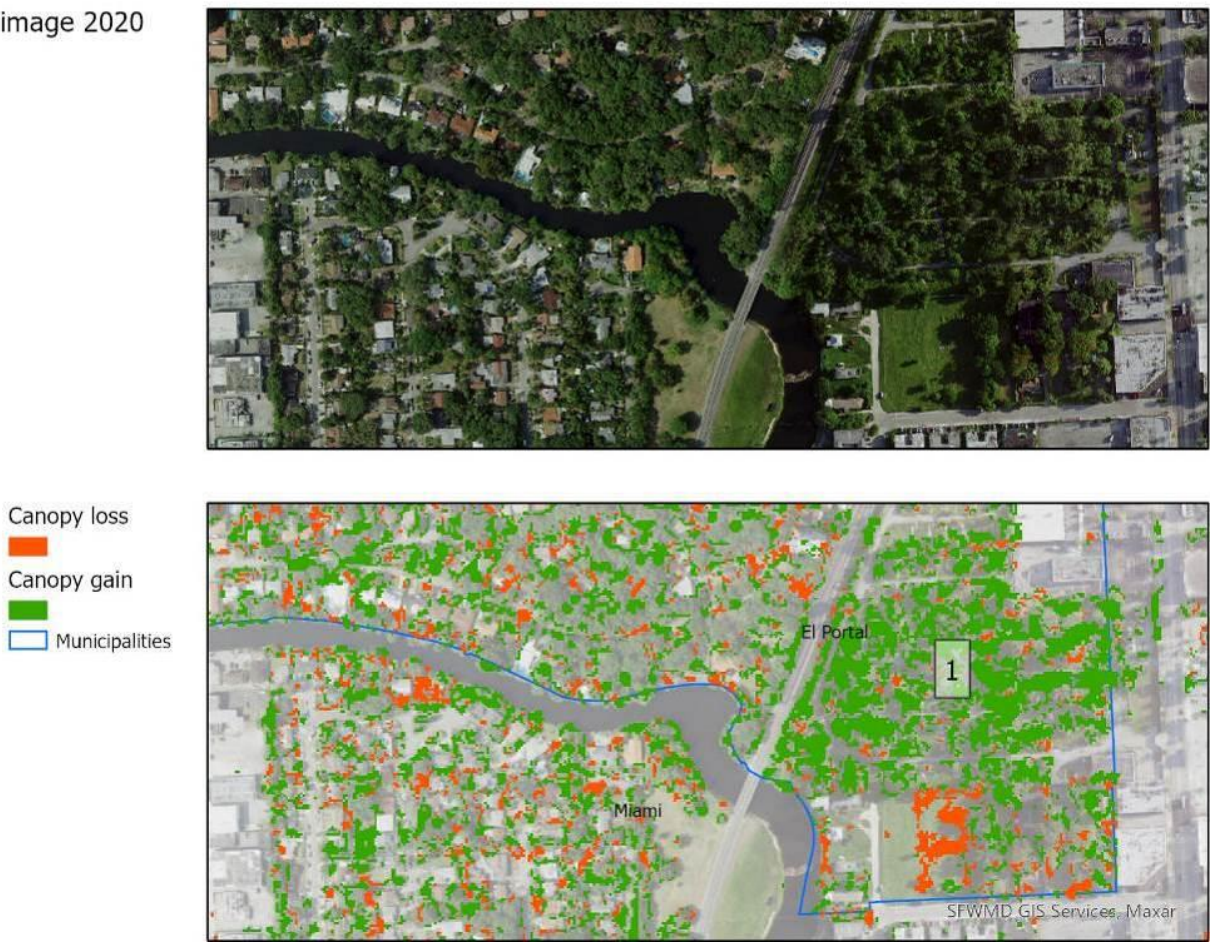
Large-scale construction activities can lead to substantial loss in tree canopy as shown in Figure 16 for the northwestern portion of Hialeah. In this case, tree canopy has given way to construction sites (1), warehouses (2), residential developments $(3,4)$, and deforested wasteland (5). This contributed to a decline in tree canopy from 12.7\% (2016) to 7.4\% (2020).

Figure 16. Area with tree canopy lost in Hialeah
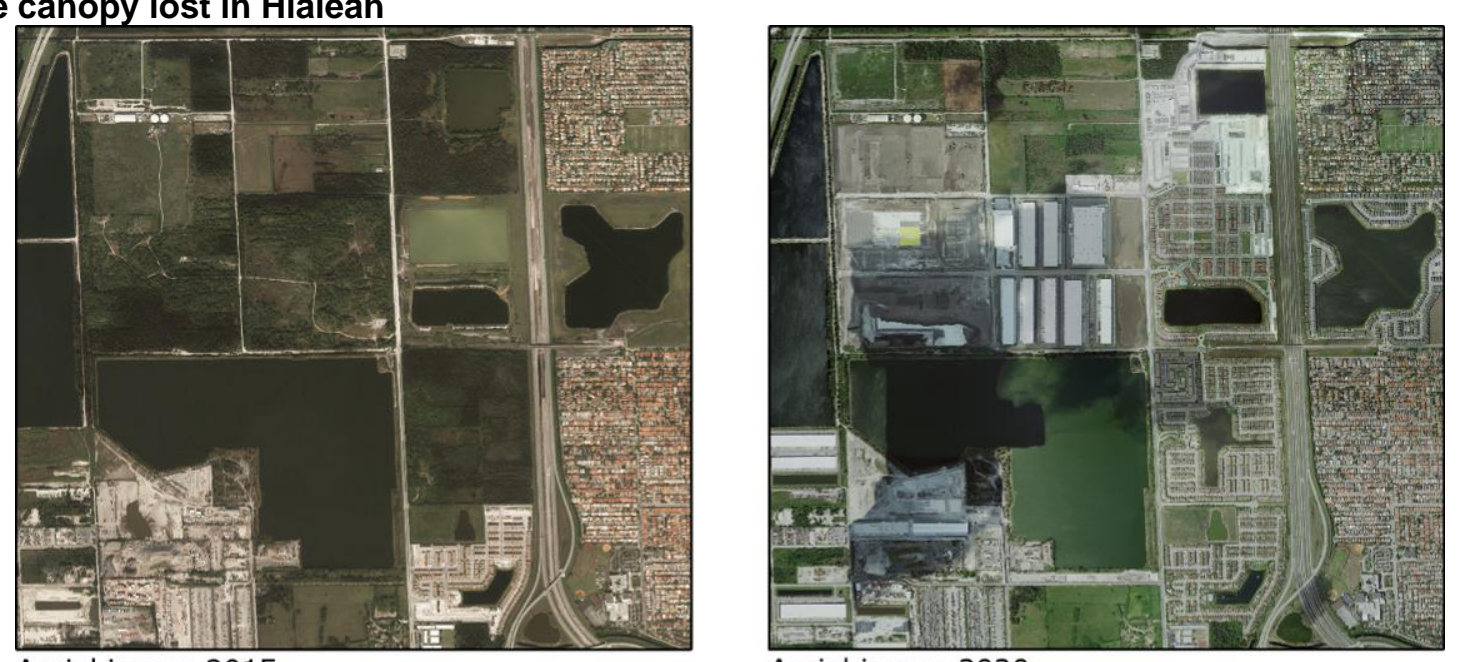

Aerial image 2015

Aerial image 2020

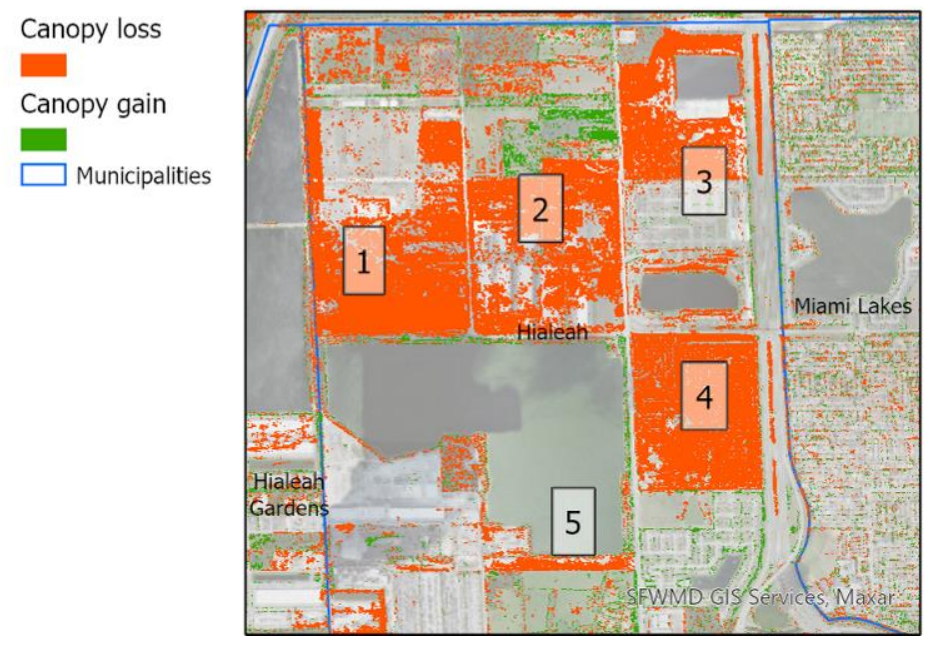


Since Hialeah is a large municipality, the percent loss in EUTC corresponds to the highest loss in tree canopy among all municipalities $\left(3.1 \mathrm{~km}^{2}\right.$ ) when measured in acreage (Figure 13b). Tree canopy loss and gain is less than $2 \mathrm{~km}^{2}$ for all other municipalities.

In undesignated areas, the percent of EUTC coverage declined from 19.7\% to 16.5\% (-3.2\%) between 2016 and 2020 (Figure $13 a$ ), which corresponds to a loss in UTC of $19.5 \mathrm{~km}^{2}$. Undesignated areas are not included in the chart in Figure $13 \mathrm{~b}$ since its acreage value would dwarf all other bars.

\section{Analysis of Census Places}

Canopy patterns were analyzed for 79 census places within the study area. Some census places extend beyond the Urban Development Boundary and were therefore clipped to the Urban Development Boundary for this analysis. Figure 17 summarizes percent UTC type by census place, sorted by percent EUTC from largest to smallest.

The largest percent of EUTC exists in three communities relatively near the coast and south of Miami with large single-family homes and mangrove forests:

- Lakes by the Bay (47.3\%)

- Coral Gables (44.2\%)

- Pinecrest (40.0\%)

The smallest percent of EUTC in a census place can be found in a spatial cluster of adjacent census places located towards the northwest portion of the county:

- Medley (4.1\%)

- Hialeah Gardens (7.1\%)

- Hialeah $(7.2 \%)$

Measured in acreage, the largest coverage of EUTC among the 79 analyzed census places is in:

- $\operatorname{Miami}\left(15.4 \mathrm{~km}^{2} / 6.0 \mathrm{mi}^{2}\right)$

- Coral Gables $\left(15.2 \mathrm{~km}^{2} / 5.9 \mathrm{mi}^{2}\right)$

- Kendall $\left(9.7 \mathrm{~km}^{2} / 3.8 \mathrm{mi}^{2}\right)$

The largest percentage of areas not suitable for UTC initiatives (e.g., houses, roads, wetland, water) are as follows:

- Surfside $(49.0 \%)$ 
- The Hammocks (48.1\%), with a large proportion of agricultural land

- Kendall West (47.5\%)

Undesignated areas outside a census place in the Urban Area exhibit an EUTC of $19.1 \%\left(45.8 \mathrm{~km}^{2} / 27.7 \mathrm{mi}^{2}\right)$ with $40.2 \%(96.5$ $\mathrm{km}^{2} / 37.7 \mathrm{mi}^{2}$ ) of land rendered unsuitable for UTC initiatives. 
Figure 17. UTC metrics summarized by census places

a)

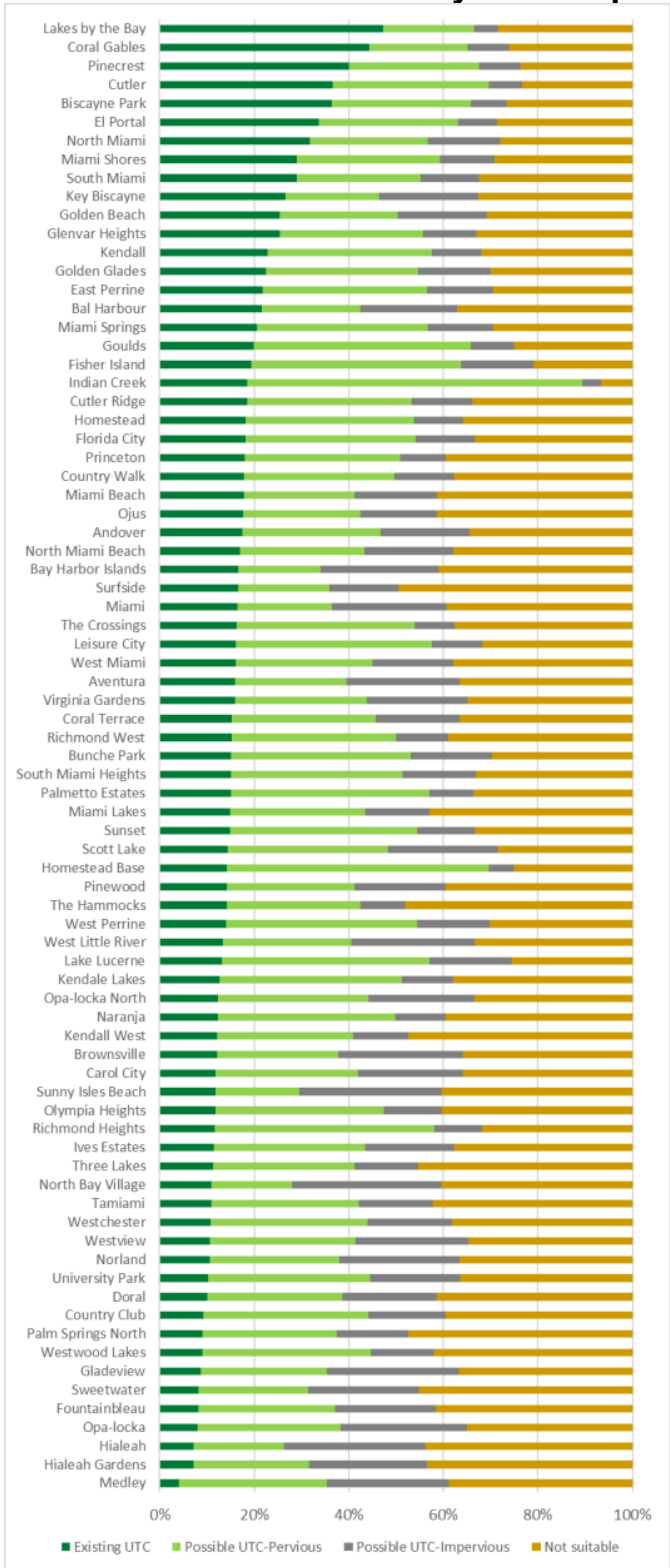

b)

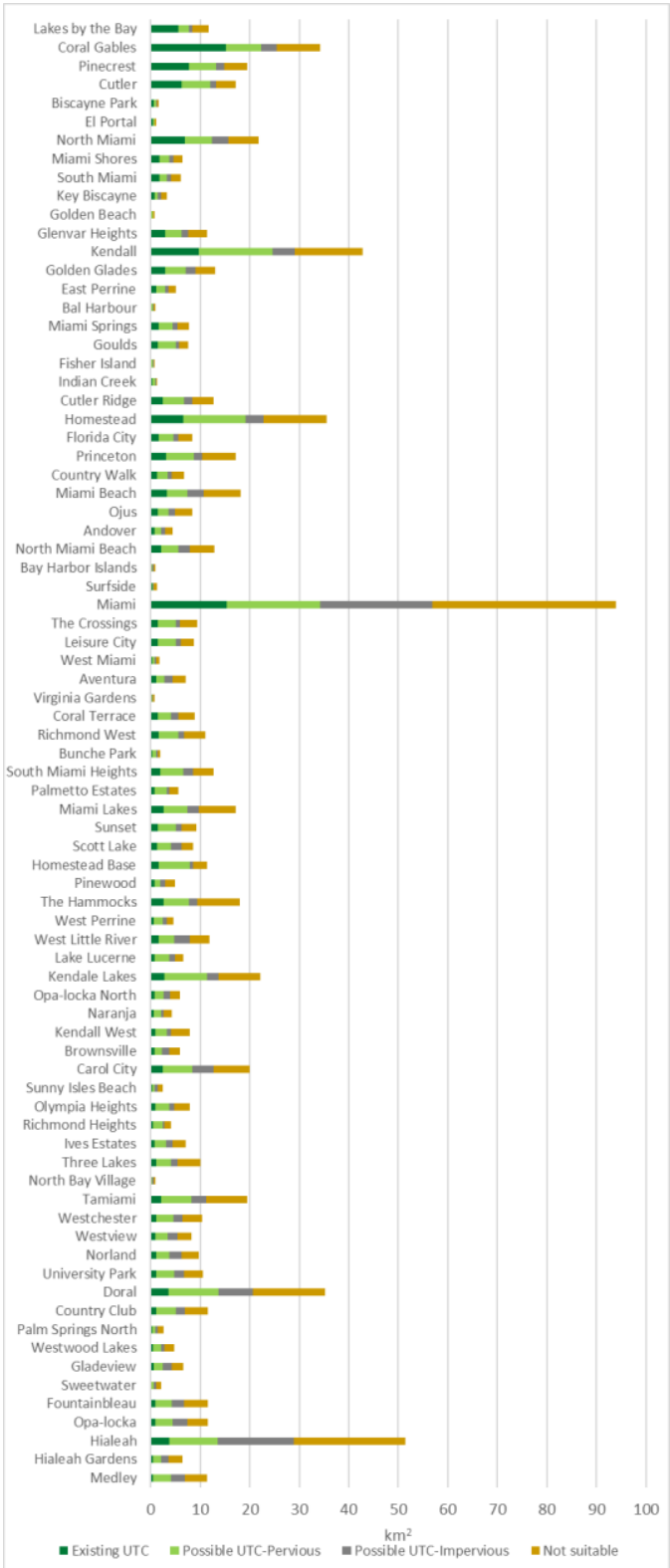


Figure 18 maps the two conceptual ends of urban tree canopy analysis, namely percent EUTC (a) and percent not suitable for UTC (b), summarized by census place. Indian Creek is an outlier in the right figure in the sense that it has the lowest percentage of land not suitable for UTC. This can be attributed to the layout of Indian Creek where almost the entire island consists of residential houses wrapping around a golf course in the middle.

\section{Figure 18. Percent EUTC (a) and non-suitable area for UTC (b) by census place}

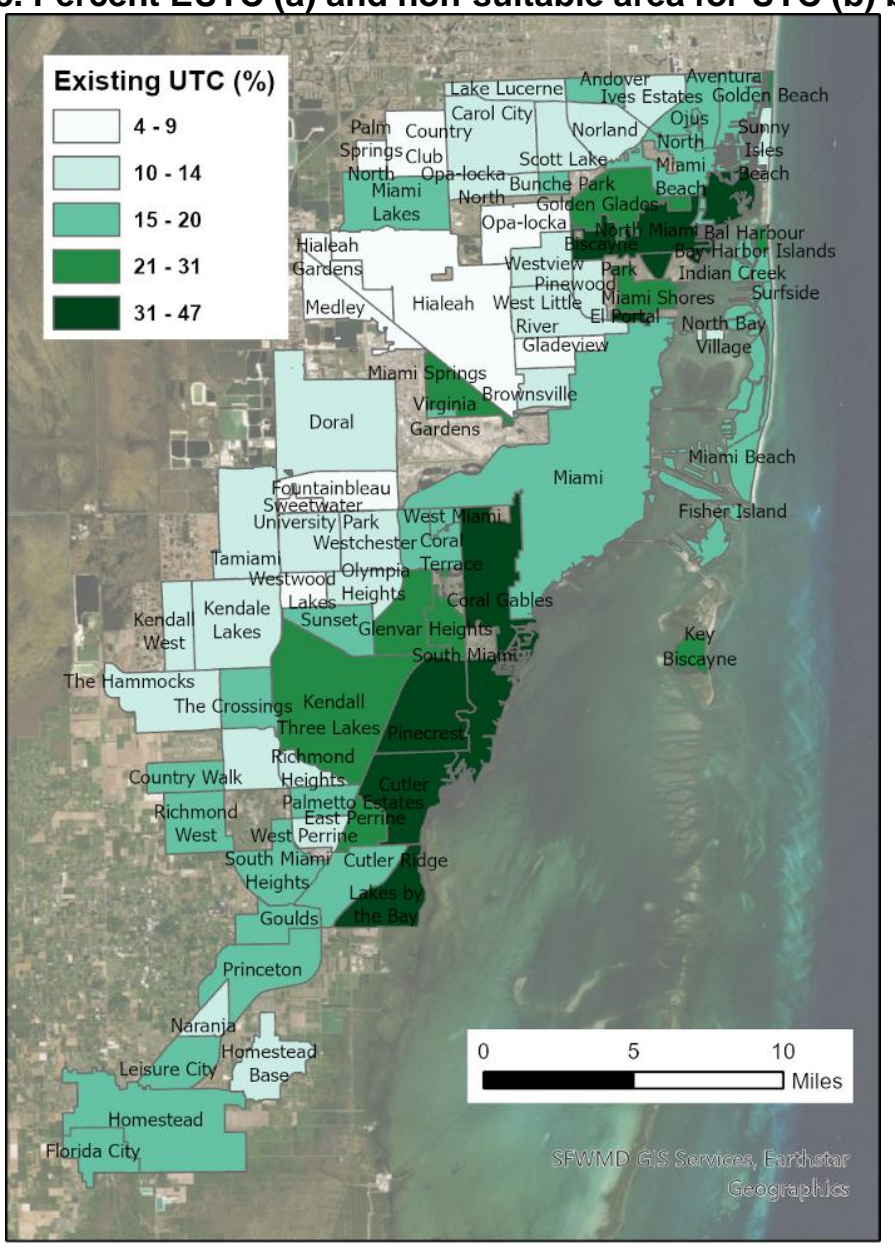

a)

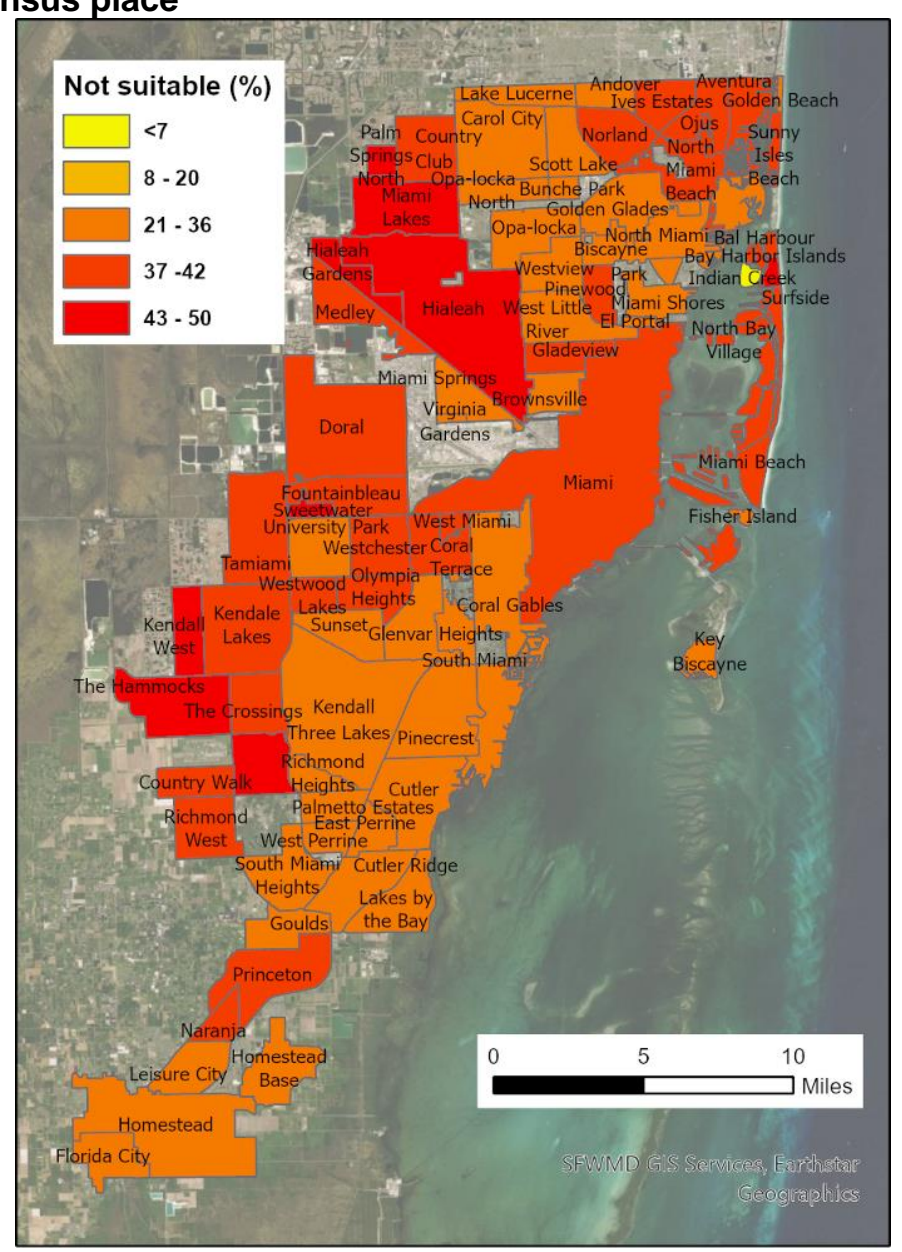

b) 


\section{Canopy change in census places}

Comparison of land cover between the 2016 and 2020 classification maps yields tree canopy loss and gain in percent (Figure 19a) and in $\mathrm{km}^{2}$ (Figure 19b) for census places. As the largest census place, Miami exhibits an increase of $1.5 \%\left(1.4 \mathrm{~km}^{2}\right)$ in EUTC. The largest loss of tree canopy in acreage can be observed in Kendall $\left(2.0 \mathrm{~km}^{2}\right)$ corresponding to a drop in EUTC by $4.7 \%$. Undesignated areas outside a census place in the Urban Area experience a $5.1 \%$ loss in UTC, corresponding to $12.3 \mathrm{~km}^{2}$. 
Figure 19. Change in percent (a) and $\mathrm{km}^{2}$ (b) of UTC in census places

a)

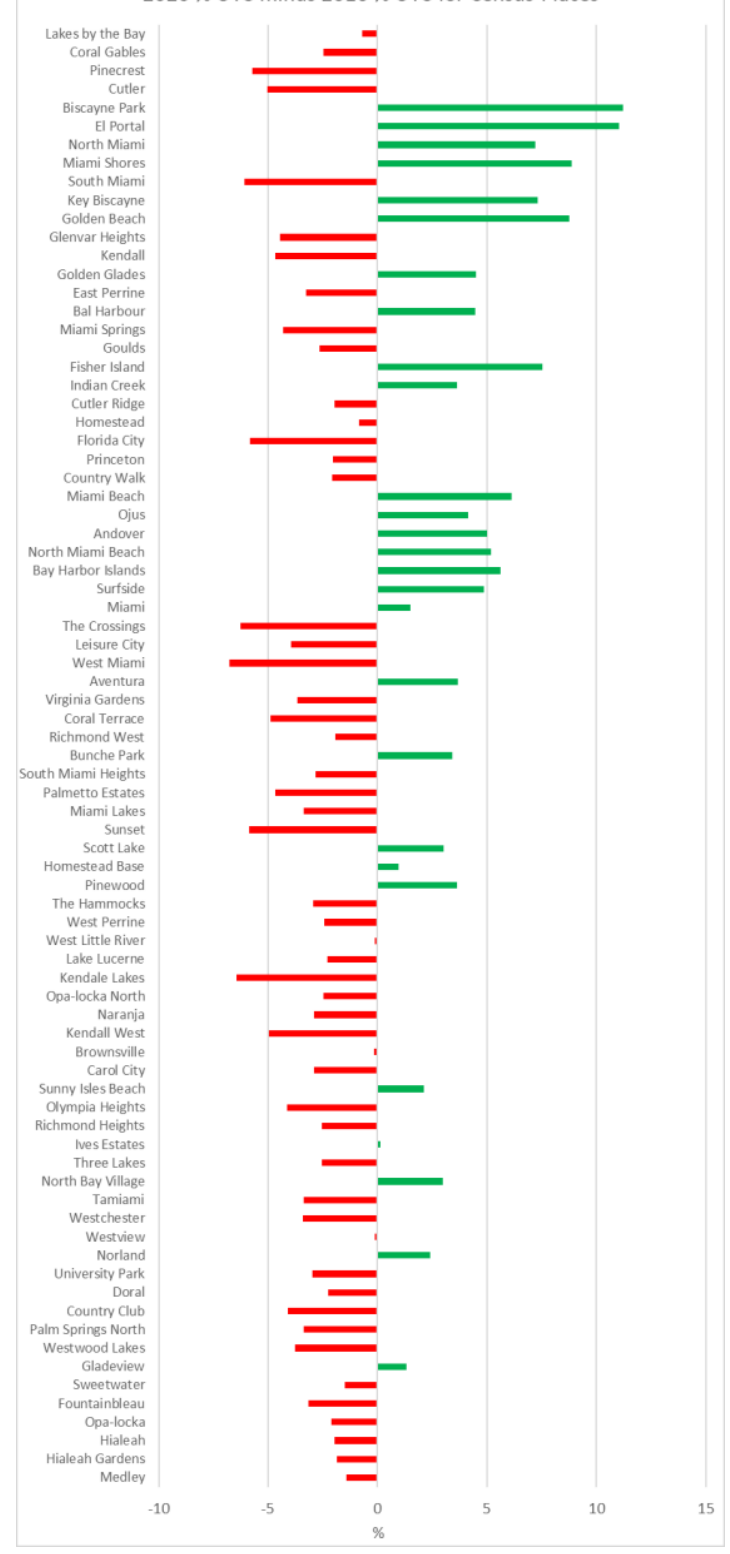

b)

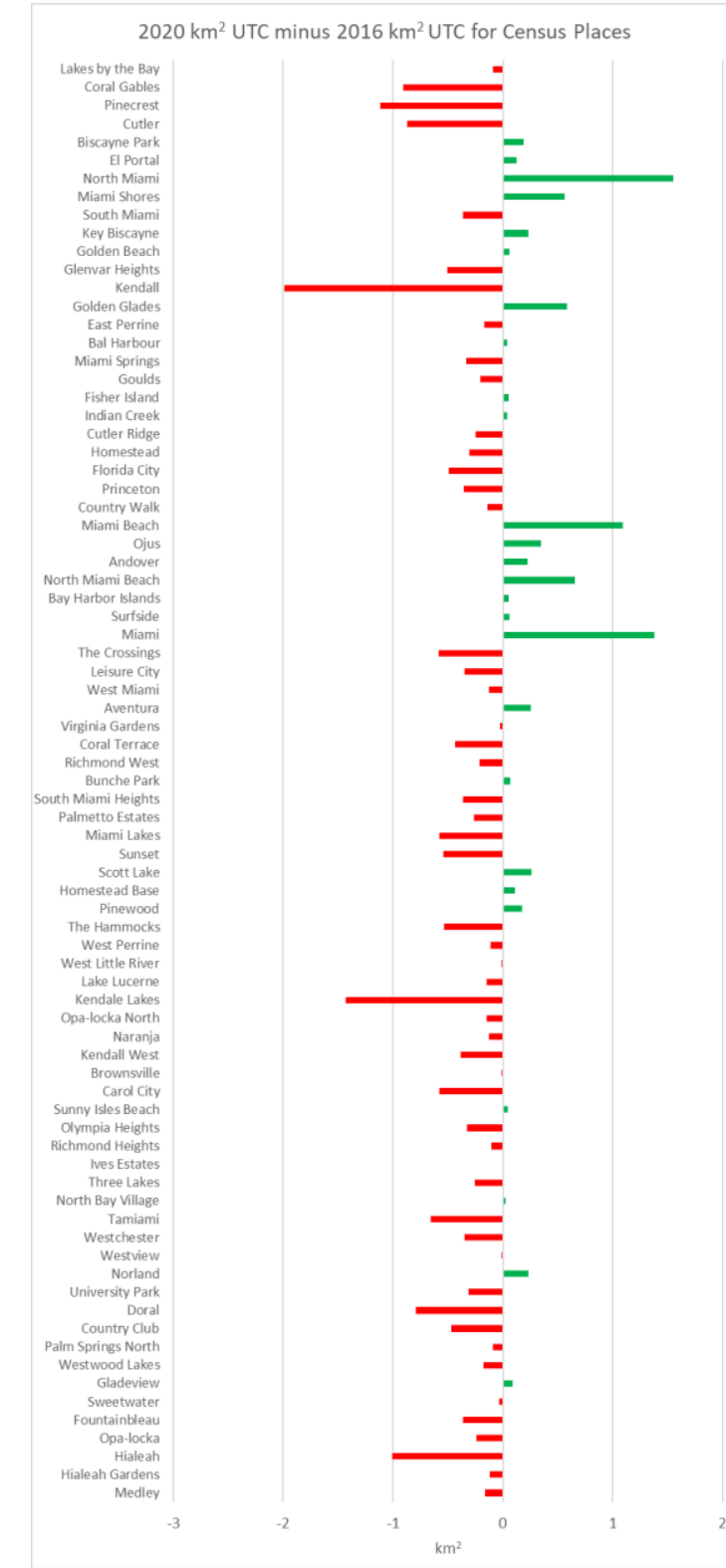


Figure 20, which maps the statistics from Figure 19a, suggests relative tree gain taking place mostly in the northeast portion of the Urban Area including beach areas. Meanwhile, new construction further inland tended to reduce EUTC.

\section{Figure 20. Mapping percent change of EUTC in census places}

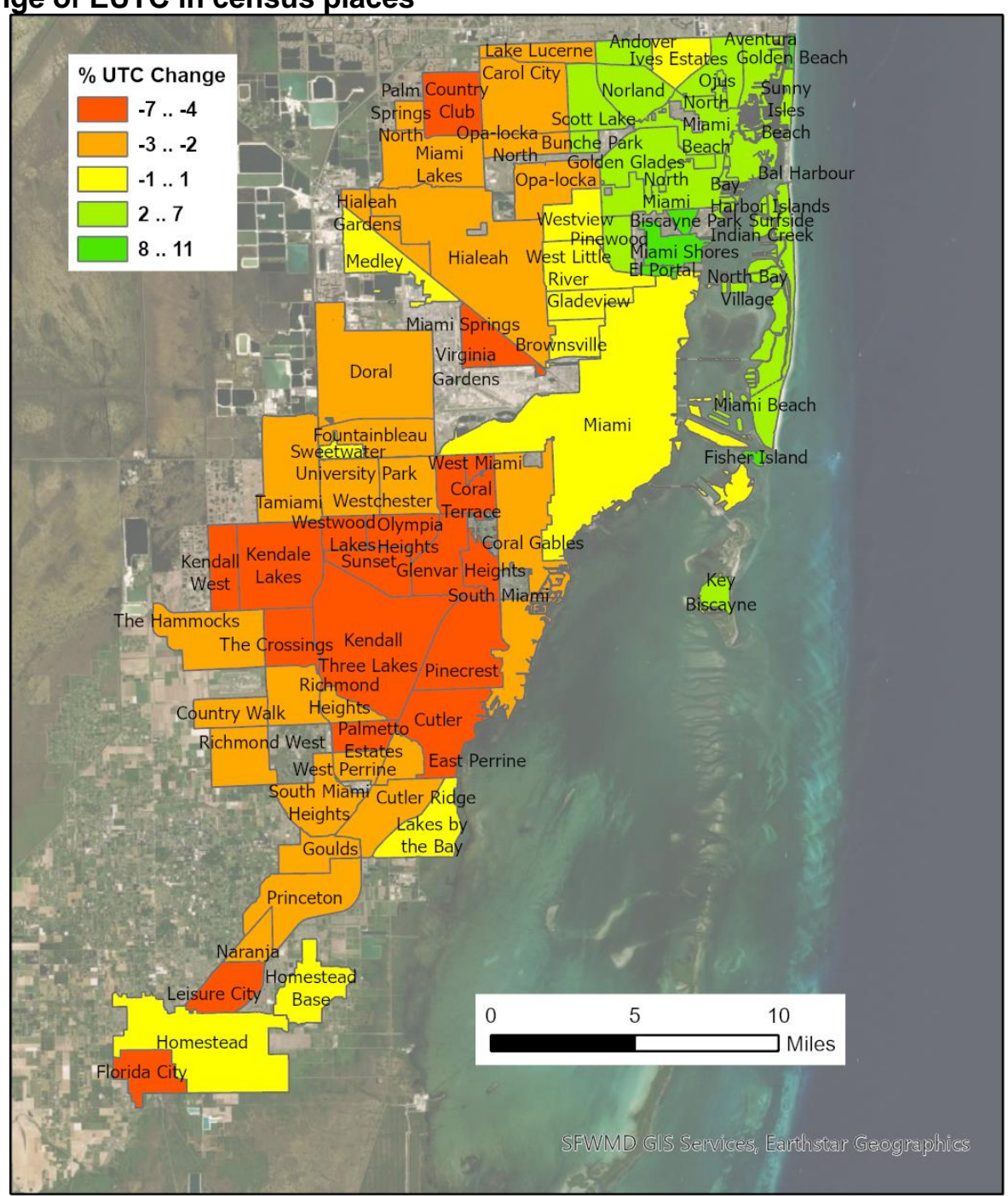




\section{Analysis of Commission Districts}

Canopy patterns were analyzed for the Urban Area portions of 13 commission districts in Miami-Dade County (Figure 21).

Figure 21. Commission districts clipped to the Miami-Dade Urban Area

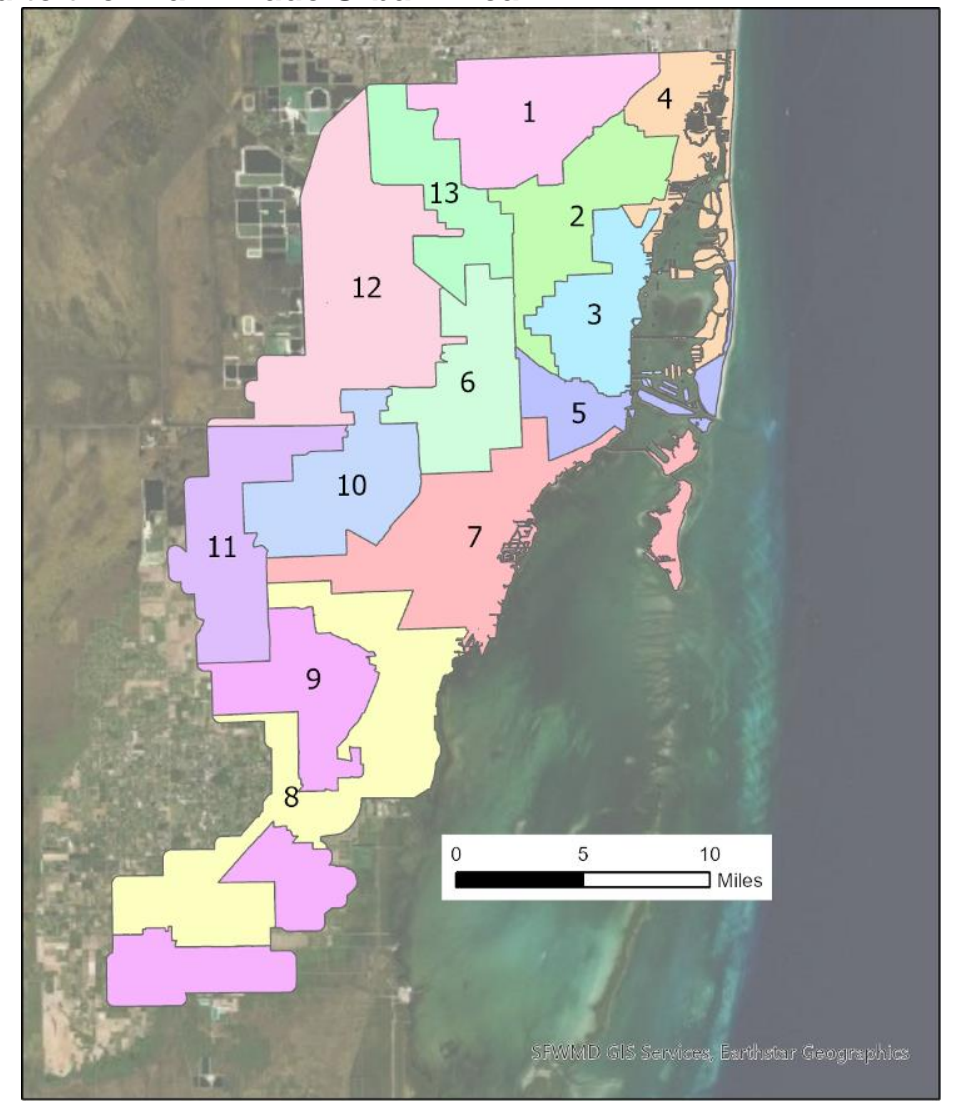

UTC metrics by commission district are summarized in Figure 22. The bars in the left figure (Figure 22a) show percent UTC type by commission district, whereas the right figure (Figure 22b) shows the corresponding areas expressed in $\mathrm{km}^{2}$. Since the analysis 
covers only areas within the Urban Development Boundary and many commission districts extend beyond the Urban Development Boundary, the areas denoted in Figure $22 \mathrm{~b}$ do not reflect the total area for some of the commission districts.

\section{Figure 22. UTC metrics summarized by commission district}

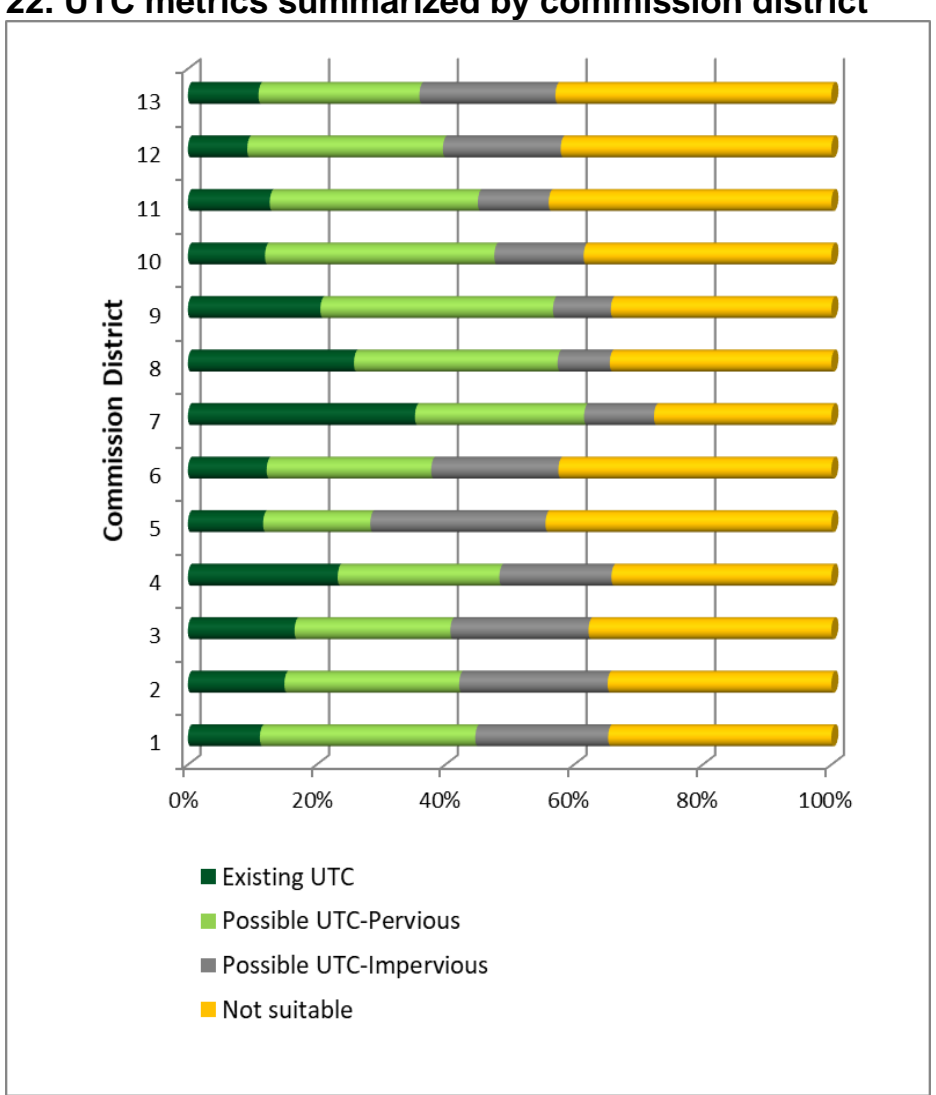

(a)

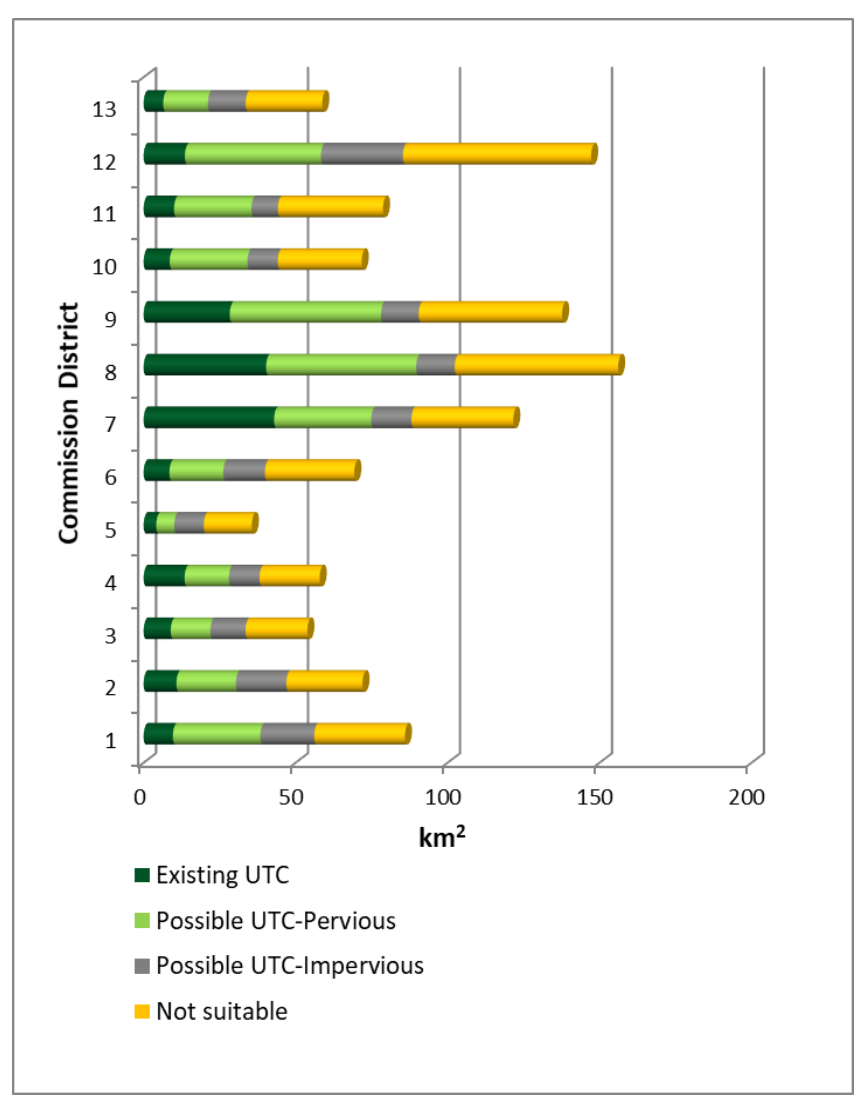

(b)

Due to tree canopy frequently found in residential neighborhoods and mangrove forests along the eastern coastline, the highest amount of EUTC, both in percentage and acreage, is found in:

- District $7\left(35.3 \%, 46.8 \mathrm{~km}^{2}\right)$

- District $8\left(25.8 \%, 40.3 \mathrm{~km}^{2}\right)$ 
The highest percent of PUTC canopy on pervious surfaces is found in:

- District 9 (36.2\%), which contains Miami Zoo, Homestead Base, and Homestead-Miami Speedway, all with substantial grass areas

- District 10 (35.6\%), which includes farm properties in Kendall as well as many sport fields with large grass or sand coverage, respectively

\section{Canopy change in commission districts}

Figure 23a shows a gain or loss of \% UTC between 2016 and 2020 for commission districts based on land cover classification. Figure 23b shows those changes in acreage $\left(\mathrm{km}^{2}\right)$.

\section{Figure 23. Change in \% UTC(a) and area $\left(\mathrm{km}^{2}\right)$ UTC (b) for commission districts between 2016 and 2020}

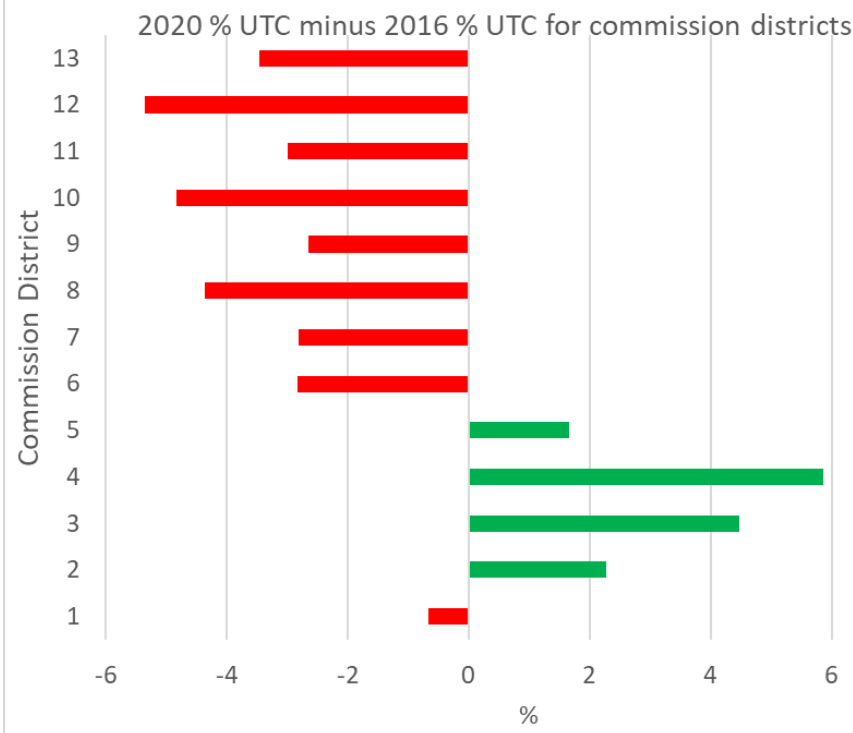

(a)

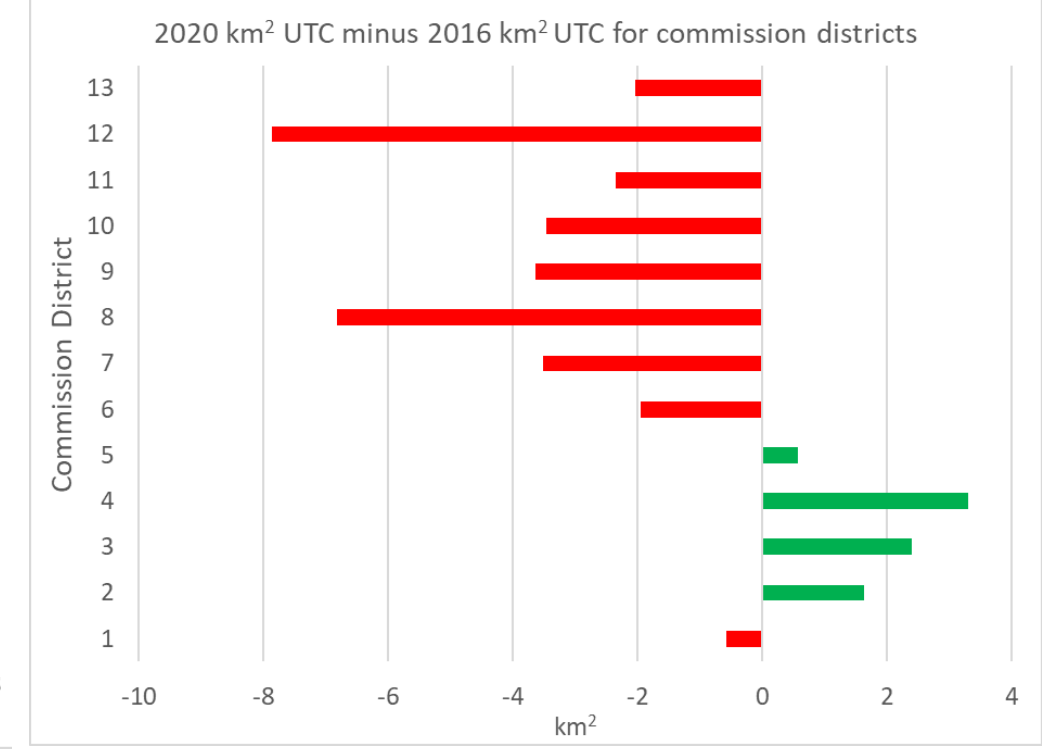

(b)

The urban area covered by District 12 registers the largest loss in tree canopy both when measured in percent and in acreage, which can be partially attributed to large scale building activities over the last few years. The example shown in Figure 16 (Hialeah) is located in District 12. District 10 reveals similarly high tree canopy loss numbers in percentage, which are caused by both construction projects and changes in the type of plants grown on agricultural areas. The latter can fluctuate depending on crop 
rotations and planting needs. Tree canopy gain in District 4 is primarily caused by densification of previously EUTC (e.g., growth over canals) in large park areas such as Oleta River State Park. These growth patterns may fluctuate between years since canopy density and vitality depends on weather, including precipitation, when satellite images are captured. Additionally, maturing of recently planted trees (e.g., on golf courses) has contributed to a growth in tree canopy as well. As an example, Figure 24 shows tree growth in Oleta River State Park in an area that was formerly primarily covered with bare ground and some shrub (1). It also shows the planting of trees in a previously open grassy field (2). 
Figure 24. Tree loss and gain in park area in Commission District 4

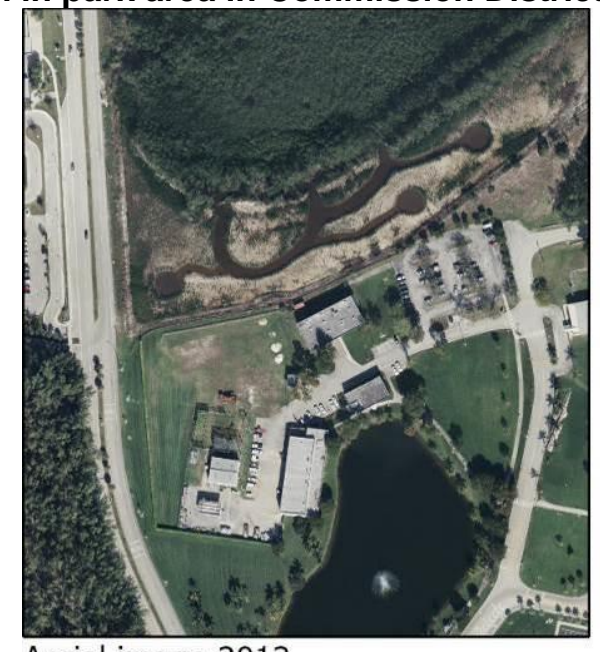

Aerial image 2013

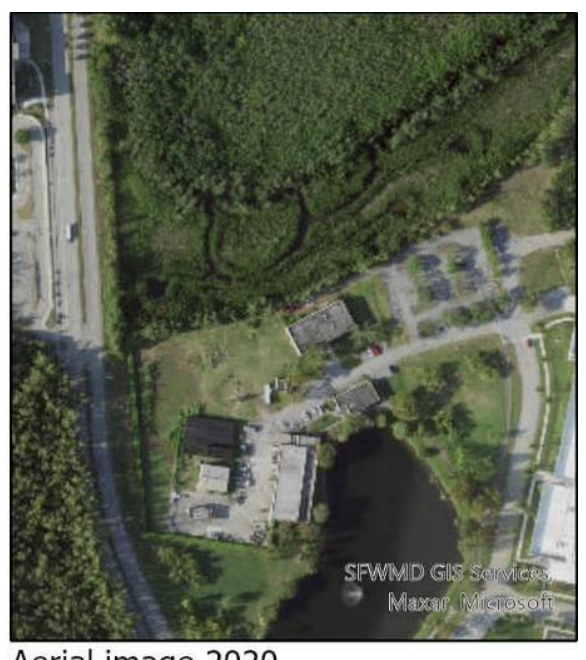

Aerial image 2020

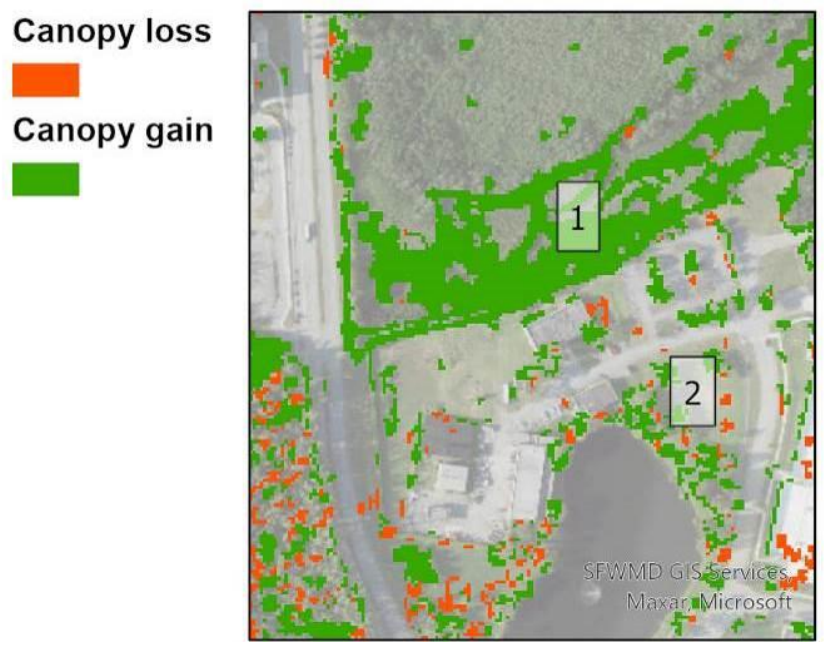




\section{Analysis of Parcels}

Based on the generated land cover map, the percentage of EUTC and PUTC on pervious land, including grass and bare soil can be computed for each property parcel. This breakdown provides more detailed information about tree canopy on each ownership unit. The following example (Figure 25) shows the area around Dr. Michael M. Krob Senior High School and Ives Estates Park. Whereas the high school area (western elongated polygon) offers a higher density of EUTC (24.8\%) than the park to its east (12.4\%), the large open grass areas in the park provide a higher PUTC on pervious land (77.7\%) than the school area (34.7\%). The map reveals

numerous locations with a high proportion of PUTC on pervious land. However, for many of these parcels, this large number is only of theoretical nature. For example, additional tree canopy on golf courses, sports facilities (baseball fields), beaches, and airports would be detrimental to their primary intended usage. 


\section{Figure 25. EUTC and PUTC (pervious) in parcels}
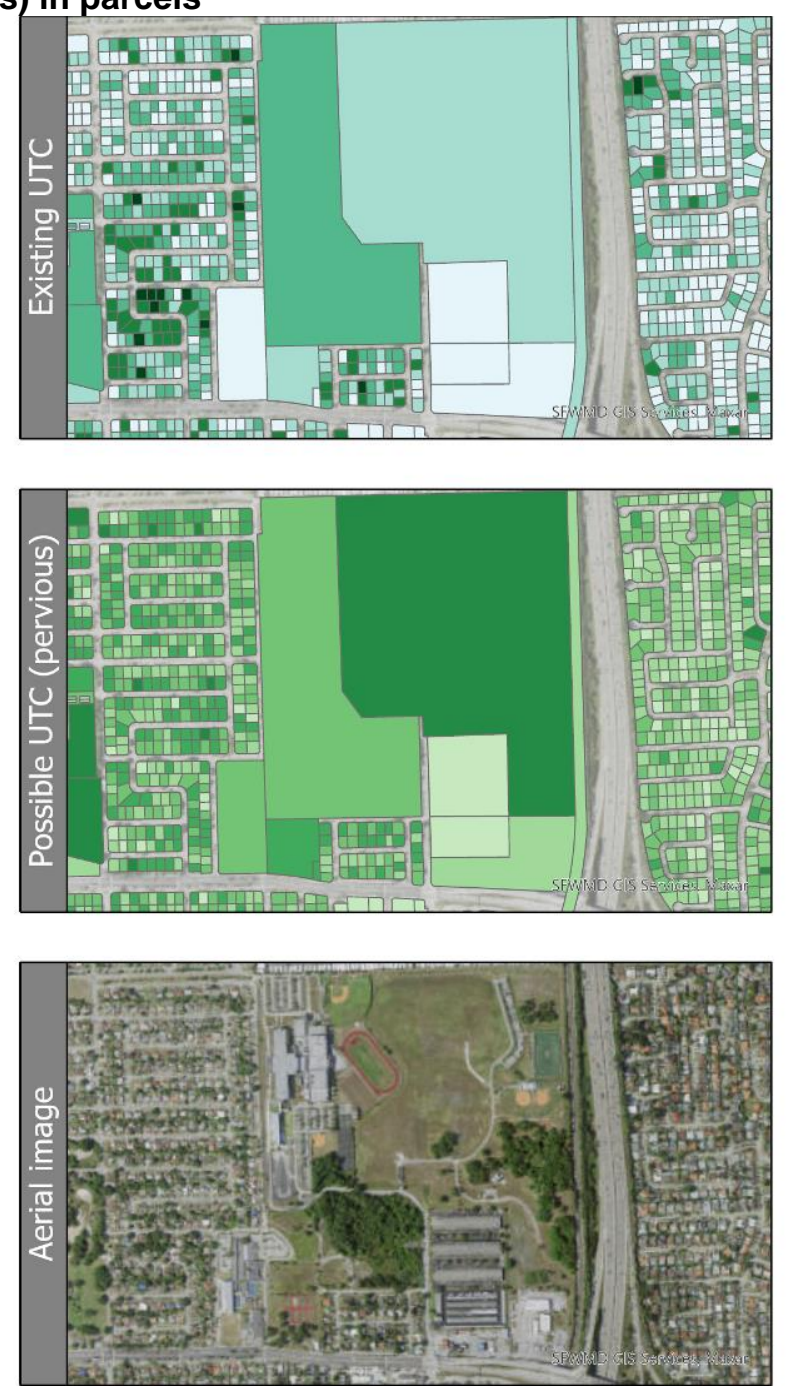

Existing UTC (\%)

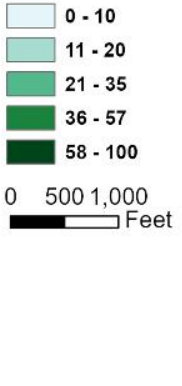

Possible UTC pervious (\%)

$\square 0.13$

$14-26$
$27-41$

$42 \cdot 64$

$65 \cdot 100$

$0 \quad 5001,000$

5001,000 


\section{Analysis of Land Use Patterns}

For further analysis, UTC types (EUTC, PUTC/pervious, PUTC/impervious, Not suitable for UTC) were summarized by land use category (Figure 26). For this purpose, selected land use categories from the Miami-Dade County general land use classification map were aggregated as follows:

- Institutional: Cemeteries; colleges and universities; governmental/public administration (other than military or penal); hospitals; nursing homes, houses of worship and religious; military facilities; penal and correctional; private schools including playgrounds; social services, fraternal, charitable; parking - public and private garages and lots;

- Public Schools: Public schools including playgrounds;

- Recreation: Golf courses, public and private, recreational vehicle parks/camps; municipal operated parks and county operated parks;

- Multiple Family: Multi-family with high-density and low-density; government-owned or government subsidized multi-family residential or elderly housing;

- Single-family : Mobile home parks and permanent mobile homes; single-family with high-density, low-density, mediumdensity;

- Industrial: Industrial extensive; industrial intensive, commercial condominium type of use, industrial intensive, heavy-light manufacturing, and warehousing-storage type of use; industrial intensive, office type of use;

- Office / Business: Office and/or business and other services (ground level) / residential (upper levels); office building, office/business/hotel/residential;

This analysis found:

- Existing UTC: The highest percentage of EUTC can be found in recreation areas (30.3\%), followed by single-family land (22.9\%).

- Possible UTC - pervious: The highest percentage of PUTC (pervious) comprised of grass and bare ground is found in recreation areas $(57.6 \%)$, followed by public schools $(43.2 \%)$. 
- Possible UTC - impervious: PUTC (impervious) replacing impervious surface is highest for shopping centers (46.2\%), followed by office / business facilities (39.4\%).

- Not suitable for UTC: Townhouse areas provide the largest percent of land cover not suitable for tree canopy (46.5\%), followed by industrial sites (40.5\%).

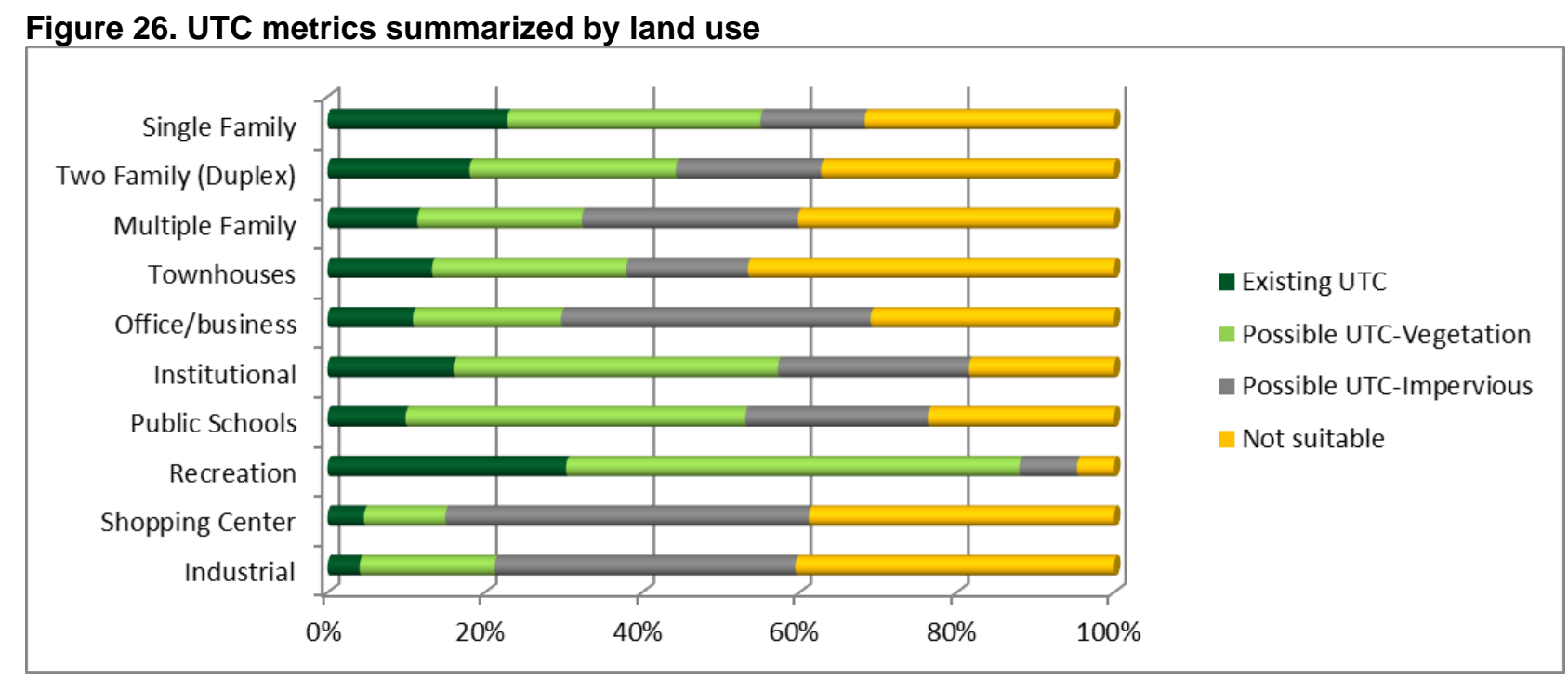

Additional UTC metrics, sorted by UTC type, are summarized for the 10 dominant land used types in Table 3 . For each land use category, UTC metrics were computed as a percentage of the total study area (\% Land), as a percentage of the land area by land use category (\% Category), and as a percentage of the area for the UTC type relative to the total study area (\% UTC Type). Bars in Figure 26 are based on values in the \% Category columns in Table 3, adding up to $100 \%$ for each land use type.

The large values of percent Land and percent UTC Type for EUTC in the single-family home land-use category (7\%) can be attributed to the large number of single-family residential areas $\left(\sim 335 \mathrm{~km}^{2} / 129 \mathrm{mi}^{2}\right)$, together with a relatively high proportion of EUTC areas within the single-family land use category (23\%). Single-family home areas also provide the largest total area of PUTC on grass and bare ground ( $9 \%$ ) and impervious surfaces (4\%). Equations and examples for all three types of percentage values are provided below the table. 
Table 3. Refined UTC metrics summarized by land use, shown for eight dominant land use categories

\begin{tabular}{|c|c|c|c|c|c|c|c|c|c|}
\hline \multirow[b]{2}{*}{ Land use } & \multicolumn{3}{|c|}{ Existing UTC } & \multicolumn{3}{|c|}{ Possible UTC-Vegetation } & \multicolumn{3}{|c|}{ Possible UTC-Impervious } \\
\hline & $\begin{array}{c}\text { \% Land } \\
\text { (Chg.) }\end{array}$ & $\begin{array}{c}\text { \% Category } \\
\text { (Chg.) }\end{array}$ & $\begin{array}{l}\text { \% UTC Type } \\
\text { (Chg.) }\end{array}$ & $\%$ Land & $\%$ Category & $\%$ UTC Type & $\%$ Land & $\%$ Category & $\%$ UTC Type \\
\hline Single-family & $7^{*}(-0.8)$ & $23^{* *}(-2.8)$ & $28^{\star * *}(-3.1)$ & 9 & 32 & 41 & 4 & 13 & 23 \\
\hline Two Family (Duplex) & $0(0.0)$ & $18(0.9)$ & $1(0.1)$ & 0 & 26 & 2 & 0 & 18 & 2 \\
\hline Multiple Family & $1(0.0)$ & $11(-0.4)$ & $2(0.0)$ & 1 & 21 & 5 & 1 & 27 & 8 \\
\hline Townhouses & $0(0.0)$ & $13(-1.7)$ & $1(0.0)$ & 0 & 25 & 2 & 0 & 15 & 2 \\
\hline Office/business & $0(0.0)$ & $11(-1.0)$ & $0(-0.1)$ & 0 & 19 & 1 & 0 & 39 & 2 \\
\hline Institutional & $1(0.0)$ & $16(-0.7)$ & $3(-0.1)$ & 2 & 41 & 8 & 1 & 24 & 6 \\
\hline Public Schools & $0(0.0)$ & $10(0.7)$ & $1(0.1)$ & 1 & 43 & 3 & 0 & 23 & 2 \\
\hline Recreation & $1(0.0)$ & $30(-0.1)$ & $6(0.0)$ & 3 & 58 & 11 & 0 & 7 & 2 \\
\hline Shopping Center & $0(0.0)$ & $5(0.1)$ & $0(0.0)$ & 0 & 10 & 0 & 0 & 46 & 1 \\
\hline Industrial & $0(0.0)$ & $4(-0.8)$ & $1(-0.1)$ & 1 & 17 & 4 & 2 & 38 & 11 \\
\hline
\end{tabular}

Notes:

$\%$ Land $=$ (Area of UTC type for specified land use) / (Area of all land)

$\left(^{*}\right) 7 \%$ of the land in the study area has tree canopy and falls into the single-family housing land use category.

$\%$ Category = (Area of UTC type for specified land use) / (Area of all land for specified land use)

$\left(^{* *}\right) 23 \%$ of Single-family housing land is covered by tree canopy.

$\%$ UTC Type = (Area of UTC type for specified land use) / (Area of all land for specified UTC Type)

$\left({ }^{* * *}\right) 28 \%$ of all existing tree canopy lies in the Single-family housing land use.

Changes in percentage points of EUTC for the different UTC types since 2016 are expressed in parentheses in Table 3 . For all land use types, changes are moderate. Some noticeable changes can be found for single-family land use. Land in the study area that is covered by EUTC and falls into the single-family housing land use category dropped by $0.8 \%$. EUTC coverage within single-family housing areas dropped by $2.8 \%$ and the contribution of single-family housing land use to the overall EUTC in the study area dropped by $3.1 \%$. 


\section{Surface Temperature}

\section{Change in surface temperature}

Figure $27 \mathrm{a}$ color codes surface temperature in degrees Fahrenheit $\left({ }^{\circ} \mathrm{F}\right.$ ) based on resampled 30 -m resolution (original $100 \mathrm{~m}$ resolution) Landsat-8 Thermal Infrared (TIRS) 1 satellite imagery taken on 01/05/2021. Figure 27b maps the change between surface temperature derived from satellite imagery taken on 01/24/2016 and 01/05/21 (in ${ }^{\circ} \mathrm{F}$ ). The obtained temperature depends on weather conditions during that day. Therefore, no conclusion can be drawn as to whether the surface temperature generally increased or decreased between these years. However, using the difference between temperature maps from different years allows one to compare local change patterns in temperature and explore possible reasons (e.g., land cover change). Lakes and ponds (blue) were clearly cooler in the 2021 image, as indicated by the negative difference values. In contrast, other areas demonstrate a clear increase in surface temperature as highlighted in orange and red (hotspots). Although the range of temperature changes spans $-7^{\circ} \mathrm{F}$ to almost $+16^{\circ} \mathrm{F}$ (Figure 27 ), most temperature changes that are co-located with observed land cover changes fall within a more moderate $1^{\circ} \mathrm{F}$ to $7.5^{\circ} \mathrm{F}$ range of surface temperature changes. 


\section{Figure 27. Surface temperature on 01/05/21 (a) and change in surface temperature (b)}

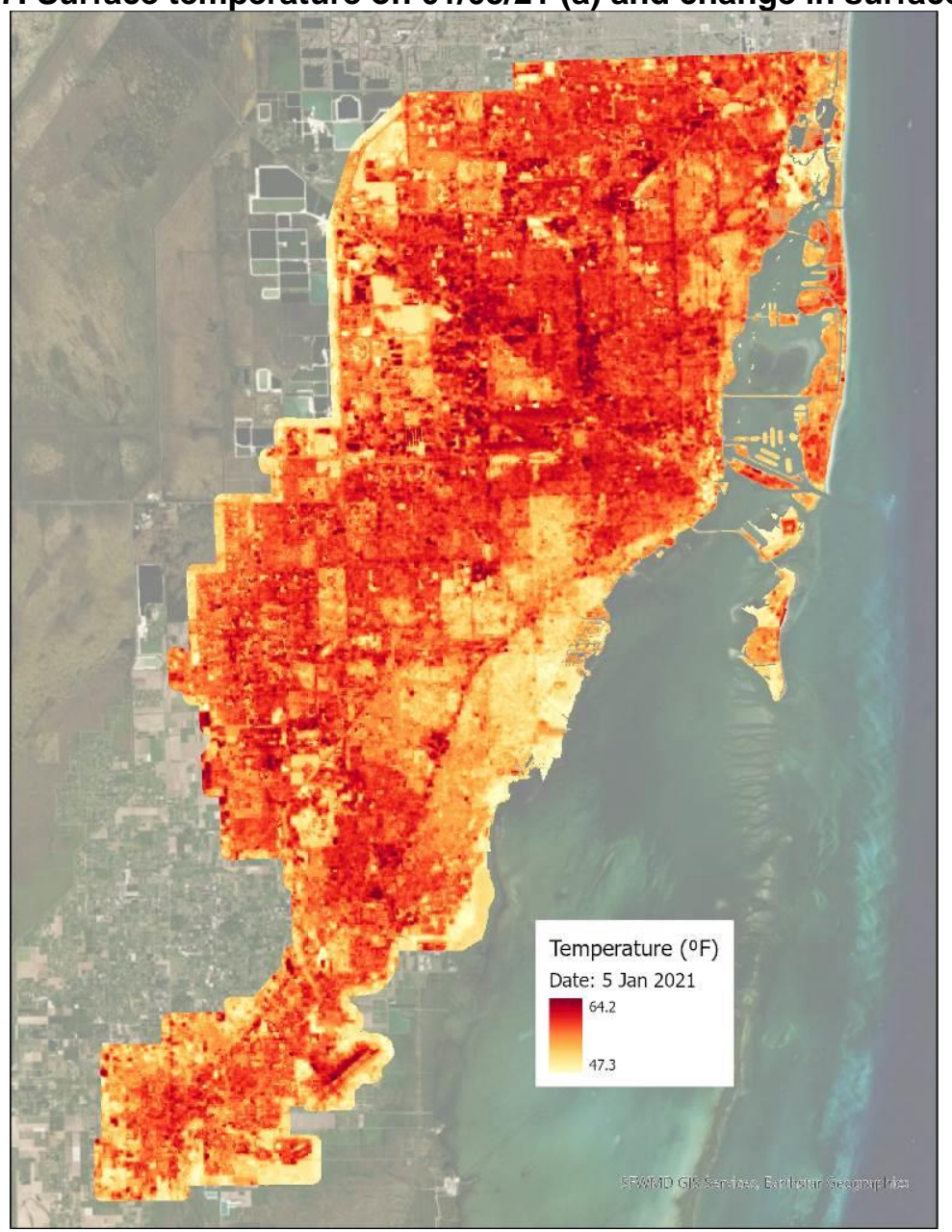

a)

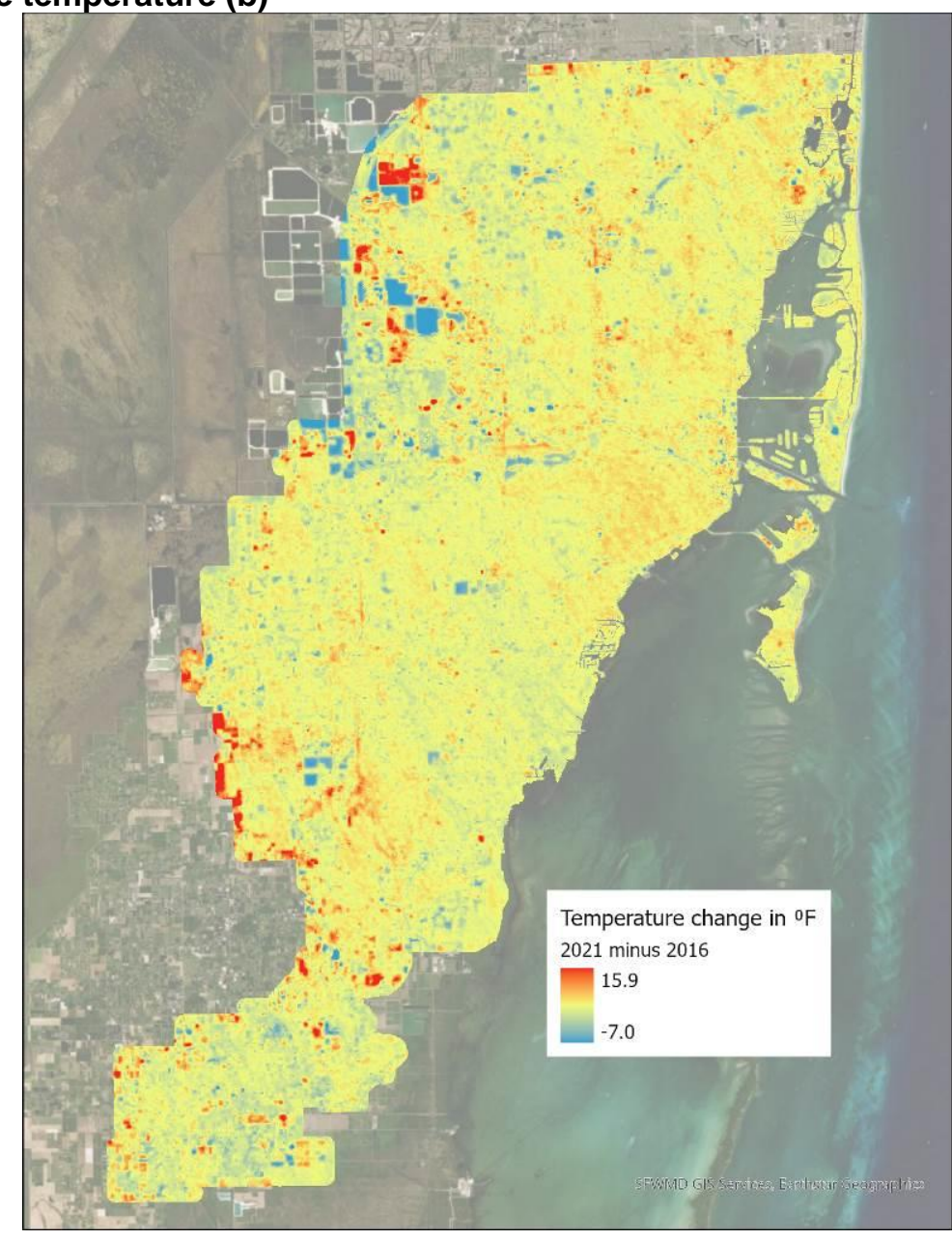

b) 


\section{Change in land cover}

To analyze the relationship between land cover change and change in surface temperature, 12 land cover change classes were aggregated from all possible land cover change combinations. Table 4 summarizes these land use changes.

Table 4. Aggregated classes considered in land use change analysis.

\begin{tabular}{|l|l|l|l|l|}
\hline From $\rightarrow$ To & Impervious & Pervious & Tree canopy & Water/wetland \\
\hline Impervious & - & imp $\rightarrow$ perv & imp $\rightarrow$ tree & imp $\rightarrow$ wtr/wld \\
\hline Pervious & perv $\rightarrow \mathrm{imp}$ & - & perv $\rightarrow$ tree & perv $\rightarrow$ wtr/wld \\
\hline Tree canopy & tree $\rightarrow \mathrm{imp}$ & tree $\rightarrow$ perv & - & tree $\rightarrow$ wtr/wld \\
\hline Water/wetland & wtr/wld $\rightarrow \mathrm{imp}$ & wtr/wld $\rightarrow$ perv & wtr/wld $\rightarrow$ tree & - \\
\hline
\end{tabular}

The typical range of surface temperature changes between $1^{\circ} \mathrm{F}$ and $7.5^{\circ} \mathrm{F}$ was divided into classes of a half degree range. For each class, a sample of several hundred points was selected that was spatially co-located with an observed change in land cover between 2016 and 2021. Next, the proportion of land cover change classes in each temperature change class was computed based on the point sample.

Figure 28 visualizes the relationship between land cover change and temperature change where the left half of the chart shows a relative cooling effect based on land cover change, and the right side demonstrates a stronger than average temperature increase. Whereas some change combinations can be rarely observed and thus appear to be absent from the chart, some clear patterns emerge. For example, higher surface temperature increases are tied to a higher proportion of change from tree canopy to pervious (beige), from tree canopy to impervious (orange), and from pervious to impervious land cover (gray). As opposed to this, a change from pervious surfaces to tree canopy (dark green) and impervious to pervious (brown) is primarily found in the lower temperature change regions of the chart. Furthermore, replacing pervious surfaces (dark blue) or trees (light blue) with water or wetland have a cooling effect. 
Figure 28. Proportion of land cover change classes for different surface temperature change classes

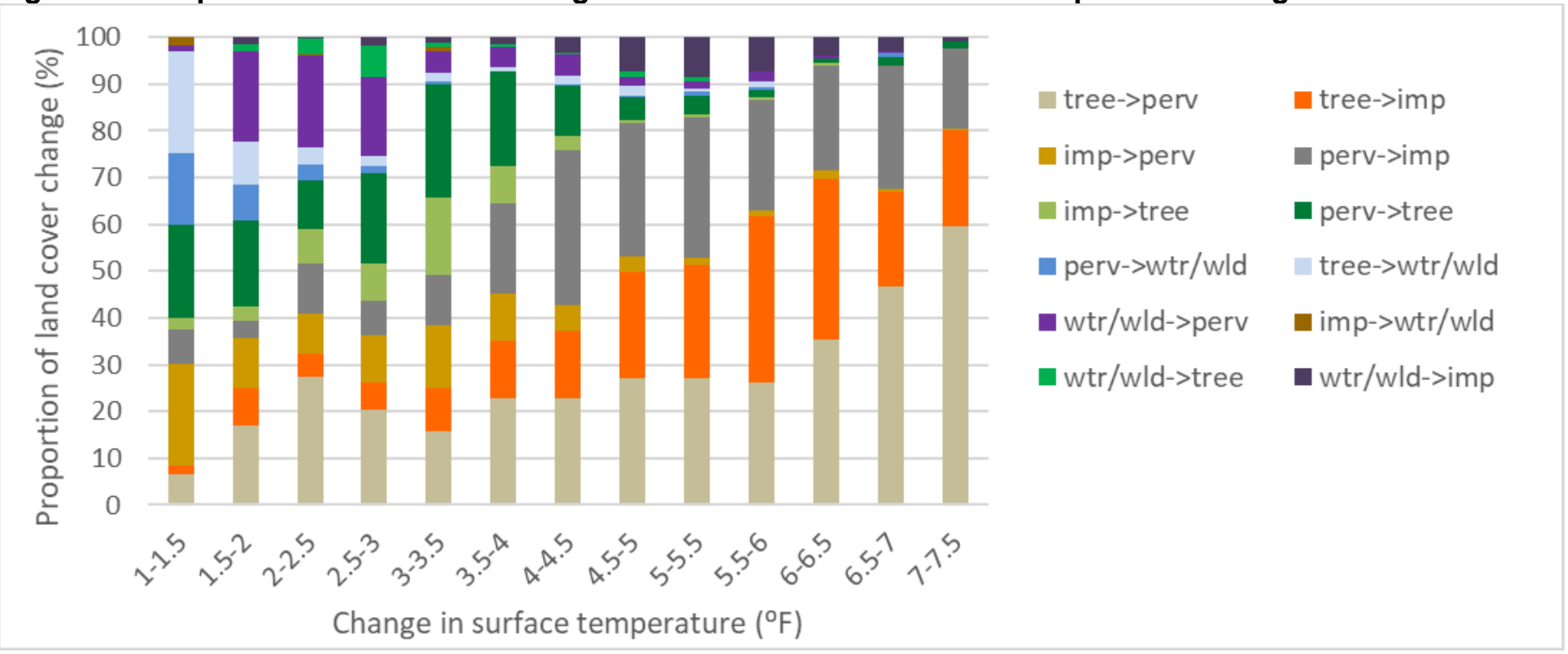

Figure 29 demonstrates for an area west of Medley, which underwent a construction project between 2014 and 2020 , the relationship between land cover change and change in surface temperature. Several types of land cover changes can be observed. Former tree canopy was replaced with impervious land (e.g., buildings, parking lots) primarily on the western half of the plot as shown in orange $(1,2)$. Gray areas show replacement of pervious land (e.g., sand, soil, grass) with impervious surfaces $(3$, 4). Furthermore, tree canopy was converted to pervious land in the northeast corner (5). All these changes in land cover corresponded to increased surface temperatures as shown in the local temperature change map to the lower right. 
Figure 29. Co-location of land cover and surface temperature change

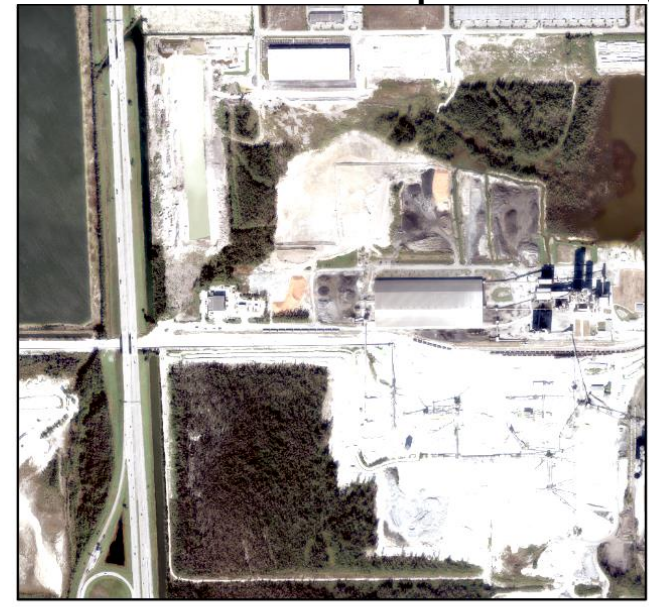

Aerial image 2014

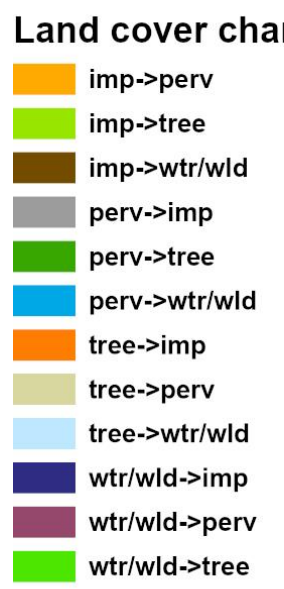

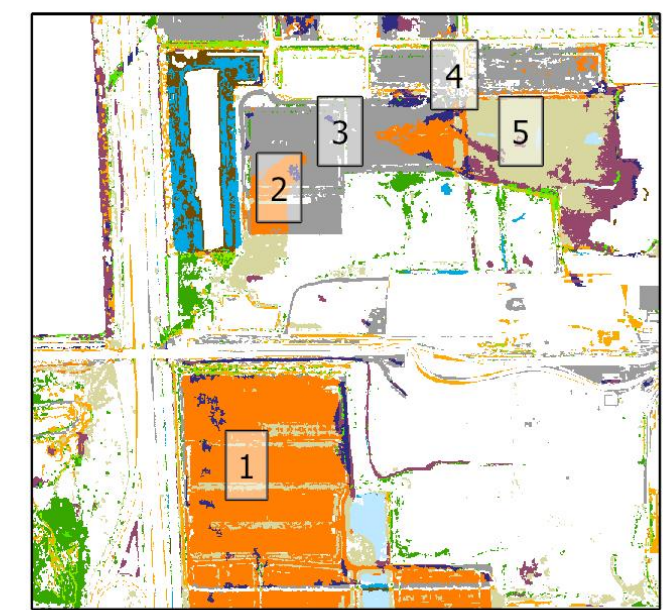

Change in land cover

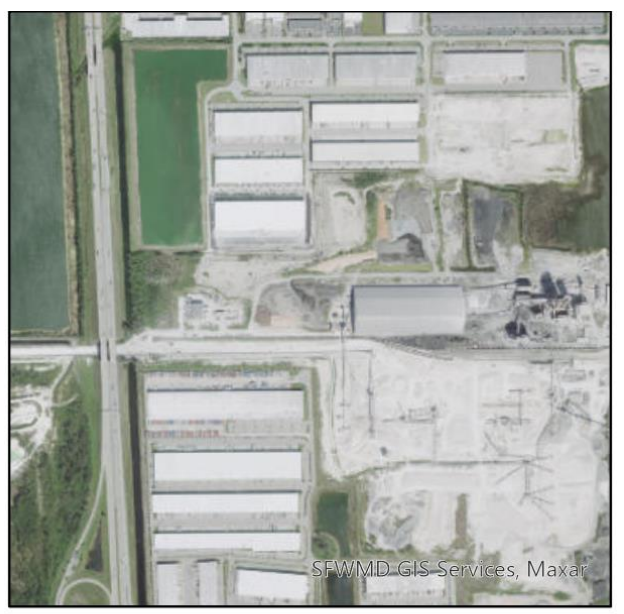

Aerial image 2020

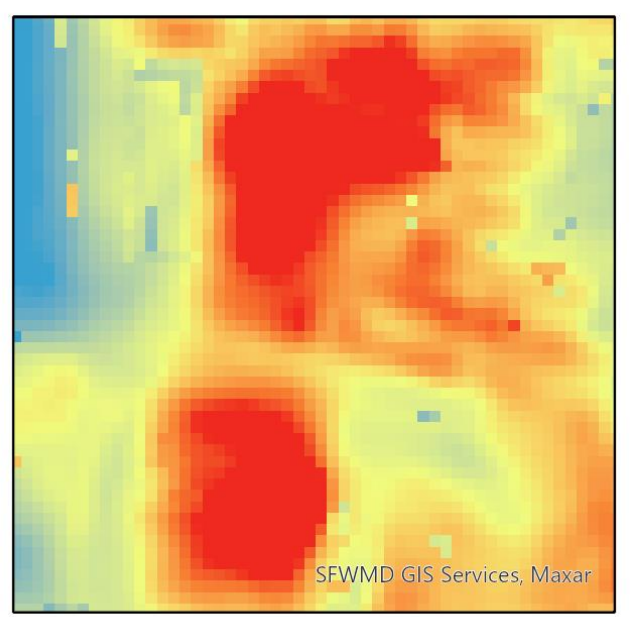

Change in surface temperature
Temperature change $\left({ }^{\circ} \mathrm{F}\right)$
15.9
-7.0 


\section{Analysis of Socio-economic Variables}

Tree canopy increases quality of life in neighborhoods (e.g., by providing shade for outdoor activities, fresh air, and cooling the ground). Therefore, urban planners are interested to know if tree canopy is equally distributed among certain population groups. For a visual assessment, the following maps visualize percent EUTC (Figure 30a), median household income (Figure 30b), percent African American (Figure 31a), and percent Hispanic (Figure 31b), which were taken from America Community Survey (ACS) 201520195 -year estimates. The maps visualize the 1446 census block groups in the study area which had a complete set of socioeconomic variable values. Each variable reveals its distinct spatial pattern, where median household income and \% EUTC show some commonalities (leading to a positive correlation), while \% Hispanic and \% EUTC show some distinct differences (leading to a negative correlation). 
Figure 30. Percent EUTC (a) and median household income (b) at the Census Block Group level (2019)

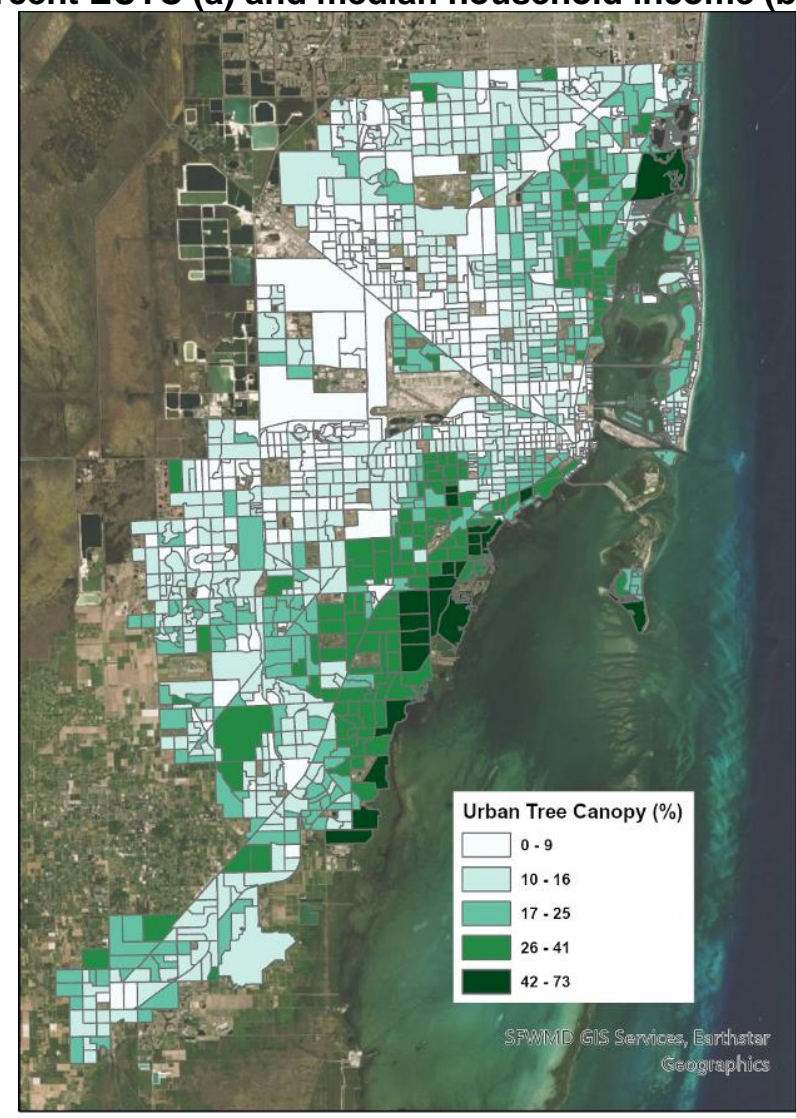

a)

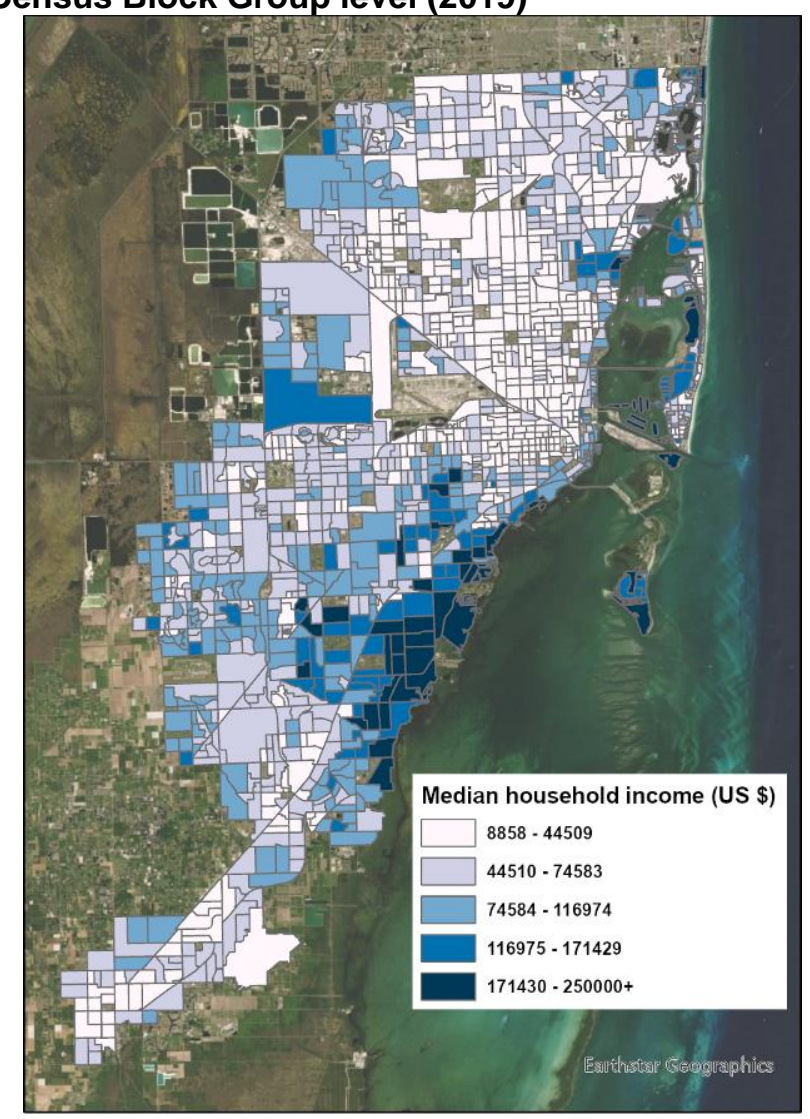

b) 
Figure 31. Percent African American (a) and Percent Hispanic (b) at the Census Block Group level (2019)

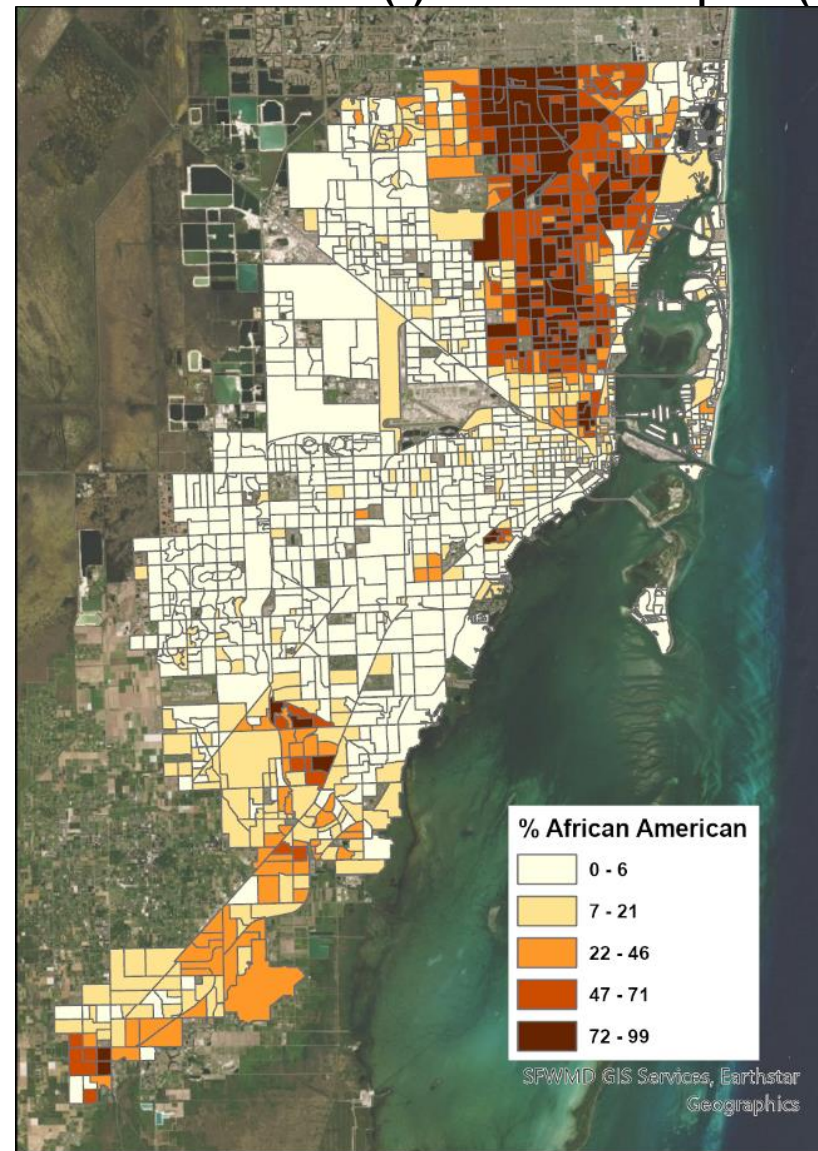

a)

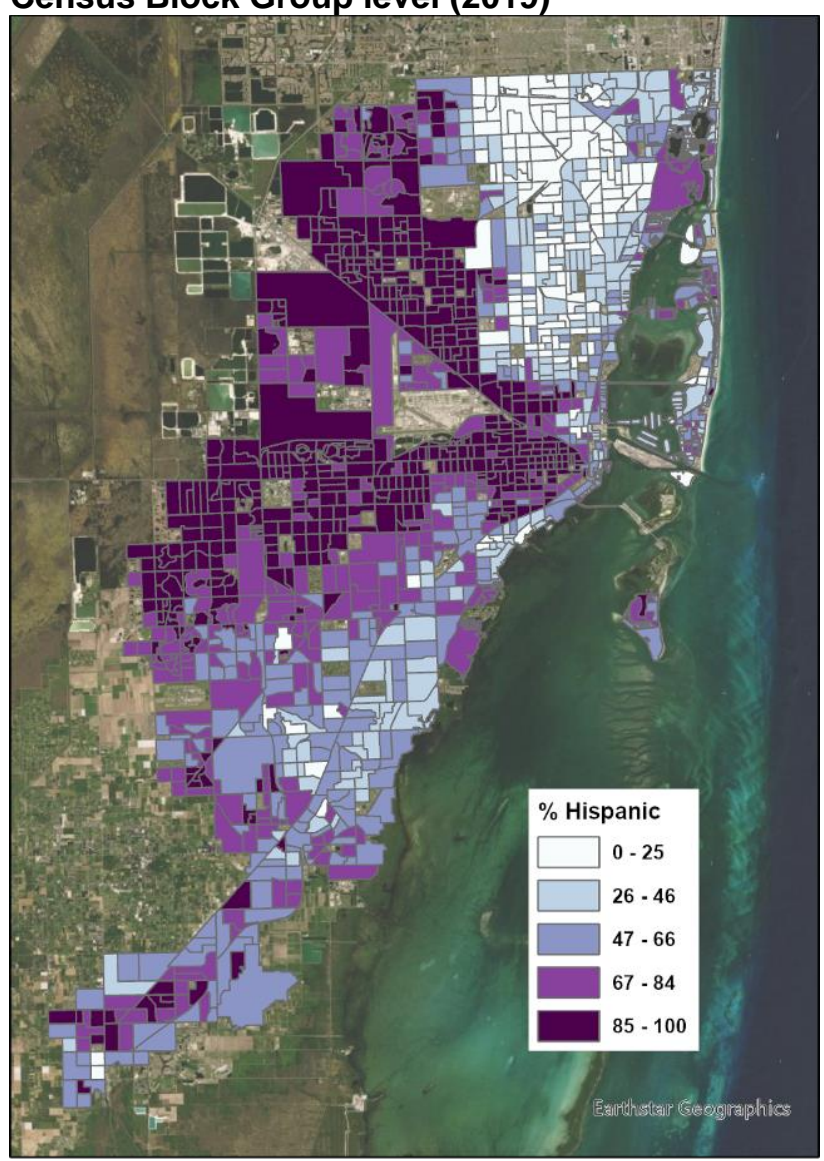

b)

A scatter plot for all three demographic variables vs. \% EUTC is provided in Figure 32 with a linear regression line that reflects significant positive (a) or negative (b) relationships between demographic variables and \% EUTC for 2019. Compared to the same relationship analysis conducted in 2014 , \% African American (c) is not significantly correlated with \% EUTC, whereas the negative association between \% Hispanic and \% EUTC increased in 2019. The role of household income remained virtually unchanged compared to 2014. 
Figure 32. Percent UTC vs. Median Household Income (a), percent Hispanic (b), and percent African American (c) at the Census Block Group level

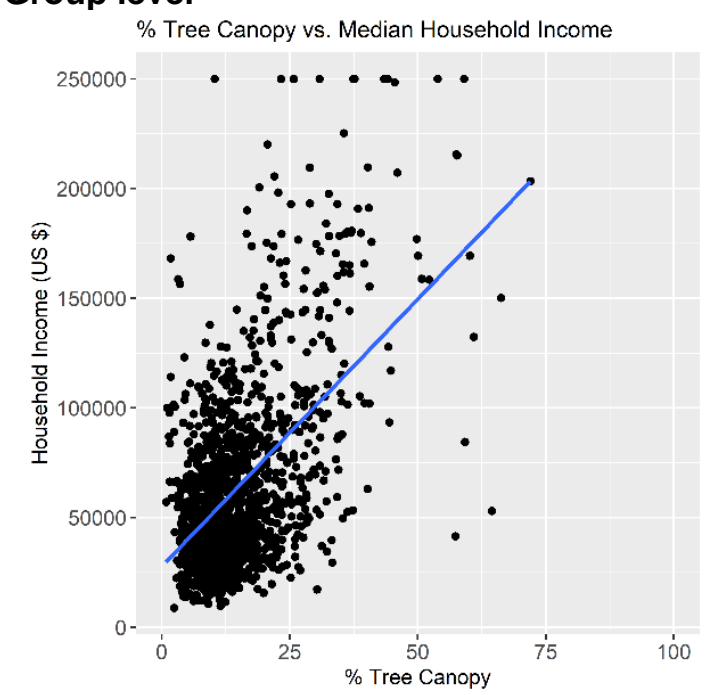

(a)

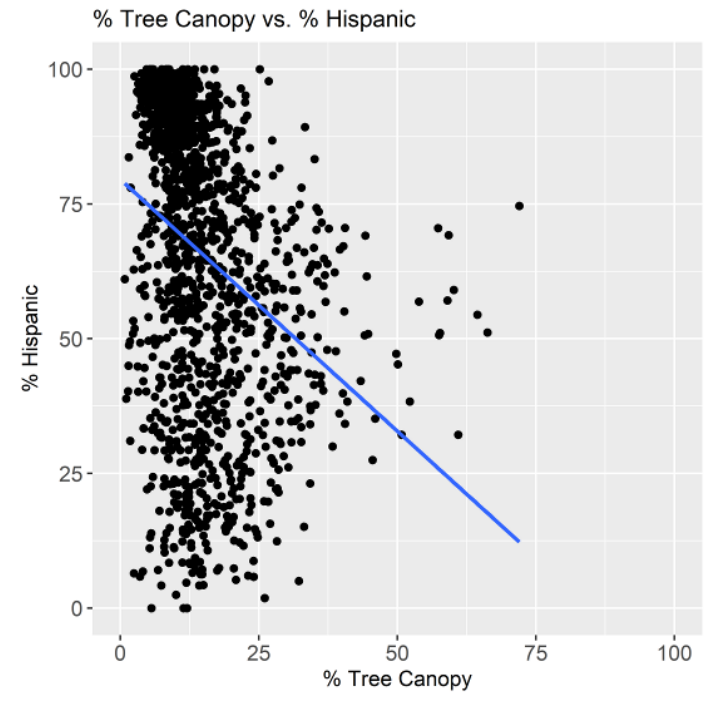

(b)

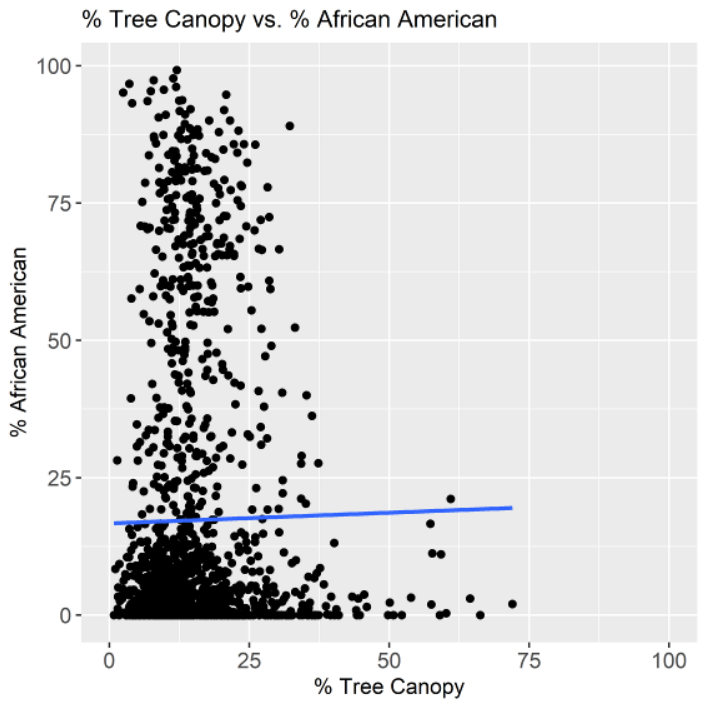

(c)

It must be noted that correlation does not imply any direct causal relationship between demographic variables and canopy density (e.g., the Hispanic population purposely seeks to live in areas with less canopy density). However, it is possible that homeowners in high-income areas have larger lots with yards and more financial means to plant and maintain trees than those homeowners in poorer neighborhoods.

\section{Analysis of Health Data}

This section assesses the relationship between respiratory-related hospitalization rates and the density of EUTC at the zip code level. Figure 33 visualizes:
(a) Percent EUTC
(b) Respiratory disease-based inpatient rate per 100,000 (100K) residents 


\section{Figure 33. Percent EUTC (a) and respiratory-related inpatient rate per 100,000 residents (b) at the zip code level}

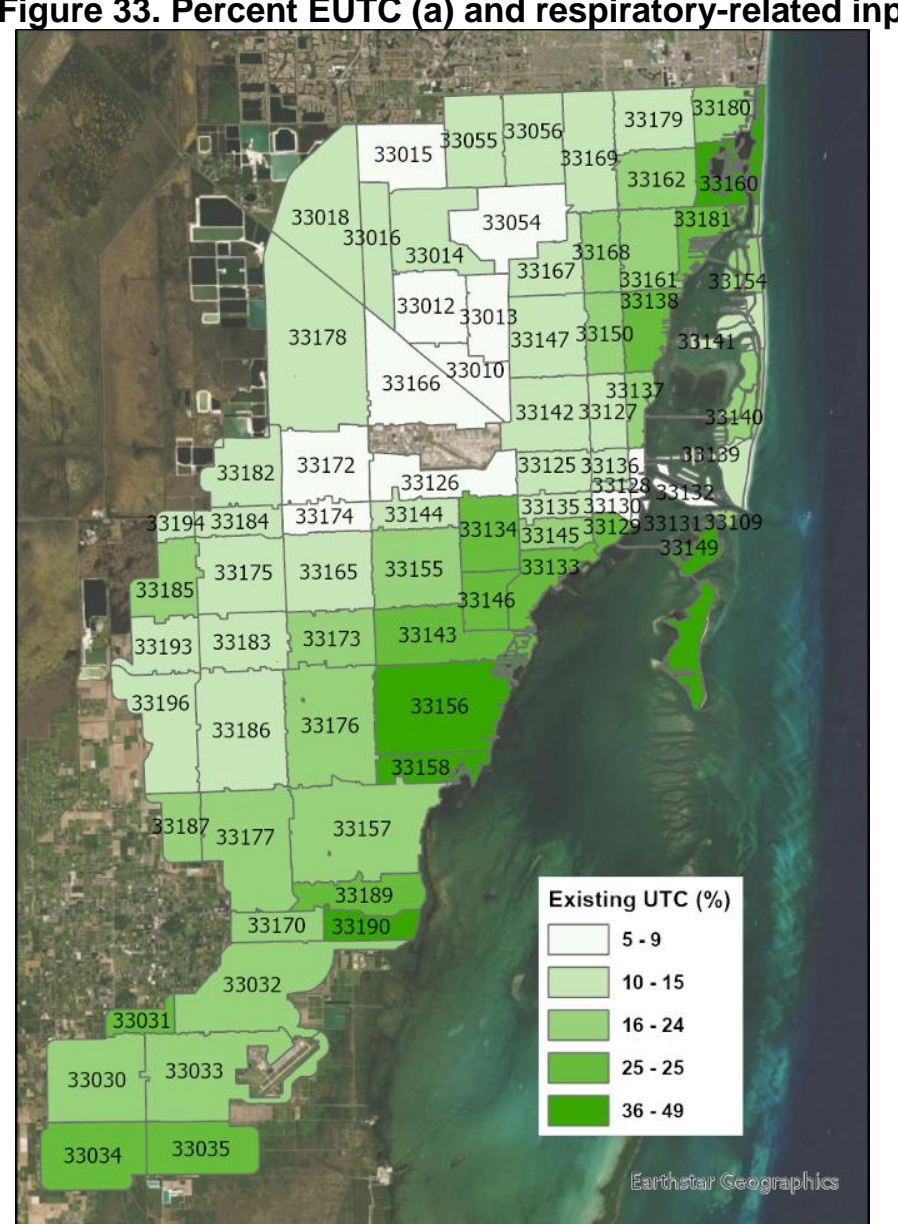

(a)

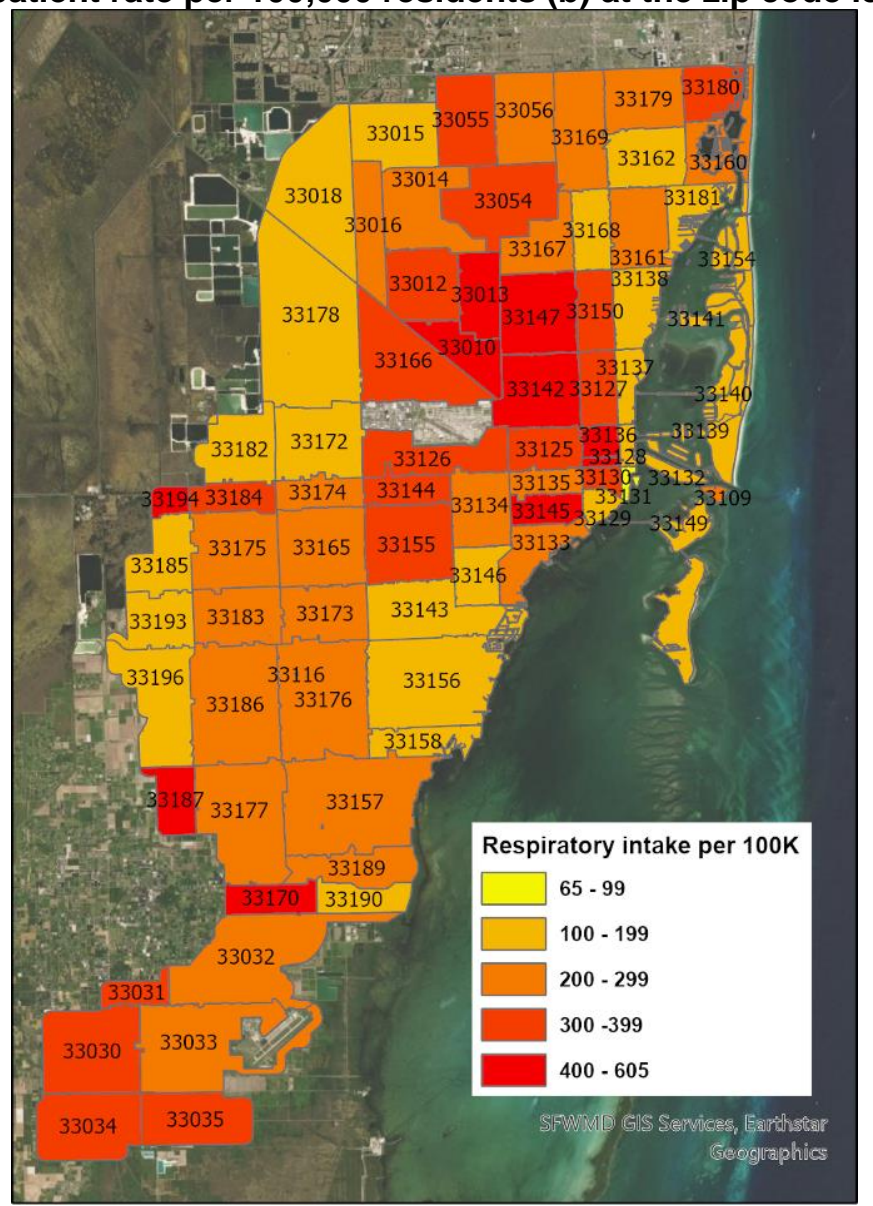

(b)

Correlation analysis showed that areas with a higher percent EUTC have smaller respiratory-related hospital rates per 100K residents and also smaller overall hospitalization rates per $100 \mathrm{~K}$ residents. This could also possibly be attributed to better health care, a healthier lifestyle, and/or better disease prevention mechanisms in higher income zip codes that tend to have higher EUTC. For details, see the notes in the methodology section. The scatter plot for these two examined health-related variables vs. percent EUTC is provided in Figure 34 with a linear regression line. Comparison of slopes in Figure 34a) and b) as well as comparison of correlation coefficients (see methodology section) shows that higher density of EUTC does not directly affect respiratory-related 
diseases in this study area. Instead, the findings indicate areas with healthier lifestyles, which reduces all kinds of causes leading to hospitalization. Household income is an even stronger indicator of hospitalization rates than tree canopy in this study area.

Figure 34. Respiratory disease-based (a) and overall (b) hospitalization inpatient rate per 100,000 residents at the zip code level

$\%$ Tree Canopy vs. Respiratory Hospital Intake

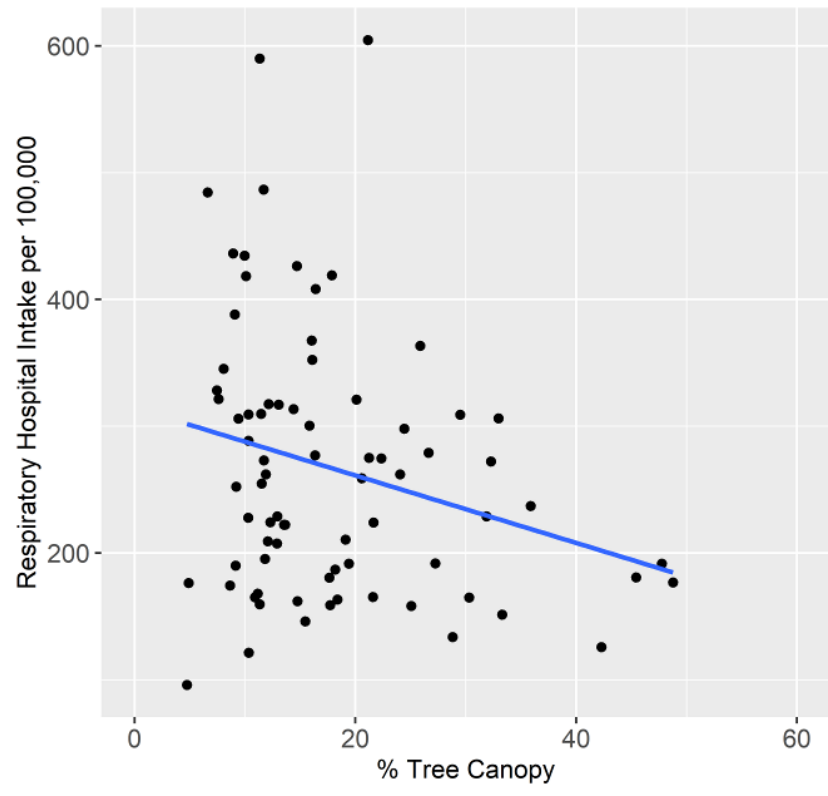

(a)

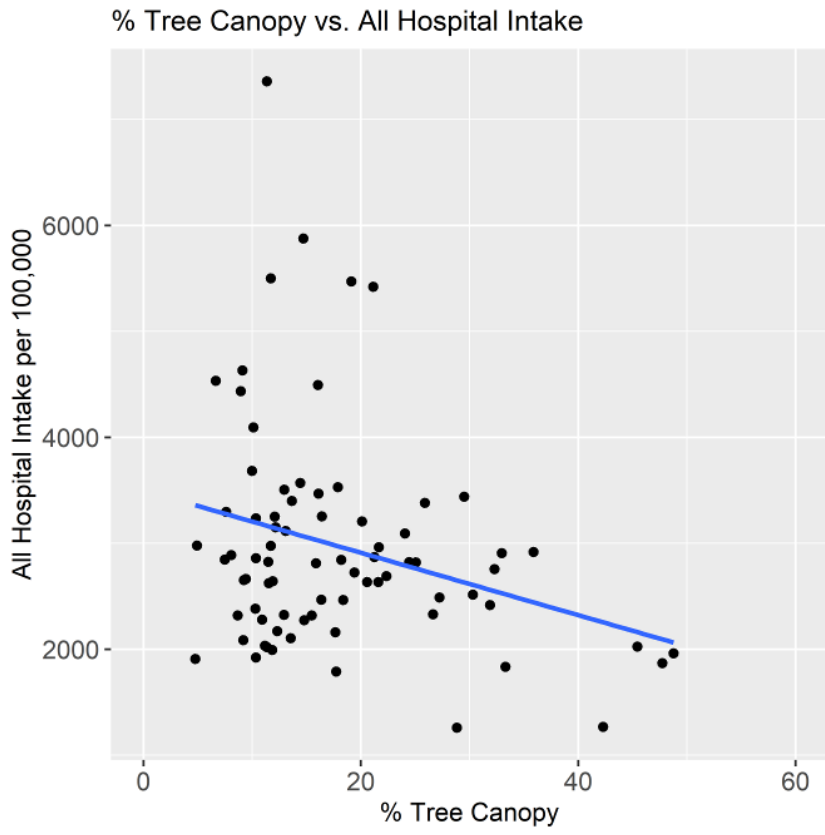

(b)

\section{Methodology Notes}

\section{Overall assessment}

The study uses multi-spectral (eight-band spectral resolution, $2 \mathrm{~m}$ spatial resolution) satellite imagery together with selected vector feature layers for analysis and classification of land cover data. Additionally, a resampled $2 \mathrm{~m}$ resolution digital canopy height model (DCHM) derived from 2016 Lidar (Light Detection and Ranging) point cloud data is used to reclassify wetland areas with a height of at least $50 \mathrm{~cm}$ as tree canopy. Based on the generated land cover classification map, a Geographic Information System (GIS) was used to estimate the EUTC and PUTC for predefined areal units (municipalities, census places, property parcels, commission districts). 
The aggregated estimates are available as GIS polygon feature layers in an ESRI geodatabase, which can be subsequently integrated with other GIS or web mapping applications.

The land cover analysis was completed using remotely sensed imagery. It does not study the specific species of trees that are present in the project area. To catalog the species that compose the urban tree canopy, ground surveys or higher spatial and spectral (hyper-spectral) remotely sensed data sets would be required.

\section{Land cover classification}

A land cover classification map was generated using WorldView-2 data acquired on 11/28/2019 and 3/27/2020 for different parts of the study area. Atmospherically corrected, multi-spectral reflectance values were used in the classification of nine land cover classes.

The initial land-cover detection was based on a random forest classification algorithm (Liaw and Wiener 2002; Svetnik et al. 2003) in the caret R-package (Kuhn et al. 2021), which used the WorldView-2 spectral information. Next, various vector data layers, provided by Miami-Dade County, were updated, and incorporated into the map generation process for quality enhancement after the initial classification. The vector layers included:

- Buildings (polygons)

- Edge of pavement (polylines converted to polygons)

- Railroads (polylines buffered with a 3m distance)

- Water bodies (polygons)

- Agricultural areas (polygons)

To remove spurious pixels, the final map was smoothed with a 4-edge kernel using a nearest neighbor replacement method with varying minimum mapping units (MMU) for the different classes (Table 5). 
Table 5. Minimum mapping unit (MMU) for different land cover classes

\begin{tabular}{lcc}
\hline \multicolumn{1}{c}{ Class } & MMU (pixels) & MMU $\left(\mathbf{m}^{\mathbf{2}}\right)$ \\
\hline Tree Canopy & 2 & 8 \\
Street/Railroad & 10 & 40 \\
Building & 2 & 8 \\
Wetland & 50 & 200 \\
Water & 50 & 200 \\
Grass & 5 & 20 \\
Bare Ground & 5 & 20 \\
Impervious & 10 & 40 \\
Cropland & 50 & 200 \\
\hline
\end{tabular}

Class-specific map accuracies ranged from $67.2 \pm 5.8 \%$ for bare ground to $98.5 \pm 1.5 \%$ for the streets/railroads and cropland classes (Table 1). Buildings were mapped with an adjusted accuracy of $95.5 \pm 2.5 \%$, grass with $80.6 \pm 4.9 \%$, trees/shrubs with $85.1 \pm 4.4 \%$ and impervious with $86.6 \pm 4.2 \%$. Grass was predominantly misclassified as trees and shrub at $16.4 \%$ and vice versa at $11.9 \%$, bare ground as impervious (19.4\%), and impervious as buildings (9.0\%) (Table 6).

A design-based accuracy assessment of land-cover class stratified random samples $(\mathrm{N}=564$; multinomial distribution sampling based on a $95 \%$ confidence) estimated the bias adjusted overall accuracy of the map to be $87.4 \%$, with a standard error of $1.5 \%$ which means that the $95 \%$ upper and lower confidence of the true accuracy is estimated to be between $85.9 \%$ and $91.3 \%$. Areas in Table 1 are error-adjusted estimators with their standard errors and based on the accuracy assessment and the constructed error matrix, following the procedures described in (Olofsson et al. 2013). 
Table 6. Confusion matrix. Values are percent (\%) of samples classified (rows) and referenced (columns).

\begin{tabular}{|c|c|c|c|c|c|c|c|c|c|}
\hline \multirow[b]{2}{*}{ Prediction } & \multicolumn{9}{|c|}{ Reference } \\
\hline & Bare Ground & Building & Cropland & Grass & Impervious & Street/Railroad & Tree Canopy & Wetland & Water \\
\hline Bare Ground & 67.16 & 1.49 & 2.99 & 5.97 & 19.40 & 1.49 & 1.49 & 0.00 & 0.00 \\
\hline Building & 0.00 & 95.52 & 0.00 & 2.99 & 1.49 & 0.00 & 0.00 & 0.00 & 0.00 \\
\hline Cropland & 0.00 & 0.00 & 98.51 & 0.00 & 0.00 & 0.00 & 0.00 & 0.00 & 1.49 \\
\hline Grass & 0.00 & 0.00 & 0.00 & 80.60 & 2.99 & 0.00 & 16.42 & 0.00 & 0.00 \\
\hline Impervious & 0.00 & 8.96 & 0.00 & 2.99 & 86.57 & 0.00 & 1.49 & 0.00 & 0.00 \\
\hline Street/Railroad & 0.00 & 0.00 & 0.00 & 0.00 & 0.00 & 98.51 & 1.49 & 0.00 & 0.00 \\
\hline Tree Canopy & 0.00 & 1.49 & 0.00 & 11.94 & 0.00 & 0.00 & 85.07 & 1.49 & 0.00 \\
\hline Wetland & 3.57 & 0.00 & 0.00 & 0.00 & 0.00 & 0.00 & 0.00 & 92.86 & 3.57 \\
\hline Water & 0.00 & 0.00 & 0.00 & 0.00 & 0.00 & 0.00 & 0.00 & 2.99 & 97.01 \\
\hline
\end{tabular}

\section{Change in surface temperature and land cover}

To assess the statistical association between surface temperature change and change of land-cover class, a random sample of 1,535 points was drawn from the land cover change raster with its 12 aggregated land use change values (Table 4) for locations where such a land cover change was observed. For each sample point, the change in Degrees Fahrenheit (from Figure 27b) and the land use change code was read out. This information was used in a linear regression model with temperature change as the predicted variable and 11 land use change categories as binary (dummy) variables, where a change from impervious to pervious land use was used as the default change category (Table 7). Therefore, a coefficient value expresses how much more or less the surface temperature is predicted to increase for a given change category compared to a change from impervious to pervious land cover. For land cover change categories that demonstrate a $p$-value $<0.05$, this difference can be considered statistically significant.

Results show that several change categories lead to different temperature changes than the default change category. As for change categories that involve tree canopy, tree canopy to impervious and tree canopy to pervious indicate a higher increase in temperature than when changing impervious to pervious land. Hence, removal of trees tends play a large rule in the increase of surface temperatures. Furthermore, changing water/wetland to tree canopy leads to a relative decrease in surface temperature compared to the default change category, as shown by the negative coefficient. As for changes that do not involve tree canopy, a change from pervious to impervious land cover and water/wetland to impervious land cover is associated with a higher increase in temperature than the default, as expected. The latter has the largest heating effect among all five significant variables and is therefore to be avoided if local heat islands are not desirable. 
Table 7. Results for linear regression of temperature change

\begin{tabular}{|c|c|c|c|c|}
\hline Parameter & Coefficient & & Standard error & $\mathrm{p}$-value \\
\hline Intercept & 3.312 & 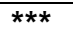 & 0.041 & 0.000 \\
\hline imp->tree & 0.000 & & 0.055 & 0.994 \\
\hline imp->wtr/wld & 0.210 & & 0.330 & 0.524 \\
\hline perv->imp & 0.348 & $\star \star \star *$ & 0.055 & 0.000 \\
\hline perv->tree & 0.034 & & 0.050 & 0.495 \\
\hline perv->wtr/wld & 0.068 & & 0.257 & 0.790 \\
\hline tree->imp & 0.272 & $\star \star \star *$ & 0.062 & 0.000 \\
\hline tree->perv & 0.240 & $* * *$ & 0.053 & 0.000 \\
\hline tree->wtr/wld & 0.003 & & 0.257 & 0.989 \\
\hline wtr/wld->imp & 1.018 & $\star \star \star *$ & 0.205 & 0.000 \\
\hline wtr/wld->perv & 0.120 & & 0.094 & 0.203 \\
\hline wtr/wld->tree & -0.342 & * & 0.157 & 0.030 \\
\hline$N$ & 1,535 & & & \\
\hline$r^{2}$ & 0.087 & & & \\
\hline Adj. $r^{2}$ & 0.081 & & & \\
\hline
\end{tabular}

\section{Analysis of socio-economic variables}

A bivariate correlation (Pearson's $r$ ) was determined between percent existing UTC and median household income, percent African American population, and percent Hispanic population at the Census Block Group level for years 2019 (Table 8) and 2014 (Table 10). Socioeconomic data for Table 7 were obtained from the America Community Survey (ACS) 2015-2019 5-year estimate, and corresponding data for Table 10 from the ACS 2010-2014 5-year estimate. Household incomes listed as > $\$ 250,000$ in ACS tables were counted as $\$ 250,000$ due to the lack of more precise numbers. To generate statistics from both tables, only block groups which had completed data in both years $(\mathrm{N}=1446)$ were used for better comparability.

For 2019, a moderate significant positive correlation was found between Median Household Income and percent UTC ( $r=0.543$, $\mathrm{p}=0.000)$, and a moderate weak significant negative correlation between percent EUTC and percent Hispanic $(r=-0.313, p=0.000)$. Comparison of correlation results show that in 2019 the trend of Hispanic population living in areas with less EUTC strengthened compared to 2014. Conversely, census block groups with a higher percentage of African American population tended to live in areas 
with less tree canopy in 2014; however, this relationship could not be observed in 2019 (Table 8). Median household income was again a strong predictor for percent EUTC in census block groups, similar to 2014 (Table 9).

Table 8. Bivariate correlations between percent EUTC and 2019 socioeconomic variables

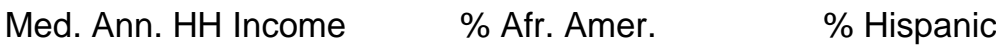

$\mathrm{p} \quad 0.000 \quad 0.605 \quad 0.000$

Bold indicates correlation significant at $p<0.001$

Table 9. Bivariate correlations between percent EUTC and 2014 socioeconomic variables

\begin{tabular}{cccc}
\hline & Med. Ann. HH Income & \% Afr. Amer. & \% Hispanic \\
$r$ & 0.541 & -0.157 & -0.111 \\
$p$ & 0.000 & 0.000 & 0.000 \\
\hline
\end{tabular}

Bold indicates correlation significant at $p<0.001$

\section{Analysis of health data}

Health data was obtained from the Agency for Health Care Administration (AHCA) at the zip code level. The data file contains hospital inpatient records for the $1^{\text {st }}$ quarter of 2020, including the patient's residential zip code and Principal Diagnosis (ICD-10-CM) Code. The principal diagnosis is the code representing the diagnosis established, after study, to be chiefly responsible for occasioning the admission to the hospital. Data was analyzed for 77 zip codes falling into the study area. The variable analyzed is the number of inpatient cases with respiratory diseases (J00-J99 ICD-10-CM code range), which was recomputed as respiratorybased inpatient cases per 100,000 (100K) residents in that zip code. For temporal comparison, hospital inpatient records for the $1^{\text {st }}$ quarter of 2014 were obtained from the same source and the number of inpatient cases with respiratory diseases (460-519 ICD-9$\mathrm{CM}$ code range) extracted. This variable was also recalculated as inpatient cases with respiratory diseases per $100 \mathrm{~K}$ residents for further analysis.

A Pearson's $r$ correlation between percent EUTC and $1^{\text {st }}$ Quarter 2020 respiratory related intakes per $100 \mathrm{~K}$ zip code residents was weakly negative and significant (Table 10). All hospital intakes per 100K zip residents were also negatively and significantly associated with areas of higher percent EUTC. Compared to 2014 data, the relationship between respiratory related intakes per $100 \mathrm{~K}$ residents and percent EUTC and between all hospital intakes per 100K residents and percent EUTC weakened, as shown by the smaller magnitude of correlation coefficients in 2020. 
Table 10. Bivariate correlations between percent EUTC and hospitalization rates for zip codes

\section{$1^{\text {st }}$ Quarter 2020}

Respiratory related intakes per $100 \mathrm{~K}$ residents

\section{$r$}

$-0.250^{*}$

0.028

${ }^{*} p<0.05 ;{ }^{* *} p<0.01 ;{ }^{* * *} p<0.001$
All hospital intakes per $100 \mathrm{~K}$ residents $-0.277^{*}$

0.015

\section{$1^{\text {st }}$ Quarter 2014}

Respiratory related intakes per $100 \mathrm{~K}$ residents $-0.296^{\star \star}$

0.009
All hospital intakes per $100 \mathrm{~K}$ residents $-0.374^{\star \star \star}$

0.001

Socioeconomic variables, such as percent households in poverty, were found to be even stronger predictors of respiratory-based and general hospital intakes per $100 \mathrm{~K}$ residents than tree canopy. This emphasizes the positive role of income on public health. Pearson's $r$ correlation values between respiratory-related and overall intakes per 100K residents (2020) and percent households in poverty (2019) are provided in Table 11.

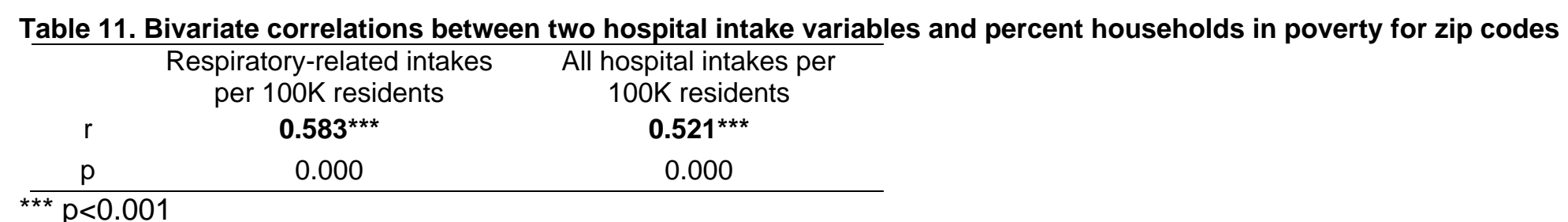

\section{References}

Kuhn, M., Wing, J., Weston, S., Williams, A., Keefer, C., Engelhardt, A., Cooper, T., Mayer, Z., Kenkel, B., Benesty, M., Lescarbeau, R., Ziem, A., Scrucca, L., Tang, Y., Candan, C., and Hunt, T. (2021). caret: Classification and Regression Training. R package version 6.0-88. https://cran.r-project.org/web/packages/caret/index.html

Liaw, A. and Wiener, M. (2002). Classification and Regression by randomForest. $R$ News, 2 (3), 18-22.

Olofsson, P., Foody, G. M., Stehman, S. V., and Woodcock, C. E. (2013). Making better use of accuracy data in land change studies: Estimating accuracy and area and quantifying uncertainty using stratified estimation. Remote Sensing of Environment, 129 (February 2013), 122-131.

Svetnik, V., Liaw, A., Tong, C., Culberson, J. C., Sheridan, R. P., and Feuston, B. P. (2003). Random Forest: A Classification and Regression Tool for Compound Classification and QSAR Modeling. Journal of Chemical Information and Computer Sciences, 43, 1947-1958. 